OPEN ACCESS

Edited by:

Sébastien Roger, Université de Tours,

France

Reviewed by:

Raphael Rapetti-Mauss, INSERM U1091 Institut de biologie de

Valrose, France

Andrea J. Yool, University of Adelaide,

Australia

*Correspondence:

Verena Hofschröer verena.hofschroeer@ uni-muenster.de

Specialty section: This article was submitted to Pharmacology of Ion Channels and

Channelopathies,

a section of the journal

Frontiers in Pharmacology

Received: 23 July 2020 Accepted: 30 October 2020

Published: 19 January 2021

Citation:

Hofschröer V, Najder K, Rugi M, Bouazzi R, Cozzolino M, Arcangeli A,

Panyi $G$ and Schwab A (2021) Ion

Channels Orchestrate Pancreatic Ductal Adenocarcinoma Progression and Therapy.

Front. Pharmacol. 11:586599. doi: $10.3389 /$ fphar.2020.586599

\section{Ion Channels Orchestrate Pancreatic Ductal Adenocarcinoma Progression and Therapy}

\author{
Verena Hofschröer ${ }^{1 *}$, Karolina Najder ${ }^{1}$, Micol Rugi ${ }^{1}$, Rayhana Bouazzi ${ }^{2}$, Marco Cozzolino ${ }^{3}$, \\ Annarosa Arcangeli ${ }^{2}$, Gyorgy Panyi ${ }^{3}$ and Albrecht Schwab ${ }^{1}$ \\ ${ }^{1}$ Institute of Physiology II, University of Münster, Münster, Germany, ${ }^{2}$ Department of Experimental and Clinical Medicine, Section \\ of Internal Medicine, University of Florence, Florence, Italy, ${ }^{3}$ Department of Biophysics and Cell Biology, Faculty of Medicine, \\ University of Debrecen, Debrecen, Hungary
}

Pancreatic ductal adenocarcinoma is a devastating disease with a dismal prognosis. Therapeutic interventions are largely ineffective. A better understanding of the pathophysiology is required. Ion channels contribute substantially to the "hallmarks of cancer." Their expression is dysregulated in cancer, and they are "misused" to drive cancer progression, but the underlying mechanisms are unclear. Ion channels are located in the cell membrane at the interface between the intracellular and extracellular space. They sense and modify the tumor microenvironment which in itself is a driver of PDAC aggressiveness. Ion channels detect, for example, locally altered proton and electrolyte concentrations or mechanical stimuli and transduce signals triggered by these microenvironmental cues through association with intracellular signaling cascades. While these concepts have been firmly established for other cancers, evidence has emerged only recently that ion channels are drivers of PDAC aggressiveness. Particularly, they appear to contribute to two of the characteristic PDAC features: the massive fibrosis of the tumor stroma (desmoplasia) and the efficient immune evasion. Our critical review of the literature clearly shows that there is still a remarkable lack of knowledge with respect to the contribution of ion channels to these two typical PDAC properties. Yet, we can draw parallels from ion channel research in other fibrotic and inflammatory diseases. Evidence is accumulating that pancreatic stellate cells express the same "profibrotic" ion channels. Similarly, it is at least in part known which major ion channels are expressed in those innate and adaptive immune cells that populate the PDAC microenvironment. We explore potential therapeutic avenues derived thereof. Since drugs targeting PDAC-relevant ion channels are already in clinical use, we propose to repurpose those in PDAC. The quest for ion channel targets is both motivated and complicated by the fact that some of the relevant channels, for example, $\mathrm{K}_{\mathrm{Ca}} 3.1$, are functionally expressed in the cancer, stroma, and immune cells. Only in vivo studies will reveal which arm of the balance we should put our weights on when developing channeltargeting PDAC therapies. The time is up to explore the efficacy of ion channel targeting in (transgenic) murine PDAC models before launching clinical trials with repurposed drugs.

Keywords: pancreatic ductal adenocarcinoma, ion channels, therapy, immune cells, fibrosis 


\section{INTRODUCTION}

Pancreatic ductal adenocarcinoma (PDAC) progresses rapidly once fully developed and can easily overcome current treatment strategies. The aggressiveness of the disease leads to a disastrous outcome for patients. The current 5 -year survival rate is still less than 10\% (Rawla et al., 2019). This poor prognosis is due to the absence of clinical symptoms in the early stage combined with the characteristic properties of PDAC: desmoplasia, early local invasion and metastasis, immune evasion, and resistance to radio- and chemotherapy. Desmoplasia involves a strong reaction of the tumor stroma in which matrix-producing pancreatic stellate cells (PSCs) play a central role. Mutual stimulation of tumor, stroma, and immune cells leads, in a positive feedback cycle, to enhanced growth factor and matrix production, creating a microenvironment conducive to tumor growth, migration/invasion of tumor cells into the tumor stroma, and metastasis (Mahadevan and Von Hoff, 2007; Sperb et al., 2020). Despite knowledge of many molecular details of PDAC, the therapeutic benefit derived thereof has been disappointingly small. Thus, there is an urgent need for novel concepts and therapeutic targets for the treatment of PDAC.

A promising novel concept is the targeting of ion channels in cancer. They are a major class of membrane proteins that have the ability to sense and modify properties of the tumor microenvironment and transduce signaling cascades triggered by its constituents. Therefore, they play central roles in signaling within and among tumor and stromal cells as well as in the coupling of extracellular events with cellular responses (Djamgoz et al., 2014). Ion channels are expressed in every cell where they exert cell-specific functions and housekeeping functions such as generating the membrane potential which, in turn, is a prerequisite for many processes such as $\mathrm{Ca}^{2+}$ signaling. Being the "working horses" of epithelial cells, ion channels are also essential for the normal function of the exocrine pancreas (e.g., Hayashi and Novak, 2013; Wang et al., 2013). Conversely, ion channel mutations cause hereditary diseases, so-called channelopathies. The most frequent one in Caucasians is the mutation of the cystic fibrosis transmembrane conductance regulator, CFTR, which causes, among others, a hereditary chronic pancreatitis which is a risk factor for developing PDAC (Becker et al., 2014).

Reviews from recent years on the role of ion channels in cancer (Djamgoz et al., 2014; Klumpp et al., 2018; Prevarskaya et al., 2018; Bulk et al., 2020; Ling and Kalthoff, 2020; Schnipper et al., 2020) predominantly focused on how ion channels shape the aggressive cancer cell behavior. However, cancer must be viewed as a complex tissue composed of different cell types. This is particularly relevant for PDAC: PSCs and immune cells are deeply involved in PDAC pathophysiology. PSCs have an important share in creating a tumor microenvironment in PDAC that contributes to immune evasion and thereby to the aggressiveness and therapy refractoriness of the disease (Wang et al., 2020b; Hessmann et al., 2020; Sperb et al., 2020). So far, there is still a considerable lack of knowledge on how ion channels and the (ionic) tumor microenvironment contribute to these aspects of PDAC pathophysiology. Yet, it has become evident that the function of ion channels in noncancerous cells has to be considered, too. Recent work in prostate cancer has started to go into this direction (Farfariello et al., 2020).

This review will put a special emphasis on the role of ion channels in stromal and immune cells. We will propose concepts on how fibrosis and immune evasion could be addressed in PDAC therapy by ion channel targeting. Due to their location in the plasma membrane, ion channels are easily accessible and well-characterized. Drugs targeting those have been in clinical use since decades. This is clearly exemplified by $\mathrm{Na}^{+}$channel blockers acting as local anesthetics, antiarrhythmics, anticonvulsants, and diuretics. Moreover, there are drugs whose side effects involve ion channel blockade (e.g., $\mathrm{K}_{\mathrm{V}} 11.1$ blockade by haloperidol, fluoxetine, tamoxifen and amitriptyline (Pointer et al., 2017) or $\mathrm{K}_{\mathrm{V}} 10.1$ blockade by astemizole or imipramine (GarcíaFerreiro et al., 2004)). Other channel-targeting drugs such as the $\mathrm{K}_{\mathrm{Ca}} 3.1$ blocker senicapoc have gone through phase III clinical trials (Ataga et al., 2011). The availability of such drugs provides us with an enormous advantage as they may be repurposed within the cancer treatment context (Kale et al., 2015). While developing a new drug "from scratch" takes on average 12 years and costs one billion dollars, repurposing requires only $2-3$ years and 10 million dollars (Zheng et al., 2013).

\section{REGULATION OF PANCREATIC CANCER CELL BEHAVIOR BY ION CHANNELS}

\section{$\mathrm{K}^{+}$Channels in Pancreatic Cancer Cells}

By controlling the flow of potassium ions across the cell membrane, $\mathrm{K}^{+}$channels regulate a multitude of processes, both in healthy and pathological conditions, including cancer (Huang and Jan, 2014). In proliferating cells, such as cancer cells, the $\mathrm{K}^{+}$efflux mediated by $\mathrm{K}^{+}$channels modulates cancer cell behavior by 1) providing the electrochemical force needed for the influx of $\mathrm{Ca}^{2+}$ (e.g., through store-operated $\mathrm{Ca}^{2+}$ channels (Feske et al., 2015)), which is known to be important for $G_{0} / G_{1}$ and $G_{1} / S$ transitions; 2) by transiently hyperpolarizing the membrane potential, which is also an important feature for cell cycle progression (Urrego et al., 2014); or by 3) being involved in cell volume regulation that highly relies on $\mathrm{K}^{+}$efflux (Hoffmann et al., 2009). $\mathrm{K}^{+}$channels may also work in a nonconductive manner by promoting signal transduction pathways involved in cell proliferation through interaction with other membrane proteins such as integrins (see below) (Becchetti et al., 2019).

Voltage-gated $\mathrm{K}^{+}$channels $\left(\mathrm{K}_{\mathrm{V}}\right.$ channels) are a large family of 40 genes grouped into 12 subfamilies. One of their key functions is the repolarization of the cell membrane potential of excitable cells (Wulff et al., 2009; Arcangeli and Becchetti, 2017). However, they are also found in nonexcitable cells where $\mathrm{K}_{\mathrm{V}}$ channels play important roles in cell proliferation, $\mathrm{Ca}^{2+}$ signaling, migration, and cell volume regulation. Moreover, they promote cancer progression (Huang and Jan, 2014). The involvement of ion channels in PDAC, such as $\mathrm{K}_{\mathrm{V}}$ channels, is summarized in Table 1.

$\mathrm{K}_{\mathrm{V}} 1.3$ channels: In healthy humans, the $\mathrm{K}_{\mathrm{V}} 1.3$ channels are mainly expressed in the central nervous system and in immune 
TABLE 1 | lon channel expression and their functional role in pancreatic cancer and stellate cells.

Channel Reference

\section{$\mathbf{K}^{+}$channels}

$\mathrm{K}_{\mathrm{Ca}} 3.1$

$\mathrm{K}_{\mathrm{ir}} 3.1$

$\mathrm{K}_{2 \mathrm{P} 1.1}$ (TWIK-1)

$\mathrm{K}_{2 \mathrm{P}} 2.1$ (TREK-1)

$\mathrm{K}_{2 \mathrm{P}} 3.1$ (TASK-1)

$\mathrm{K}_{\mathrm{v} 1.3}$

Mitochondrial channel

mitoK 1.3

$\mathrm{K}_{\mathrm{v}} 10.1$ (hEAG)

$\mathrm{K}_{\mathrm{v}} 11.1$ (hERG)

TRP channels
TRPC1
TRPC3
TRPC6
TRPM2
TRPM7

TRPM8

TRPV1

TRPV4

TRPV6

\section{Other ion channels ASICs \\ ASIC1, ASIC3 \\ P2X receptors \\ P2X7}

\section{Piezo1}

ORAI1/STIM1

CaCC (TMEM16A)
Functional expression in PDAC cell lines and elevated expression in PDAC tissue; cell proliferation Functional expression in PDAC cells; cell migration, proliferation, and invasion Subset of PDAC cell lines: Oxygen consumption, ATP production, and cellular proliferation Expression in PSC; migration and chemotaxis, $\left[\mathrm{Ca}^{2+}\right]_{i}$ signaling, calpain activity, functional cooperation with TRPC3

High expression correlates with poor patient prognosis in PDAC

Macrophage infiltration into cancer tissue via a $\mathrm{Ca}^{2+}$-dependent activation of CXCL5-CCL20 secretion by PDAC cells

Highly expressed in PDAC

mRNA up-regulation in PDAC tissue

Expressed in PDAC cells (BxPC-3)

Mediates $\mathrm{pH}$-sensitive $\mathrm{K}^{+}$current

Modulates the membrane potential $\left(\mathrm{V}_{\mathrm{m}}\right)$

PSCs: mRNA expression

mRNA down-regulation in tissues from PDAC patients

Reduced primary tumor weight in vivo by inhibitor clofazimine

Decreased expression in PDAC, associated with metastatic tumors

Apoptosis of cancer cells, cancer development, and progression in mouse models of PDAC

Inhibition of channel activity by monoclonal antibodies; inhibition of tumor cell growth in mouse xenograft model of pancreatic cancer

Expression in PDAC samples

Cell growth and invasiveness

PDAC malignancy in vitro and in vivo; diagnostic and prognostic biomarker

PDAC cell migration, modulator of $\mathrm{f}$-actin organization, and $\mathrm{Ca}^{2+}$ signaling

TGF- $\beta$ stimulated $\mathrm{Ca}^{2+}$-responses; migration and invasion (BxPc3 cells)

Mechanosignaling of murine PSC, pressure-dependent PSC activation

Up-regulated in PDAC stroma; functional cooperation with $\mathrm{K}_{\mathrm{Ca}} 3.1$; PSC migration and

chemotaxis; and $\mathrm{Ca}^{2+}$ signaling

PSCs: Cell migration, $\mathrm{Ca}^{2+}$ signaling, and cytokine secretion in hypoxia

SIRT6-elevated ADPr levels increase TRPM2 activation; migration (BxPc3 cells)

Overexpressed in PDAC tissue; correlated with poor patient survival

Overexpression correlates with increased tumor size and advanced tumor stages

PDAC cell invasion in Panc-1/MiaPaCa2; expression in lymph node metastasis and primary tumo correlation in human PDAC

Up-regulated in PDAC cell lines and tissue; cell proliferation

Functional expression in the plasma membrane; cell migration (Panc-1 cells)

Overexpressed in PDAC and the involved neurons; potential link to pain intensity reported by

cancer patients

Prolonged high fat/alcohol exposure increases TRPV4 expression in PSCs, fibrosis

Pressure-modulated mRNA expression in PSCs

Up-regulated in pancreatic cancer tissue; affects proliferation, migration, invasion, and apoptosis in PDAC

Down-regulated in PDAC cell line and in the tumor epithelium of PDAC tissue

Loss of function variants linked to early onset chronic pancreatitis (a risk factor for PDAC development)

Functional (over-)expression in PDAC; $\left[\mathrm{Ca}^{2+}\right]_{i}$ signaling, EMT, liver and lung metastasis

PSC proliferation and death

Overexpressed in PDAC cell lines; cell survival, migration, and invasion

Tumor growth; PSC number/activity, fibrosis

High mRNA levels in PSCs

PSCs: $\mathrm{Ca}^{2+}$ influx, cytoskeletal architecture, cell invasion, $\mathrm{pH}$-dependent mechanosensation

Prosurvival antiapoptotic role by mediating store-operated $\mathrm{Ca}^{2+}$ entry

Functionally overexpressed in human PDAC cells; supports migration, but not proliferation

Promotes pathogenesis of acute pancreatitis via $\mathrm{IP}_{3} \mathrm{R} / \mathrm{Ca}^{2+} / \mathrm{NF} \mathrm{KB} / \mathrm{IL}-6$ signaling

Essential for EGF-induced store-operated $\mathrm{Ca}^{2+}$ entry during pancreatic cancer cell migration;

overexpression correlates with low patient survival probability
Jäger et al. (2004)

Bonito et al. (2016)

Kovalenko et al. (2016

Storck et al. (2017)

Zaccagnino et al. (2016); Jiang et al.

(2017)

Jiang et al. (2019)

Brevet et al. (2009).

Williams et al. (2013).

Sauter et al. (2016).

Fels et al. (2016)

Williams et al. (2013)

Zaccagnino et al. (2017)

Brevet et al. (2009)

Leanza et al. (2017) and Zaccagnino et al. (2017)

Gómez-Varela et al. (2007)

Zhou et al. (2012)

Feng et al. (2014)

Lastraioli et al. (2015)

Manoli et al. (2019)

Dong et al. (2010)

Fels et al. (2016)

Storck et al. (2017)

Nielsen et al. (2017)

Bauer et al. (2012) and Lin et al. (2018)

Rybarczyk et al. (2012)

Yee et al. (2015)

Rybarczyk et al. (2017)

Yee et al. (2010)

Cucu et al. (2014)

Hartel et al. (2006)

Zhang et al. (2013)

Fels et al. (2016)

Song et al. (2018)

Zaccagnino et al. (2016) and Tawfik et al (2020)

Masamune et al. (2020)

Zhu et al. (2017)

Haanes et al. (2012)

Giannuzzo et al. (2015)

Giannuzzo et al. (2016)

Fels et al. (2016)

Kuntze et al. (2020)

Kondratska et al. (2014)

Sauter et al. (2015)

Wang et al. (2020a)

Crottès et al. (2019) 
cells (Cahalan and Chandy, 2009). $\mathrm{K}_{\mathrm{V}} 1.3$ channel expression is found up-regulated in several PDAC cell lines (Zaccagnino et al., 2017). Overexpression of the channel is an advantage for cancer cells to promote proliferation and cell survival. This was illustrated by targeting PDAC cells with a $\mathrm{K}_{\mathrm{V}} 1.3$ inhibitor (clofazimine) which induces apoptosis and reduces the weight of tumors grown from orthotopically transplanted PDAC cells (Zaccagnino et al., 2017). $\mathrm{K}_{\mathrm{V}} 1.3$ is also expressed in the mitochondria $\left(\mathrm{mitoK}_{\mathrm{V}} 1.3\right)$, where it regulates apoptosis in PDAC cells (Leanza et al., 2017). The above-cited data from PDAC cell lines, however, differ from those obtained in tissue samples from PDAC patients where $\mathrm{K}_{\mathrm{V}} 1.3$ expression is downregulated. This down-regulation correlates with metastasis. The diminished expression of $\mathrm{K}_{\mathrm{V}} 1.3$ was explained as a result of the methylation of its promoter (Brevet et al., 2009).

$K_{\mathrm{V}} 10.1$ and $K_{\mathrm{V}} 11.1$ channels: The EAG family of voltagegated $\mathrm{K}^{+}$channels comprises at least two members, $\mathrm{K}_{\mathrm{V}} 10.1$ (EAG1) and $\mathrm{K}_{\mathrm{V}} 11.1$ (hERG1), which are deeply involved in the regulation of different cancer hallmarks (Pardo and Stühmer, 2014). These channels have been identified as a potential target for anticancer therapies (Arcangeli and Becchetti, 2017; Xu et al., 2018), and both channels are expressed in PDAC ( $\mathrm{K}_{\mathrm{V}} 10.1$ (Gómez-Varela et al., 2007); $\mathrm{K}_{\mathrm{V}} 11.1$ (Feng et al., 2014; Lastraioli et al., 2015)).

In the healthy organism, $\mathrm{K}_{\mathrm{V}} 10.1$ and $\mathrm{K}_{\mathrm{V}} 11.1$ are expressed in excitable cells such as neurons and muscle cells. In addition to its expression in PDAC, both channels have been detected in many other tumor cell lines and primary tumors including neuroblastoma (Meyer and Heinemann, 1998; Pardo et al., 1999), melanoma (Nilius and Wohlrab, 1992; Meyer et al., 1999; Gavrilova-Ruch et al., 2002) as well as different tumors of epithelial origin (Ouadid-Ahidouch et al., 2001; Lastraioli et al., 2004; Hemmerlein et al., 2006; Ding et al., 2007; Ousingsawat et al., 2007), and leukemias (Pillozzi et al., 2002). The expression of $\mathrm{K}_{\mathrm{V}} 10.1$ seems to correlate with high-grade tumors and may confer a proliferative advantage for tumor cells (Comes et al., 2015).

$\mathrm{K}_{\mathrm{V}} 11.1$ channels are preferentially expressed in cardiac myocytes and required for the ordered repolarization of cardiac action potentials. $\mathrm{K}_{\mathrm{V}} 11.1$ expression in cancer cells has also been linked to high-grade tumors and has been strongly implicated in cell proliferation and migration of several cancers (Comes et al., 2015). $\mathrm{K}_{\mathrm{V}} 11.1$ expression is elevated in PDAC tumor cells, in particular in lymph node-positive PDAC (Feng et al., 2014). In contrast, cells of the tumor stroma and the normal ductal epithelium do not express $\mathrm{K}_{\mathrm{V}} 11.1$ (Lastraioli et al., 2015). $\mathrm{K}_{\mathrm{V}} 11.1$ supports cancer cell proliferation, vitality, migration, and invasion also in several PDAC cell lines (J. Feng et al., 2014; E. Lastraioli et al., 2015; Zhi et al., 2017). It is involved in cell cycle regulation as $\mathrm{K}_{\mathrm{V}} 11.1$ silencing promotes cell cycle arrest in the $\mathrm{G}_{1}$ phase (Feng et al., 2014). In primary PDAC cultures, $\mathrm{K}_{\mathrm{V}} 11.1$ blockage was found to be cytotoxic.

$\mathrm{K}_{\mathrm{V}} 11.1$ physically and functionally interacts with other plasma membrane proteins, such as the epidermal growth factor receptor (EGF-R) and adhesion receptors of the integrin family (Arcangeli and Becchetti, 2006; Lastraioli et al., 2015), which strongly contribute to PDAC aggressiveness (Sun et al., 2018). In addition, EGF-R inhibition represents one of the therapeutic strategies for nonresectable PDAC (Hessmann et al., 2020). The interaction between $\mathrm{K}_{\mathrm{V}} 11.1$ and EGF-R stimulates an EGF-R-dependent phosphorylation of ERK1 and ERK2, which are key signaling proteins downstream to EGF-R, and are involved in cell proliferation (Lastraioli et al., 2015). As stated in the introduction about $\mathrm{K}^{+}$channels, $\mathrm{K}_{\mathrm{V}} 11.1$ modulates cell proliferation through a conductive mechanism by its impact on the cell membrane potential (Becchetti et al., 2017). $K_{\mathrm{V}} 11.1$ also regulates cell migratory programs of PDAC cells by modulating stress fiber dynamics and $\mathrm{f}$-actin organization by its impact on the intracellular $\mathrm{Ca}^{2+}$ concentration (Manoli et al., 2019). This effect relies on nonconductive mechanisms and is based on the formation of a complex with $\beta 1$ integrins, which leads to the activation of downstream signaling processes involving paxillin.

$\mathrm{K}_{\mathrm{V}} 11.1$ is a target for both posttranscriptional and posttranslational modifications by small noncoding RNA molecules (miRNAs). miRNAs participate in human tumorigenesis and/or metastasis because of their ability to target oncogenes and/or tumor suppressors (Feng et al., 2014). $\mathrm{K}_{\mathrm{V}} 11.1$ is a direct target of mir-96 and mir-493 in human PDAC (Feng et al., 2014; Zhi et al., 2017; Xu et al., 2018), where both miRNAs are down-regulated. These data are recapitulated in PDAC cell lines. In vivo and in vitro, mir-96 and mir-493 silencing increases proliferation, migration, and invasion of PDAC cells, while their overexpression highly suppresses tumorigenicity and metastasis of PDAC. These observations suggest that the above miRNAs can work as tumor suppressors in PDAC in a $\mathrm{K}_{\mathrm{V}} 11.1$-dependent manner (Feng et al., 2014; Zhi et al., 2017).

$\mathrm{K}_{\mathrm{Ca}} 3.1$ channels: $\mathrm{K}_{\mathrm{Ca}} 3.1$ channels are functionally expressed in pancreatic ducts and are part of the transepithelial ion and fluid transport machinery (Hayashi et al., 2012; Wang et al., 2013). $\mathrm{K}_{\mathrm{Ca}} 3.1$ channels are found in the luminal and basolateral membranes in the intercalated and interlobular ducts of the pancreas (Hayashi and Novak, 2013).

$\mathrm{K}_{\mathrm{Ca}} 3.1$ is one of the first $\mathrm{K}^{+}$channels that were found to be massively overexpressed in primary pancreatic cancer samples and to be functional in several pancreatic cancer cell lines (Jäger et al., 2004). Such findings were later reproduced by other groups (Zaccagnino et al., 2016; Jiang et al., 2017, 2019). $\mathrm{K}_{\mathrm{Ca}} 3.1$ expression rises in a stepwise fashion during the dedifferentitation process from the normal pancreas to PanINs and PDAC (Jiang et al., 2017). The clinical relevance of this finding is underscored by the correlation of increased $\mathrm{K}_{\mathrm{Ca}} 3.1$ channel expression and patient prognosis: high $\mathrm{K}_{\mathrm{Ca}} 3.1$ channel expression is associated with poor patient survival. The predictive power of $\mathrm{K}_{\mathrm{Ca}} 3.1$ expression is not limited to PDAC. It also applies to several other cancer entities including, among others, breast (Faouzi et al., 2016), lung (Bulk et al., 2015), and ovarian cancer (Zhao et al., 2016).

Mechanistically, $\mathrm{K}_{\mathrm{Ca}} 3.1$ channels regulate pancreatic cancer cell behavior in several ways. First of all, they provide the electrochemical driving force needed for $\mathrm{Ca}^{2+}$ entry by counterbalancing the depolarization of the membrane potential caused by $\mathrm{Ca}^{2+}$ influx channels such as TRP channels or $\mathrm{Cl}^{-}$efflux through anion channels. The former has been observed in PSCs 
(Storck et al., 2017) and is known from many immune cells such as macrophages (Gao et al., 2010) and lymphocytes (see Ion Channel Involvement in Desmoplasia). The latter appears to be relevant for pancreatic cancer cells. $\mathrm{K}_{\mathrm{Ca}} 3.1$ channels interact with the gamma-aminobutyric acid (GABA) receptor subunit pi (GABRP). Thereby, they maintain the cell membrane potential and allow efficient $\mathrm{Ca}^{2+}$ signaling to enhance CXCL5-CCL20 secretion. This, in turn, causes macrophage infiltration into the cancer tissue and tumor growth (Jiang et al., 2019). $\mathrm{K}_{\mathrm{Ca}} 3.1$ mediated $\mathrm{K}^{+}$efflux is also necessary for volume dynamics during the cell cycle (Bonito et al., 2016) and migration. Accordingly, $\mathrm{K}_{\mathrm{Ca}} 3.1$ can promote tumor progression by modulating cell proliferation as well as cell migration and invasion (Schwab et al., 2012; Bonito et al., 2016). Finally, $\mathrm{K}_{\mathrm{Ca}} 3.1$ channels are not only expressed in the plasma membrane but also in the inner membrane of mitochondria (De Marchi et al., 2009). There is indirect evidence that $\mathrm{K}_{\mathrm{Ca}} 3.1$ channels are also present in the mitochondria of pancreatic cancer cells and regulate metabolic activity of mitochondria, potentially by modulating their membrane potential (Kovalenko et al., 2016). However, the relative importance of the plasma membrane vs. mitochondrial $\mathrm{K}_{\mathrm{Ca}} 3.1$ channels in regulating the cellular metabolism still remains to be determined. The common link could be the intracellular $\mathrm{Ca}^{2+}$ concentration, which also affects mitochondrial function (Delierneux et al., 2020).

$\mathbf{K}_{2 \mathbf{P}}$ channels: There is very limited information about $\mathrm{K}_{2 \mathrm{P}}$ channels in pancreatic cancer. A systematic review of public databases identified the up- or down-regulation of $\mathrm{K}_{2 \mathrm{P}} 1.1$ or $\mathrm{K}_{2 \mathrm{P}} 3.1 \mathrm{mRNA}$, respectively. However, these findings were not complemented by any functional data (Williams et al., 2013). $\mathrm{K}_{2 \mathrm{P}} 2.1$ modulates migration and proliferation of PDAC cell lines (Sauter et al., 2016).

\section{TRP Channels in Pancreatic Cancer Cells}

TRPM channels: An analysis of published genomic data from PDAC patients revealed an overexpression and the occurrence of somatic mutations of TRPM2. Both of them are negatively correlated with patient survival. TRPM2 overexpression or silencing modulates migration and proliferation of a PDAC cell line. So far, it remains to be determined how the somatic mutations of TRPM2 affect channel activity (Lin et al., 2018).

Similar observations were made for TRPM7. It is overexpressed in PDAC tissue, and this correlates with poor patient survival (Rybarczyk et al., 2012; Rybarczyk et al., 2017) as well as increased tumor size and advanced PDAC stages (Yee et al., 2015). In the zebra fish model, TRPM7 contributes to the development of the pancreas and carcinogenesis (Yee et al., 2011). Somatic TRPM7 mutations have been detected in several cancer entities (reviewed in Yee (2017)). Their functional significance has yet to be determined. On the cellular level, TRPM7 regulates proliferation and cell cycle progression (Yee et al., 2011). In zebra fish, the defects in cell cycle progression of the $\operatorname{trpm} 7^{\mathrm{b508}}$ mutants can be partially rescued by supplementary $\mathrm{Mg}^{2+}$ (Yee et al., 2011). TRPM7 knockdown reduces PDAC cell chemotaxis and invasion (Yee et al., 2015), at least in part by regulating the intracellular
$\mathrm{Mg}^{2+}$ homeostasis and via the Hsp90a/uPA/MMP-2 proteolytic axis (Rybarczyk et al., 2012, Rybarczyk et al., 2017).

TRPM8 is also overexpressed in human PDAC compared to normal tissue and required for cell proliferation (Yee et al., 2010). PDAC cells express functional TRPM8 channels as shown by whole-cell patch-clamp experiments. Channel activation inhibits PDAC cell motility (Cucu et al., 2014). Moreover, TRPM8 silencing increases the sensitivity to gemcitabine (Liu et al., 2018).

TRPV6: The high $\mathrm{Ca}^{2+}$ selectivity is a distinguishing feature of TRPV6 (and TRPV5) channels (Fecher-Trost et al., 2017). So far, there are only very few publications on TRPV6 channels in pancreas physiology and pathophysiology. Immunohistochemistry revealed their expression in acinar cells (Zhuang et al., 2002). A transcriptomic analysis indicates however that they are expressed at higher levels in the ductal epithelium (Segerstolpe et al., 2016).

Overexpression of TRPV6 appears to be common in cancers of epithelial origin. Thus, its tumor-promoting role in prostate cancer is well established (Raphaël et al., 2014). However, there is a controversy with respect to TRPV6 expression in PDAC. While Song et al. (2018) reported an overexpression, we found a reduced expression in microdissected PDAC samples (Zaccagnino et al., 2016). However, both of these studies did not take into account whether the tissue samples were from invasive or noninvasive parts of the tumor. This is a relevant distinction: A preponderance of TRPV6 expression was shown for the invasive parts of breast cancer (Dhennin-Duthille et al., 2011). Loss-offunction variants of TRPV6 channels are linked to another pancreas pathology: Early onset chronic pancreatitis (Masamune et al., 2020). We already mentioned in the introduction that an early onset (hereditary) chronic pancreatitis, which can also be caused by a mutation of the CFTR channel, leads to an increased risk to develop PDAC (Becker et al., 2014). The potential clinical relevance of TRPV6 channels in PDAC is further underpinned by observations from a phase I dose escalation study with the TRPV6 inhibitor SOR-C13 in cancer patients. Stable disease and a reduction in the CA 19-9 tumor biomarker were observed in both PDAC patients participating in this study (Fu et al., 2017).

\section{$\mathrm{Cl}^{-}$Channels in Pancreatic Cancer Cells}

ANO1 (TMEM16A) is a $\mathrm{Ca}^{2+}$-activated $\mathrm{Cl}^{-}$channel (CaCC). In freshly isolated murine pancreatic acini, $\mathrm{HCO}_{3}{ }^{-}$exits the cells through the apical ANO1 channel, which controls luminal $\mathrm{pH}$ balance. Luminal $\mathrm{pH}$ may be perturbed by the exocytotic release of the acid content of zymogen granules, both under physiologic condition and upon supramaximal stimulation, which represents an in vitro model of acute pancreatitis (Han et al., 2016). In acute pancreatitis, IL-6 promotes ANO1 expression via IL-6R/STAT3 signaling. ANO1 overexpression, in turn, increases IL-6 secretion via $\mathrm{IP}_{3} \mathrm{R} / \mathrm{Ca}^{2+} / \mathrm{NFkB}$ signaling activation (Wang et al., 2020a). Thus, ANO1 appears to be involved in a positive feedback loop in this inflammatory disorder.

CFTR and ANO1 are highly expressed in Capan-1 cells, where they mediate ATP/UTP-regulated $\mathrm{Cl}^{-}$secretion (Wang et al., 2013). ANO1 is overexpressed in several PDAC cell lines when its expression is compared to that in HDPE cells which are suggested 


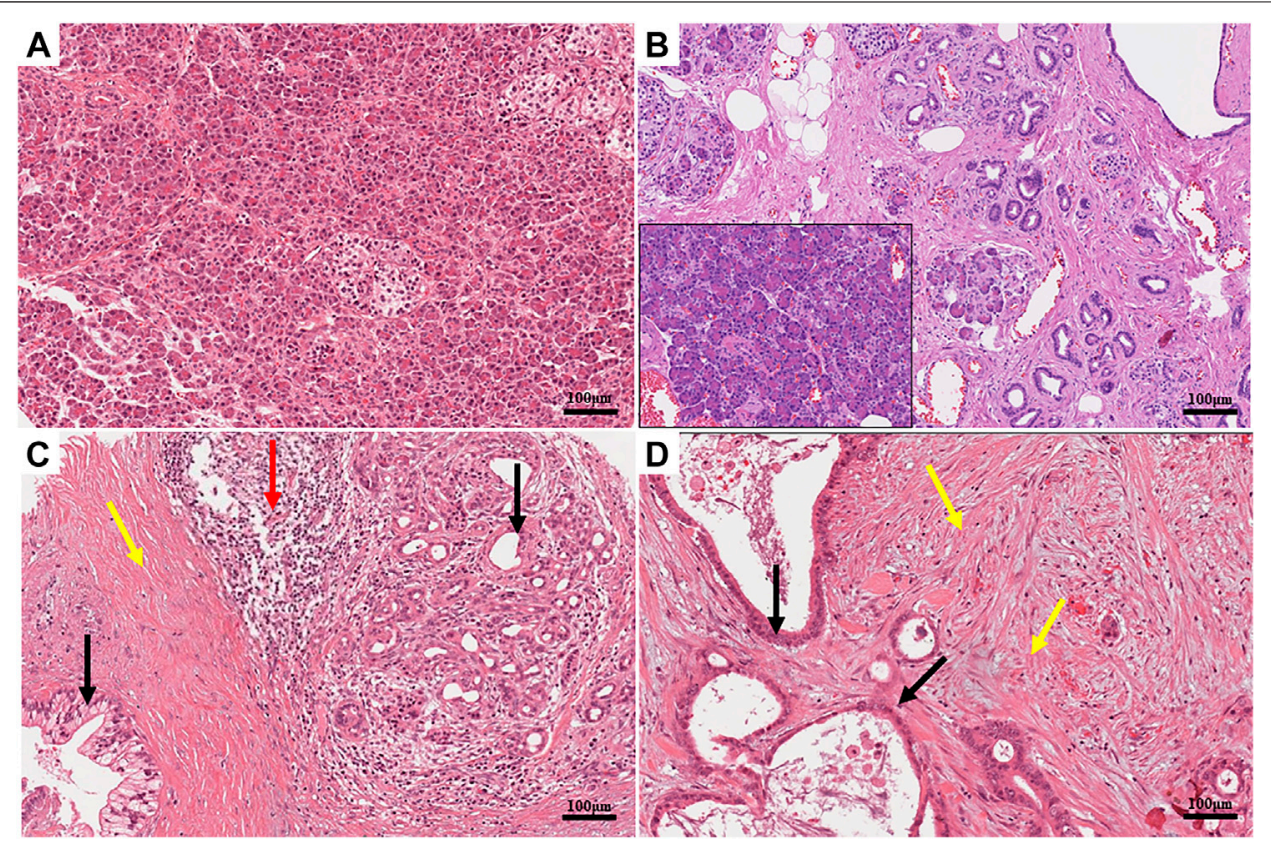

FIGURE 1 | (A) Histomorphology of a healthy human pancreas, hematoxylin and eosin (H\&E). The parenchymal structure of the organ is clearly visible. Acinar cells are identifiable by their typical round shape. Their bases are stained in blue due to the presence of the nuclei, while their apices are pink due to the high concentration of zymogen. Two islets are located in the central and right parts of the image. The cytoplasm of the islet cells is paler than the surrounding acinar cells. (B) Histomorphology of a chronic pancreatitis, hematoxylin and eosin (H\&E). The tissue is characterized by an evident increase in interlobular fibrosis, atrophy of the acini, and inflammatory infiltrate, which is evident when compared to the healthy component of the same sample (inset). (C,D) Histomorphology of two human pancreatic ductal adenocarcinomas (PDACs), hematoxylin and eosin (H\&E). The normal architecture of the parenchyma is lost. Multiple layers of cells highlight the neoplastic lesions in panel (C). High levels of desmoplasia (colored in pink) are present especially in panel (D). Distribution of different cell populations is detectable in the tumor tissue; neoplastic cells (pointed by black arrows) are embedded in a dense desmoplastic stroma (pointed by yellow arrows). Evident immune cells infiltration (pointed by red arrows) is present on the right side of the figure. Immune cells are identifiable by their small sizes and the intense basophilic staining of the nuclei. Scale bars: $100 \mu \mathrm{m}$.

to represent a model of the normal human pancreatic ductal epithelium (Sauter et al., 2015). Indeed, the analysis of patient material shows that ANO1 mRNA and protein are up-regulated in $75 \%$ of the cases. This is associated with a poor probability of survival (Crottès et al., 2019).

An EGFR-related signaling pathway, requiring ANO1, regulates $\mathrm{Cl}^{-}$and $\mathrm{Ca}^{2+}$ homeostasis in pancreatic cancer cells. This EGF-induced store-operated $\mathrm{Ca}^{2+}$ entry is required for the migration of pancreatic cancer cells (Crottès et al., 2019). Interestingly, ANO1 has a promigratory role in PDAC cells but has no effect on cell proliferation. Whole-cell patch-clamp experiments reveal functional ANO1 as a major mediator of PDAC CaCC currents. While knockdown of ANO1 using siRNA nearly completely abolishes the CaCC-mediated currents, the three tested ANO1 inhibitors T16Ainh-A01, CaCCinh-A01, and NS3728 show unspecific side effects and limited specificity (Sauter et al., 2015).

\section{ION CHANNEL INVOLVEMENT IN DESMOPLASIA}

Fibrosis is a pathological outcome common for many chronic inflammatory diseases including chronic pancreatitis (Wynn and Ramalingam, 2012). The abundant stroma reaction (desmoplasia) is a hallmark common to both chronic pancreatitis and PDAC (Haeberle et al., 2018). Chronic pancreatitis is considered a risk factor for pancreatic cancer, and indeed, it frequently evolves to a true PDAC (McKay et al., 2008). In both cases, the normal pancreatic parenchyma is markedly remodeled (as shown in Figure 1) so that the normal organ function is eventually lost. The poorly vascularized desmoplastic tissue is characterized by high stiffness, low elasticity, and high tissue pressure (up to $100 \mathrm{mmHg}$ ) (Stylianopoulos et al., 2012; Fels et al., 2016; Pethő et al., 2019), which leads to impaired perfusion of the tumor tissue with the further result of tissue hypoxia. The pancreatic stellate cells (PSCs) are believed to be the key effectors behind the stroma deposition in PDAC and chronic pancreatitis (Haeberle et al., 2018). Desmoplasia represents an important challenge that new PDAC therapies have to deal with (Henke et al., 2020). The absence of vascularization combined with vessel compression because of the massive fibrosis prevents the efficient delivery of the chemotherapeutic drugs (Dauer et al., 2018).

Consequently, new strategies targeting the stroma compartment have emerged. This includes the attempt to attenuate/reverse the activation of the cancer-associated fibroblasts (CAFs) which also includes PSCs. The results of these studies however are contradictory. Inhibiting the TGF- $\beta$ signaling pathway with the anticancer compound Minnelide, 
which is able to reverse the activation state of the CAFs, has a similar positive effect in a murine PDAC model (Dauer et al., 2018) as the inhibition of hedgehog signaling in CAFs with IPI926. Moreover, IPI-926 also increases the delivery and the efficacy of gemcitabine in mice (Olive et al., 2011). However, other studies highlighted that an uncontrolled depletion of the stroma compartment rather promotes PDAC progression than slowing it down (Özdemir et al., 2014). Consequently, the understanding of the stromal compartment in PDAC has to be further refined. It has become apparent that cancerassociated fibroblasts constitute a heterogeneous cell population with distinct gene expression profiles, location within the tumor, and function (Von Ahrens et al., 2017; Öhlund et al., 2017; Miyai et al., 2020). Öhlund et al. propose a distinction between inflammatory fibroblasts, mainly responsible for the secretion of inflammatory factors, and myofibroblasts that are responsible for the ECM production (Öhlund et al., 2017). PSCs are included in this last category. To the best of our knowledge, it has not yet been studied whether these two types of CAFs are also equipped with distinct sets of ion channels.

\section{Pancreatic Stellate Cells}

In a healthy pancreas, PSCs are usually kept in a quiescent state, and they are responsible for the maintenance of the tissue integrity by regulating the ECM turnover (Haeberle et al., 2018). In PDAC, PSCs become strongly activated by the secretome and the physicochemical properties of the PDAC microenvironment (Omary et al., 2007a). Thus, PSCs are activated among others by inflammatory mediators, growth factors (PDGF and TGF- $\beta 1$ ), cytokines (IL-1, IL-6, and IL-8), hormones, angiotensin II, intracellular signaling molecules, and reactive oxygen species (ROS) as well as hypoxia (Nielsen et al., 2017) and mechanical stimuli (Omary et al., 2007b; Fels et al., 2016, Fels et al., 2018; Ferdek and Jakubowska, 2017; Lachowski et al., 2017). Activated PSCs, in turn, secrete growth factors themselves so that they are engaged in a mutual positive feedback loop of other cells of the PDAC tissue (Fu et al., 2018). In addition, activated PSCs proliferate, migrate (Omary et al., 2007b), and secrete copious amounts of ECM components, especially collagen I and III (Ferdek and Jakubowska, 2017). The resulting changes in the $\mathrm{pH}$ values and increased stiffness of the desmoplastic tissue also feed back onto the behavior of PSCs (Lachowski et al., 2017). One of the mechanosensitive ion channels, Piezo1, that senses the mechanical properties of the PDAC microenvironment is inhibited by an acidic $\mathrm{pH}$. This could prevent PSCs to be overridden by the mechanically triggered $\mathrm{Ca}^{2+}$ influx via Piezo1 channels (Kuntze et al., 2020).

\section{Ion Channels and Fibrosis}

The function of ion channels in tumor stroma cells is far from being fully understood, especially regarding PDAC. Nonetheless, we already know that some ion channels play a significant role in the development of fibrosis in other organs such as $\mathrm{K}_{\mathrm{Ca}} 3.1$ in lungs, kidneys (Roach et al., 2013), and heart (Zhao et al., 2015); $\mathrm{K}_{2 \mathrm{P}} 2.1$ in cardiac fibrosis (Abraham et al.,
2018); and TRPV4 in liver (Songa et al., 2014), heart (Adapala et al., 2013), and lung fibrosis (Rahaman et al., 2014). Usually the inhibition of these ion channels attenuates the profibrotic response of the fibroblasts (Cruse et al., 2011; Adapala et al., 2013; Rahaman et al., 2014; Abraham et al., 2018; Roach and Bradding, 2019).

Ion channel research in PSCs is still in its infancy. We will therefore draw some analogies from hepatic stellate cells that are closely related to PSCs and in which these ion channels may play a similar role. Hepatic stellate cells are responsible for matrix homeostasis in healthy livers (Puche et al., 2013). Similar to the PSCs in PDAC, they are mainly responsible for the excessive production and remodeling of the ECM in the fibrotic liver (Puche et al., 2013; Freise et al., 2015; Ezhilarasan et al., 2018). For this reason, these types of cells have been suggested as a possible target for antifibrotic therapy.

$\mathbf{K}_{\mathbf{C a}}$ 3.1: We do not have much information on the role of $\mathrm{K}_{\mathrm{Ca}} 3.1$ channels in PDAC-associated fibrosis, which is largely driven by PSCs. It is only known that $\mathrm{K}_{\mathrm{Ca}} 3.1$ channels regulate migration of PSCs (Storck et al., 2017).

So far, it is under debate whether $\mathrm{K}_{\mathrm{Ca}} 3.1$ has pro- or antifibrotic effects in the liver (Roach and Bradding, 2019). $\mathrm{K}_{\mathrm{Ca}} 3.1$ expression is increased in hepatic stellate cells after the incubation with TGF- $\beta$, a known activator of hepatic stellate cells. In both in vitro and in vivo experiments, the inhibition of $\mathrm{K}_{\mathrm{Ca}} 3.1$ shows an antifibrotic effect and decreases the expression of profibrotic genes (Freise et al., 2015). On the contrary, in the work of Møller et al., the inhibition or the absence of $\mathrm{K}_{\mathrm{Ca}} 3.1$ in hepatic stellate cells and hepatocytes worsens liver fibrosis (Møller et al., 2016). This information highlights the possible problems that ion channel therapies could face; the inhibition of an ion channel expressed in different cell types could have different effects.

$\mathbf{K}_{2 \mathbf{P}} \mathbf{2 . 1}$ : So far, we only know that PSCs express $\mathrm{K}_{2 \mathrm{P}} 2.1$ (previously designated as TWIK-related potassium channel-1; TREK1) (Fels et al., 2016). In fact, $\mathrm{K}_{2 \mathrm{P}} 2.1$ is a mechanosensitive ion channel that can be modulated by pressure and membrane stretch (Lauritzen et al., 2005; Honoré, 2007) but also by $\mathrm{pH}$. $\mathrm{K}_{2 \mathrm{P}} 2.1$ contributes to setting the resting membrane potential of the cells (Bittner et al., 2014), and it is strongly correlated with proliferation and cell cycle in some tumors (Pethö et al., 2019). The mechanosensitive function of $\mathrm{K}_{2 \mathrm{P}} 2.1$ is postulated to be involved in the migration, especially in the coordination of the front and rear ends of the cells (Pethö et al., 2019). Sauter et al. observed that the activation of $\mathrm{K}_{2 \mathrm{P}} 2.1$ with $\mathrm{BL} 1249$ in a PDAC line, BxPC-3, inhibits cell proliferation and migration through the hyperpolarization of the membrane (Sauter et al., 2016). Controversially, the absence of $\mathrm{K}_{2 \mathrm{P}} 2.1$ in heart myofibroblasts from pressure-overloaded mice attenuates cardiac fibrosis also by decreasing fibroblast proliferation and migration (Abraham et al., 2018). This highlights again how the same ion channel can have a different impact on the behavior of different cell types and how this topic must be considered during the development of new therapies. However, it may also be seen as an indication that the "natural," possibly fluctuating, activity is what matters physiologically. Clamping channel activity to a maximum or a minimum impairs cell function. It remains to be seen whether 
TABLE 2 | Ion channel expression and function in innate and adaptive immune cells of pancreatic ductal adenocarcinoma.

\begin{tabular}{|c|c|c|}
\hline Channel & Function & Reference \\
\hline \multicolumn{3}{|l|}{ Neutrophils } \\
\hline $\mathrm{K}_{\mathrm{Ca}} 3.1$ & Chemotaxis & Henríquez et al. (2016) \\
\hline $\mathrm{K}_{\mathrm{ir}} 2.1$ & Possible role in neutrophil proliferation, membrane potential regulation, and $\mathrm{Ca}^{2+}$ influx & Masia et al. (2015) \\
\hline $\mathrm{K}_{\mathrm{V}} 1.3$ & Membrane potential regulation and electric field detection & Kindzelskii and Petty (2005) \\
\hline TRPC1 & fMLF-stimulated migration and chemotaxis & Lindemann et al. (2015) \\
\hline TRPC6 & Chemotaxis and CXCL1-induced recruitment from the vasculature & Lindemann et al. (2013) and Lindemann et al. (2020) \\
\hline TRPM2 & In vitro transmigration & Yamamoto et al. (2008) \\
\hline P2X7 & IL-1 $\beta$ secretion & Karmakar et al. (2016) \\
\hline \multirow[t]{2}{*}{$H_{\vee} 1$} & $\mathrm{Ca}^{2+}$ entry regulation, ROS production, and neutrophil migration & El Chemaly et al. (2010) \\
\hline & & Ramsey et al. (2009) \\
\hline \multicolumn{3}{|c|}{ Monocytes/macrophages } \\
\hline $\mathrm{K}_{\mathrm{Ca}} 3.1$ & M1 polarization & Xu et al. (2017) \\
\hline $\mathrm{K}_{2 \mathrm{P}} 6.1$ & Inflammasome formation & Di et al. (2018) \\
\hline TRPC1 & M1 polarization & Chauhan et al. (2018) \\
\hline TRPM2 & Chemokine production & Yamamoto et al. (2008) \\
\hline TRPM7 & $\mathrm{Ca}^{2+}$-induced macrophage stimulation, proliferation, and M2 polarization & Schilling et al. (2014) and Schappe et al. (2018) \\
\hline $\mathrm{H}_{\vee} 1$ & Phagosomal $\mathrm{pH}$ regulation and $\mathrm{ROS}$ production & El Chemaly et al. (2014) \\
\hline \multicolumn{3}{|l|}{ Dendritic cells } \\
\hline $\mathrm{K}_{v} 1.3, \mathrm{~K}_{v} 1.5$ & MHCll expression, migration, and cytokine production & Matzner et al. (2008) \\
\hline $\mathrm{Na} 1.7$ & Migration & Zsiros et al. (2009) \\
\hline P2X7 & Antigen presentation and migration & Mutini et al. (1999) and Saéz et al. (2017) \\
\hline $\mathrm{H}_{\vee} 1$ & ROS production & Szteyn et al. (2012) \\
\hline \multicolumn{3}{|c|}{ Myeloid-derived suppressor cells (MDSCs) } \\
\hline TRPV1 & Promotes MDSC formation & Hegde et al. (2011) \\
\hline $\mathrm{P} 2 \times 7$ & ARG-1, TGF- $\beta 1$, and ROS up-regulation & Bianchi et al. (2014) \\
\hline \multicolumn{3}{|l|}{ NK cells } \\
\hline $\mathrm{K}_{\mathrm{Ca}} 3.1$ & Negatively influencing proliferation, degranulation, and cytotoxicity & Koshy et al. (2013) \\
\hline $\mathrm{K}_{\mathrm{v} 1.3}$ & Positively influencing proliferation and degranulation & Koshy et al. (2013) \\
\hline \multicolumn{3}{|c|}{$\mathrm{CD4}^{+}$and $\mathrm{CDB}^{+} \mathrm{T}$-cells } \\
\hline $\mathrm{K}_{\mathrm{Ca}} 3.1$ & Sustaining $\mathrm{Ca}^{2+}$ influx during $\mathrm{T}$-cell activation & Ghanshani et al. (2000) and Wulff et al. (2003) \\
\hline$K_{V} 1.3$ & Sustaining $\mathrm{Ca}^{2+}$ influx during $\mathrm{T}$-cell activation & Wulff et al. (2003) \\
\hline TRPM4 & Motility and cytokine production & Weber et al. (2010) \\
\hline $\mathrm{CRAC}^{\mathrm{a}}$ & $\mathrm{Ca}^{2+}$ influx during $\mathrm{T}$-cell activation & Feske et al. (2012) \\
\hline \multicolumn{3}{|l|}{$T_{\text {reg }} s$} \\
\hline $\mathrm{K}_{\mathrm{Ca}} 3.1$ & Still unclear & Estes et al. (2008) \\
\hline$K_{v} 1.3$ & Still unclear & Varga et al. (2009) \\
\hline $\mathrm{CRAC}^{\mathrm{b}}$ & Development and differentiation & Vaeth et al. (2019) \\
\hline \multicolumn{3}{|l|}{ B cells } \\
\hline $\mathrm{K}_{\mathrm{Ca}} 3.1$ & Sustaining $\mathrm{Ca}^{2+}$ influx during B-cell activation & Wulff et al. (2004) \\
\hline $\mathrm{K}_{\mathrm{V}} 1.3$ & Sustaining $\mathrm{Ca}^{2+}$ influx during B-cell activation & Wulff et al. (2004) \\
\hline CRAC ${ }^{C}$ & $\mathrm{Ca}^{2+}$ influx during B-cell activation & Feske et al. (2012) \\
\hline
\end{tabular}

aMurine T-cells: mRNA and fluorescence-based data indicate that T-cells up-regulate Orai1 and down-regulate Orai2 when they become activated (Vaeth et al., 2017). The role of Orai3 is controversial (McCarl et al., 2010; Vaeth et al., 2017).

Human peripheral T-cells: the dominant isoform is Orai1, but all the three genes are up-regulated upon activation (Lioudyno et al., 2008). There is no difference in cell surface expression of ORAl1 between human memory and naive T-cells (Cox et al., 2013).

${ }^{b}$ Murine peripheral Tregs: mRNA data suggest the expression of Orai1 and Orai2, while much less of Orai3 (Naeth et al., 2017).

Human peripheral $T_{\text {regs: }}$ ORAl1 and ORAI2, but not ORAI3, were detected using immunocytofluorescence. The expression of Orai1 in $T_{\text {regs }}$ is significantly inferior compared to naive and activated CD4 ${ }^{+}$T-cells (Jin et al., 2013).

${ }^{c}$ Murine B cells express Orai1, Orai2 and Orai3 to a comparable extent (Gwack et al., 2008; Vaeth et al., 2017).

Human B cells: no detailed mRNA data. There is no difference in cell surface expression of ORAl1 between memory and naive B cells (Cox et al., 2013).

$\mathrm{K}_{2 \mathrm{P}} 2.1$ channels exert a similar role in PDAC desmoplasia, where the unique tumor microenvironment could influence $\mathrm{K}_{2 \mathrm{P}} 2.1$ function in many ways.

TRPV4: The transient receptor potential vanilloid channel 4 (TRPV4) is a mechanosensitive $\mathrm{Ca}^{2+}$-permeable nonselective cation channel that is expressed in many organs including the pancreas (Zhan and Li, 2018). TRPV4 is also expressed in PSCs. Its mRNA expression strongly decreases in PSCs when they are cultured under an elevated ambient pressure $(+100 \mathrm{mmHg})$, mimicking the conditions that can be found in PDAC (Fels et al., 2016; Pethő et al., 2019; Sharma et al., 2019). The functional implications of this mechanosensitive expression have not yet been published. The decreased TRPV4 mRNA expression upon mechanical stimulation can be explained as a compensatory response of the cells which prevents $\mathrm{Ca}^{2+}$ overload following the pressure stimulus (Fels et al., 2016).

Notably, PSCs also release TGF- $\beta$ upon stimulation with pressure (Sakata et al., 2004; Fels et al., 2016). TRPV4 integrates mechanical stimuli and soluble signals such as TGF$\beta$, and it drives the epithelial-mesenchymal transition (EMT) (Adapala et al., 2013; Sharma et al., 2019). TRPV4 expression is dramatically increased in many tissue samples of patients with 
liver fibrosis (Songa et al., 2014). Furthermore, TRPV4 is highly expressed in hepatic stellate cells (Songa et al., 2014). Inhibition of TRPV4 decreases cell proliferation of hepatic stellate cells, decreases their TGF- $\beta$-dependent activation and the expression of collagen $\alpha 1$ and $\alpha$-smooth muscle actin genes in in vitro cultures (Songa et al., 2014). Inhibition of TRPV4 also leads to an increase in apoptosis and inhibition of autophagy in the TGF- $\beta$-treated hepatic stellate cell line HCS-T6. These findings can be taken as indication for a similar role of TRPV4 channels in PSCs as well.

\section{IMMUNITY AND PDAC}

The description/staging of cancers has significantly evolved over the last decades to include the tumor microenvironment (TME) and the infiltration of the tumors by the immune system (e.g.) Immunoscore for colorectal cancers (Galon et al., 2014)). This is particularly important since T-cell infiltration, in general, bears a good prognostic feature: high $\mathrm{CD} 4^{+}$and $\mathrm{CD} 8^{+}$densities are associated with better overall and disease-free survival (Tang et al., 2014; Knudsen et al., 2017; Lohneis et al., 2017; Nejati et al., 2017).

The development of PDAC can be seen as a result of failed removal of malignant cells (Dunn et al., 2002). This failure might originate from the quantitative and qualitative composition of the immune cell repertoire in the TME, and/or altered function of the immune cells and their ion channels. An in-depth analysis of the immune cells in PDAC is beyond the scope of this review, and thus, we will use a simplified classification scheme and focus on the roles of the cells of innate and adaptive immunity in PDAC progression and how their roles may be modulated by ion channels. The expression of ion channels in immune cells in PDAC is summarized in Table 2. Addition of the immune component to a topical review on ion channels in PDAC is unique to this article, and thus, basic functions of immune cells have to be discussed briefly in the corresponding sections about a cell type.

Based on the relative proportion of $\mathrm{CD}^{+}$and $\mathrm{CD}^{+}$cells over all cells in the tumor (Galon and Bruni, 2019), PDAC is often ranked among the "coldest" human tumors (Maleki Vareki, 2018). Although leukocytes (CD45 ${ }^{+}$cells) comprise almost $50 \%$ of all cells isolated from murine (Clark et al., 2007) and human PDAC (Trovato et al., 2019), T lymphocytes are significantly less abundant (15\% of total cells in mice and ca. $20 \%$ in humans) compared to well-known "hot" tumors like melanoma (Sakellariou-Thompson et al., 2017; Blando et al., 2019). Low T-cell infiltration of PDAC can be due to a desmoplastic mechanical impediment, hypoxia, and low extracellular pH (Knudsen et al., 2017).

At the time of diagnosis, the TME is already highly immunosuppressive, which can be related to the high number of myeloid-derived suppressor cells in PDAC (Trovato et al., 2019). Moreover, the low $\mathrm{pH}$ and the alterations of the ionic composition of the TME may lead to the formation of tumorassociated immune cells which become the malfunctioning side of the immune response (Vesely et al., 2011; Gabrilovich et al., 2012; Girault et al., 2020). The fact that ion channels are expressed in both antitumor and protumor/suppressor immune cells allows us to consider ion channels as putative mediators of the biased immune response in PDAC (Feske et al., 2015; Fels et al., 2018).

\section{Ionic Composition of the Tumor Microenvironment}

Distinct characteristics of PDAC, that is, poor vascularization and a markedly fibrotic stroma, result in deficient oxygen supply and metabolite accumulation (Olive et al., 2009; Provenzano et al., 2012). The high metabolic rate, glycolysis (GAPDH activity; production of lactate (Dovmark et al., 2017)), implementation of the pentose phosphate pathway, and production of $\mathrm{CO}_{2}$ are the source of protons which lead to extracellular acidification in PDAC (Gillies et al., 2002; Hashim et al., 2011; High et al., 2019). Such an acidification of poorly perfused tumor areas has a profound impact on the function of ion channels in all cells of the tumor tissue (reviewed in Pethö et al. (2020)). Acidification, severe hypoxia, and mechanical stress also cause cell necrosis. This is associated with an elevation of the $\left[\mathrm{K}^{+}\right]$in the interstitium (Cruz-Monserrate et al., 2014; Eil et al., 2016; Leslie et al., 2019). Moreover, the concentration of $\mathrm{Na}^{+}$, a major contributor of osmotic pressure in the interstitium, is increased, which can have multiple implications for the infiltration of immune cells (He et al., 2020). Thus, the ionic composition of the tumor microenvironment is characterized by altered concentration gradients across the plasma membrane, that is, by altered electrochemical driving forces and by constituents, for example, protons, which have a strong impact on channel activities. Importantly, the disrupted ionic composition is sensed by ion channels in cancer, immune, and stromal cells and inevitably affects their function. The consequences of the altered tumor environment on cell function through the modification of ion channels of immune cells will be discussed in the following.

\section{Cells of the Innate Immune Response}

Neutrophils: A high number of neutrophils in the PDAC stroma is usually associated with poor prognosis (Wang et al., 2018; Oberg et al., 2019). Likewise, a high neutrophil-tolymphocyte ratio (NLR), also in peripheral blood, is associated with a lower 5-year survival rate after tumor resection (Nywening et al., 2018).

Expression of voltage-gated and $\mathrm{Ca}^{2+}$-activated channels, $\mathrm{K}_{\mathrm{V}} 1.3$ and $\mathrm{K}_{\mathrm{Ca}} 3.1$, was shown in murine and human neutrophils (Krause and Welsh, 1990; Kindzelskii and Petty, 2005; Henríquez et al., 2016). Moreover, murine neutrophils express electrophysiologically detected inwardly rectifying $\mathrm{K}_{\mathrm{ir}} 2.1$ channels which are also assumed to contribute to their resting membrane potential and $\mathrm{Ca}^{2+}$ influx (Masia et al., 2015).

Since $\mathrm{K}^{+}$channels are involved in neutrophil migration and chemotaxis like other cells present in the PDAC microenvironment, a high extracellular $\mathrm{K}^{+}$concentration may also perturb neutrophil function. This assumption is important not only in the context of their ability to reach the cancer niche but may also be a cause of unfavorable retention of neutrophils in PDAC milieu. 
While intracellular ATP is a regulator of neutrophils' Kir6.x channels (Silva-Santos et al., 2002), extracellular ATP, for example, released from necrotic cells, induces neutrophil recruitment through purinergic $\mathrm{P} 2 \mathrm{X} 7$ receptor activation (McDonald et al., 2010). Opening of the ATP-gated P2X channels leads to $\mathrm{Ca}^{2+} / \mathrm{Na}^{+}$influx (Karmakar et al., 2016). Importantly, P2X7 is expressed also in cancer and PSCs, and the P2X7 inhibitor, AZ10606120, reduces cancer cell proliferation in vitro and in vivo (Haanes et al., 2012; Giannuzzo et al., 2015).

$\mathrm{Ca}^{2+}$ signaling plays a major role in neutrophil migration, phagocytosis, and ROS production. One of the key mechanisms in the $\mathrm{Ca}^{2+}$ increase is mediated by store-operated $\mathrm{Ca}^{2+}$ entry (SOCE) and subsequent activation of Orail channels. Several other $\mathrm{Ca}^{2+}$-permeable TRP channels are also involved in the innate immune response (Najder et al., 2018). Since neutrophils express C-X-C chemokine receptor-type 2 (CXCR2), they are attracted by ligands like CXCL1/IL-8, CXCL2, and CXCL5, released in pancreatitis and pancreatic cancer (Saurer et al., 2000; Steele et al., 2016; Najder et al., 2018; Wu et al., 2019; Zhang et al., 2020). Indeed, inhibition of CXCR2 signaling in PDAC shows beneficial results (Ijichi et al., 2011; Steele et al., 2016). Recruitment of neutrophils upon CXCR2 activation is mediated by $\mathrm{Na}^{+}$and $\mathrm{Ca}^{2+}$-permeable, classical/canonical transient receptor potential 6 (TRPC6) channel (Lindemann et al., 2013, 2020). TRPC6 is also expressed in PSCs, where it mediates hypoxia-induced migration and production of cytokines (Nielsen et al., 2017). In a mouse model, it could be shown that inhibition of TRPC6 with specific antagonists (SAR7334, BI-749327) diminishes the inflammatory response in the lungs and ameliorates cardiac and renal fibrosis (Lin et al., 2019; Chen et al., 2020). One can presume that such a beneficial effect could also be elicited in PDAC, in part by inhibiting neutrophil recruitment into the tumor.

In colorectal cancer, another chemokine receptor, formyl peptide receptor (FPR1), is highly expressed in tumorinfiltrating, myeloperoxidase-positive $\left(\mathrm{MPO}^{+}\right)$cells (Li et al., 2017). Also, FPR1 is enriched in immune cells of the recently suggested L4 PDAC subtype (Zhao et al., 2018). In murine neutrophils, FPR1-mediated directed migration depends on TRPC1 channels which may therefore contribute to neutrophil infiltration in PDAC (Lindemann et al., 2015; Fels et al., 2018).

Once at the target, activated neutrophils produce ROS, release metalloproteinases (e.g., MMP-9) and cytokines, and form neutrophil extracellular traps (NETs) (Wu et al., 2019). The remarkable ability of neutrophils to produce ROS depends on the depolarizing activity of the NADPH oxidase (NOX2) and concomitant action of voltage-gated proton channels $\left(\mathrm{H}_{\mathrm{V}} 1\right)$ (DeCoursey et al., 2016). Their activity in neutrophils is very relevant for PDAC progression. Neutrophil-derived ROS may cause cancer apoptosis due to TRPM2 channel activation (Gershkovitz et al., 2018). Accordingly, pharmacological stimulation of ROS production induces pancreatic tumor cell apoptosis (Shi et al., 2008). However, channel expression in cancer cells can also promote cancer cell proliferation (Lin et al., 2018). Release of NETs, a defense mechanism of extruding DNA covered with enzymes and histones, is often ROS-dependent and is therefore indirectly mediated by $\mathrm{H}_{\mathrm{V}} \mathrm{l}$ activity. NET formation can occlude pancreatic ducts, cause pancreatitis, and promote PDAC metastasis to the liver (Leppkes et al., 2016; Takesue et al., 2020). Also, distant PDAC metastasis is facilitated by activated neutrophils in the circulation (Tao et al., 2016). Thus, aiming at the $\mathrm{H}_{\mathrm{V}} 1$ channel in cancer therapy could have potential benefits, mostly due to inhibition of ROS-related activity of neutrophils (Fernández et al., 2016).

Macrophages: Tumor-associated macrophages (TAMs) are generally divided into "classically activated" M1 and "alternatively activated" immunosuppressive M2 macrophages. The latter type is predominant in PDAC tissue (Habtezion et al., 2016; Hu et al., 2016; Liu et al., 2016). M2 polarization is induced by IL-4 and IL-13 (Biswas and Mantovani, 2010). The presence of these cells in PDAC is associated with poor prognosis. TAMs also contribute to formation of desmoplasia through interplay with PSCs and mutual stimulation of cytokine production. Moreover, macrophage-derived metalloproteinases mediate dynamic turnover of fibrotic tissue and allow for tumor expansion (reviewed in $\mathrm{Hu}$ et al. (2015)). Chemotherapy can induce macrophage polarization into the tumoricidal M1 type and improve therapy outcome (Kurahara et al., 2011; Di Caro et al., 2015). Macrophage recruitment to the tumor site is mediated by CCL2/CCR2 and CSF-1/CSF-1R axes, with the latter additionally promoting M2 polarization. Inhibition of these signaling pathways shows potential benefits so that the CCL2/CCR2 inhibitor (PF-04136309) is implemented in PDAC clinical trials (NCT01413022) (Zhu et al., 2014; Habtezion et al., 2016; Nywening et al., 2018).

Channels expressed in macrophages often overlap with those expressed in neutrophils, especially in regard to $\mathrm{K}^{+}$channels (reviewed in: Feske et al. (2015)). There is also evidence that $\mathrm{K}_{2 \mathrm{P}} 6.1$ (TWIK2) mediates $\mathrm{K}^{+}$efflux. In murine macrophages, $\mathrm{K}_{2 \mathrm{P}} 6.1$ leads to inflammasome formation and-in cooperation with the depolarizing action of P2X7-induces release of IL-1 $\beta$ (Di et al., 2018).

$\mathrm{Ca}^{2+}$ signaling plays a crucial role for macrophage function. Thus, migration and phagocytosis of macrophages depend on $\mathrm{Ca}^{2+}$-permeable channels (Desai and Leitinger, 2014). In addition, the polarization of macrophages is mediated by several $\mathrm{Ca}^{2+}$-permeable ion channels including few members of the TRP channel family. TRPM7 promotes M2 polarization and shows high activity in this type of macrophage (Schilling et al., 2014). In contrast, deletion of TRPM2 favors a proinflammatory macrophage phenotype in Helicobacter pylori infection (Beceiro et al., 2017). M1 macrophage polarization is promoted by the activity of TRPC1 and $\mathrm{K}_{\mathrm{Ca}} 3.1$ (Xu et al., 2017; Chauhan et al., 2018). These channels could be taken under consideration in approaching macrophage plasticity in PDAC, since M2 macrophages comprise the majority of infiltrated immune cells. However, since TRPC1 and $\mathrm{K}_{\mathrm{Ca}} 3.1$ channels are expressed not only in neutrophils but also in cancer and stromal cells as well as in lymphocytes, the impact of activating these channels is difficult to predict (see below, Pharmacological Targeting of Ion Channels in PDAC for a more detailed discussion). 
Dendritic cells: There are a few dendritic cells at the tumor site and in the circulation of PDAC patients. The ability of dendritic cells to present foreign antigens has been used for designing dendritic cell-based immunotherapy (dendritic cell vaccines) against pancreatic cancer (Deicher et al., 2018). Some data indicate that dendritic cells predominantly support immunological tolerance in the strongly immunosuppressive PDAC environment (Barilla et al., 2019). Encountering an antigen elicits $\left[\mathrm{Ca}^{2+}\right]_{\mathrm{i}}$ to rise in dendritic cells, which is mediated by CRAC channels. The voltage-gated $\mathrm{K}^{+}$channels, $\mathrm{K}_{\mathrm{V}} 1.3$ and $\mathrm{K}_{\mathrm{V}} 1.5$, modulate $\mathrm{Ca}^{2+}$ fluxes by hyperpolarizing the membrane potential. They are involved in major histocompatibility complex II expression, migration, cytokine production, and phagocytosis (Matzner et al., 2008). P2X7 is also expressed in murine dendritic cells, mediating antigen presentation and migration (Mutini et al., 1999; Saéz et al., 2017). However, despite their crucial role in coordinating the immune response, the involvement of ion channels in functions of dendritic cells present in PDAC tissue is not yet well-described.

Myeloid-derived suppressor cells: Myeloid-derived suppressor cells (MDSCs) are not fully differentiated myeloid cells which exhibit highly immunosuppressive features. They can be further divided into polymorphonuclear (PMN-MDSC) and monocytic (M-MDSC) in mice, and early-stage (eMDSC) MDSCs in human. They share some phenotypic features with differentiated myeloid cells but can be distinguished by their inhibitory properties (Trovato et al., 2019). PSCs are presumed culprits of promoting MDSCs in pancreatic cancer via IL-6 release (Mace et al., 2013). MDSCs themselves exhibit increased arginase 1 activity, depleting the tumor microenvironment of L-arginine, which, in turn, elicits T-cell suppression. Not surprisingly, MDSC depletion is a looked for method for PDAC treatment (Thyagarajan et al., 2019).

There is an immense lack of knowledge about the function of ion channels in MDSCs. P2X7 and TRPV1 are the only channels described in MDSCs so far. P2X7 activation in M-MDSCs increases arginase-1, TGF- $\beta$, and production of ROS (Bianchi et al., 2014). In mice, TRPV1 activation stimulates MDSCs and protects from hepatitis (Hegde et al., 2011). The role of MDSC ion channels in the PDAC environment still needs to be elucidated.

Natural killer cells: Natural killer cells (NK cells) are innate lymphoid cells, and their function is similar to that of cytotoxic $\mathrm{CD}^{+}$cells. Despite the fact that their percentage ranges around $1.5-2 \%$ of mononuclear cells (Marsh et al., 2014; Bazhin et al., 2016) (which becomes 5\% of leukocytes after a partial resection (Gürlevik et al., 2016)), their role is important. The intravenous injection of an NK cell line (LNK) into the tumor improves the survival of mice and delays PDAC growth (Hu et al., 2019b). Several clinical trials built on NK cell-based immunotherapy are on at the moment (Sunami and Kleeff, 2019).

The role of NK cells against cancer is now well documented, and their ion channels appear to be of pivotal importance (Redmond and Buchanan, 2017). Like essentially all other lymphoid cells, NK cells have CRAC currents and $\mathrm{K}^{+}$currents mediated by $\mathrm{K}_{\mathrm{V}} 1.3$ and $\mathrm{K}_{\mathrm{Ca}} 3.1$, which are crucial for their function (Redmond and Buchanan, 2017). Koshy et al. discovered that a minority of human NK cells, defined as adherent NK cells, is able to nearly double the number of their $K_{V} 1.3$ and $\mathrm{K}_{\mathrm{Ca}} 3.1$ channels after their activation by cocultured cancer cells ( $\mathrm{K}_{\mathrm{V}}$ 1.3: 50 to 125/cell; $\mathrm{K}_{\mathrm{Ca}} 3.1$ : 20 to 40/cell). Contrariwise, the majority of NK cells, named "nonadherent," up-regulate only $\mathrm{K}_{\mathrm{V}} 1.3$, while $\mathrm{K}_{\mathrm{Ca}} 3.1$ channels remain unaltered ( $\mathrm{K}_{\mathrm{V}} 1.3$ : 20 to 350/cell; $\mathrm{K}_{\mathrm{Ca}}$ 3.1: 20 to 15/cell) (Koshy et al., 2013).

\section{Cells of the Adaptive Immune Response}

The PDAC tissue is heavily infiltrated by different subsets of Tcells and B cells. Depending on the nature of the cells and the cytokines being secreted, these cells can be both protumoral and antitumoral. Unfortunately, very little information is available about the ion channel expression of the different $\mathrm{T}$-cell subsets in PDAC. To set the frame for future research on ion channels in PDAC-associated T- and B-cell subsets, we will first summarize the general scheme about the dependence of T-cell activation on ion channels and then focus on the T- and B-cell subsets relevant in PDAC (Figure 2A) along with mostly non-PDAC-specific information available about the ion channel expression of those T- and B-cell subsets. Figure 2B provides an overview with respect to the expression (changes) in two of the most important $\mathrm{K}^{+}$channels found in the various subtypes.

\section{Adaptive Immunity: Antitumor Cells}

Principal ion channels in T-cells. The function of ion channels in $\mathrm{T}$ lymphocytes has been thoroughly investigated in the last three decades (Cahalan and Chandy, 2009). T lymphocyte activation strictly depends on extracellular $\mathrm{Ca}^{2+}$ entry via $\mathrm{Ca}^{2+}$ release-activated channels, CRAC, composed of Orai (three homologues: Orai1, Orai2, and Orai3) and Stim (two homologues: Stim1 and Stim2) proteins (Feske et al., 2012). In human, $\mathrm{T}$ lymphocyte Orail is essential for correct T-cell functioning (Vaeth et al., 2017). $\mathrm{Ca}^{2+}$ entry is facilitated by the opening of two $\mathrm{K}^{+}$channels, the voltage-gated gated $\mathrm{K}_{\mathrm{V}} 1.3$ and the $\mathrm{Ca}^{2+}$-activated $\mathrm{K}_{\mathrm{Ca}} 3.1$, which is activated by the increase in the cytosolic free $\mathrm{Ca}^{2+}$ concentration above $200 \mathrm{nM}$ (Panyi et al., 2014). Like in PDAC cancer cells (see $\mathrm{K}^{+}$Channels in Pancreatic Cancer Cells), these $\mathrm{K}^{+}$channels maintain a permissive negative membrane potential for efficient $\mathrm{Ca}^{2+}$ signaling, and their inhibition interferes with T-cell activation (Panyi et al., 2006). This general mechanism is tailored to the T-cell subtypes either by changing the relative expression level of $\mathrm{K}_{\mathrm{V}} 1.3 \mathrm{vs}$. $\mathrm{K}_{\mathrm{Ca}} 3.1$, or by changing the subunit composition of the CRAC channel.

T-cell subsets in PDAC and their corresponding ion channel repertoire. The major antitumor effector cells in PDAC belong to $\mathrm{CD}^{+}$helper and $\mathrm{CD} 8^{+}$cytotoxic cells, usually present in the tumor mass in similar proportions (Carstens et al., 2017; Stromnes et al., 2017). $\mathrm{CD}^{+}$helper T-cells are actually a broad composition of several subtypes (mainly $\mathrm{T}_{h} 1, \mathrm{~T}_{\mathrm{h}} 2$, and $\mathrm{T}_{\mathrm{h}} 17$ ). The 20-year-old theory of the so-called " $\mathrm{T}_{\mathrm{h}} 1 / \mathrm{T}_{\mathrm{h}} 2$ balance" stated that the cancerous environment causes a decrease in the $T_{h} 1 / T_{h} 2$ ratio, toward a $\mathrm{T}_{\mathrm{h}} 2$-dominated and protumoral condition (Shurin et al., 1999). Also in PDAC, the helper T-cell ratio is pivotal (Wörmann et al., 2014). Thus, $\mathrm{T}_{\mathrm{h}} 2$-related cytokines like IL-4 (Piro et al., 2017) or IL-6 (Mroczko et al., 2010) have been deemed as "prognostic" by many researchers (De Monte et al., 2011; Yako et al., 2016). $\mathrm{T}_{\mathrm{h}} 17$ cells have an uncertain position in the tumor milieu, although the 

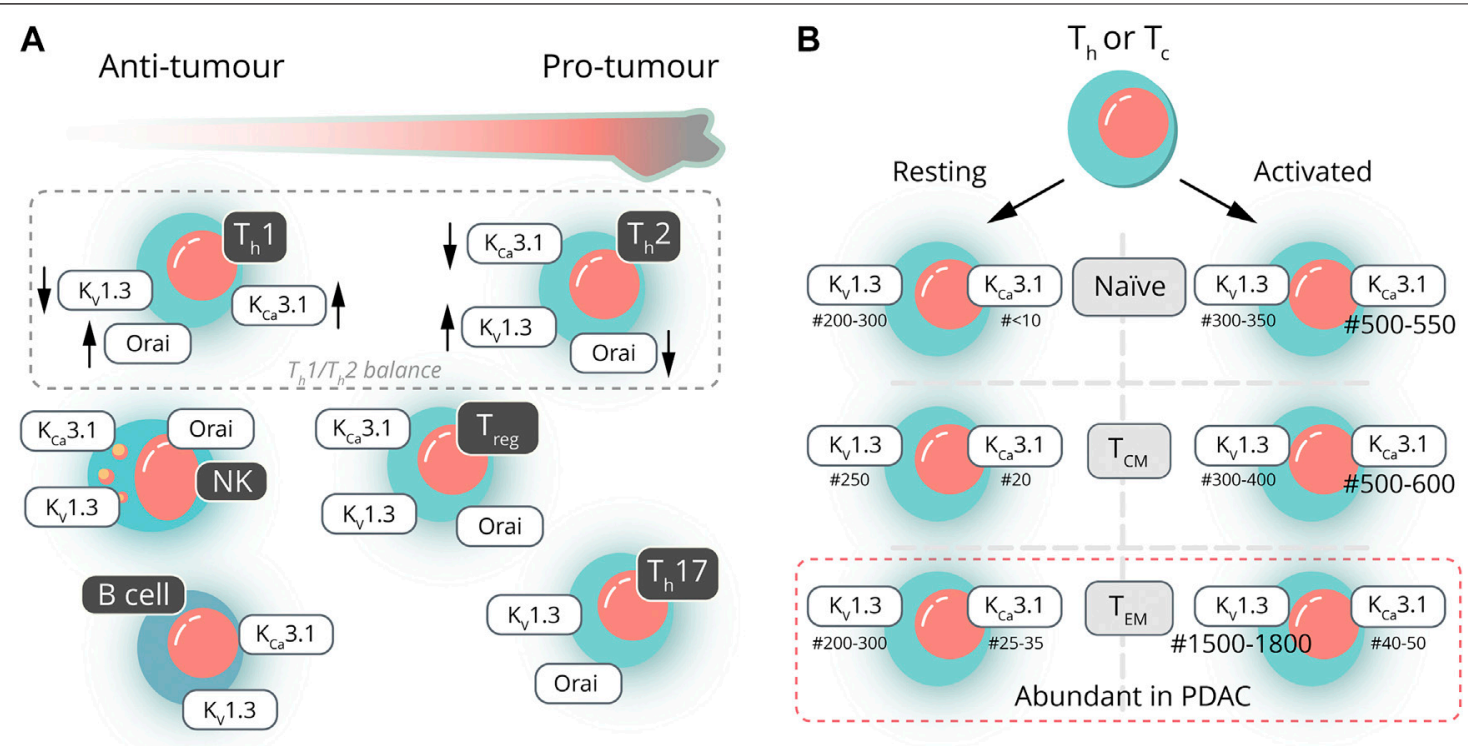

FIGURE 2 I Ion channels in pancreatic ductal adenocarcinoma-infiltrating lymphocytes. (A) Lymphocytes found in the PDAC microenvironment can be either proor antitumorigenic. The ratio of T-helper lymphocytes $\left(T_{h} 1 / T_{h} 2\right.$; dashed line) has a prognostic value in assessing therapy outcome. The presence of other lymphocytes can be either beneficial (NK and B cells) or detrimental ( $T_{\text {reg }}$ and $T_{h} 17$ ) (yet, not univocally). These PDAC-infiltrating lymphocytes often show distinct channel activities, which could be considered in targeted PDAC therapies. (B) Both helper $\left(T_{h}\right)$ and cytotoxic $\left(T_{c}\right)$ T lymphocytes can be further subdivided into naive, central memory $\left(T_{C, M}\right)$ or effector memory $\left(T_{E M}\right)$ T lymphocytes, the latter being the most abundant subtype in PDAC (indicated by the dashed line). Activation of T lymphocytes leads to characteristic changes in the numbers (\#) of $\mathrm{K}_{\mathrm{C}_{2} 3} 3.1$ and $\mathrm{K}_{\mathrm{v}} 1.3$ channels. Activation of naive and $\mathrm{T}_{\mathrm{CM}}$ is associated with an increase in $\mathrm{K}_{\mathrm{Ca}} 3.1$ expression, whereas activation of $T_{E M}$ causes a distinct increase in the number of $K_{V} 1.3$ channels.

majority of cases tends toward a protumoral effect (Murugaiyan and Saha, 2009; Ivanova and Orekhov, 2015). IL-17 and IL-22, produced by $\mathrm{T}_{\mathrm{h}} 17$ cells, are correlated with a bad prognosis in PDAC (McAllister et al., 2014; Wen et al., 2014). Contrariwise, using the murine cancer cell line PANC-02 and inducing $\mathrm{T}_{\mathrm{h}} 17$ function produced an antitumor effect (Gnerlich et al., 2010).

When naive $\mathrm{T}$-cells encounter their specific antigens, they differentiate into central memory $\mathrm{T}$-cells $\left(\mathrm{T}_{\mathrm{CM}}\right)$ and effector memory $\mathrm{T}$-cells $\left(\mathrm{T}_{\mathrm{EM}}\right)$ of either $\mathrm{CD}^{+}$or $\mathrm{CD}^{+}$phenotype. The majority of T-cells in an orthotopic mouse PANC02 PDAC model are effector/effector memory T-cells (Shevchenko et al., 2013; Bazhin et al., 2016). In a similar fashion, in human PDAC, most $\mathrm{CD}^{+}$tumor-infiltrating lymphocytes are effector memory cells (Poschke et al., 2016; Stromnes et al., 2017).

As noted above, relatively little is known about the ion channel expression pattern in various $\mathrm{T}$-cell subsets infiltrating the PDAC tissue. Compared to naive T-cells, rich in both Orail and Orai2, effector $\mathrm{CD}^{+}$and $\mathrm{CD}^{+}$T-cells down-regulate only Orai2, generating more Orail homohexamers, which are characterized by a superior $\mathrm{Ca}^{2+}$ conductance. In this manner, effector T-cells allow larger $\mathrm{Ca}^{2+}$ influxes and activate quicker after the antigen recognition than naive cells (Vaeth et al., 2017). Naive human $\mathrm{CD}^{+}$and $\mathrm{CD} 8^{+} \mathrm{T}$ lymphocytes are characterized by $200-300 \mathrm{~K}_{\mathrm{V}} 1.3$ and less than 10 functional $\mathrm{K}_{\mathrm{Ca}} 3.1$ channels, whereas their activated counterparts mildly up-regulate $\mathrm{K}_{\mathrm{V}} 1.3$ (300-350 channels/cell) and severely increase $\mathrm{K}_{\mathrm{Ca}} 3.1$ expression (500-550 channels/cell) (Ghanshani et al., 2000; Wulff et al., 2003; Cahalan and Chandy, 2009).
Murine $\mathrm{CD}^{+} \mathrm{T}_{\mathrm{h}} 1$ and $\mathrm{T}_{\mathrm{h}} 2$ have similar numbers of $\mathrm{K}_{\mathrm{V}} 1.3$ channels in their membranes, while murine $\mathrm{T}_{\mathrm{h}} 2$ cells have substantially less functional $\mathrm{K}_{\mathrm{Ca}} 3.1$ channels than $\mathrm{T}_{\mathrm{h}} 1$ lymphocytes. This difference in the $\mathrm{K}_{\mathrm{Ca}} 3.1$ expression/function may explain the larger amplitudes of the $\mathrm{Ca}^{2+}$ signals in $\mathrm{T}_{\mathrm{h}} 1$ cells (Fanger et al., 2000; Di et al., 2010). A flow cytometric analysis of $\mathrm{K}_{\mathrm{V}} 1.3$ expression in human peripheral blood lymphocytes showed that the $\mathrm{T}_{\mathrm{h}} 1$ subset has less $\mathrm{K}_{\mathrm{V}} 1.3$ channels than $\mathrm{T}_{\mathrm{h}} 2$ (Toldi et al., 2011; Orbán et al., 2014). Consistent with this, they also reported that $\mathrm{K}_{\mathrm{V}} 1.3$ inhibitors have a smaller impact on the $\mathrm{Ca}^{2+}$ transients in $\mathrm{T}_{\mathrm{h}} 1$ lymphocytes than $\mathrm{K}_{\mathrm{Ca}} 3.1$ inhibitors (Toldi et al., 2011). Moreover, $\mathrm{Ca}^{2+}$ influx through CRAC is more prevalent in $\mathrm{T}_{\mathrm{h}} 1$ than $\mathrm{T}_{\mathrm{h}} 2$ cells (Toldi et al., 2012). Both mouse and human $\mathrm{T}_{\mathrm{h}} 17$ lymphocytes have the highest $\mathrm{K}_{\mathrm{V}} 1.3$ expression, but no or little $\mathrm{K}_{\mathrm{Ca}} 3.1$ expression (Di et al., 2010; Orbán et al., 2014). It should be pointed out that the role of $\mathrm{K}_{\mathrm{V}} 1.3$ and $\mathrm{K}_{\mathrm{Ca}} 3.1$ in regulating $\mathrm{Ca}^{2+}$ signaling in human $\mathrm{T}$-cell subsets, addressed in the articles above, has not yet been confirmed using electrophysiology.

$\mathrm{T}_{\mathrm{CM}}$ and $\mathrm{T}_{\mathrm{EM}}$ memory cells not only differ in characteristic membrane markers and in their homing and trafficking ability but also in their ion channel repertoire. Human resting $\mathrm{T}_{\mathrm{CM}}$ and $\mathrm{T}_{\mathrm{EM}}$ cells, whether they are $\mathrm{CD} 4^{+}$or $\mathrm{CD}^{+}$, are similar to naive cells regarding their $\mathrm{K}_{\mathrm{V}} 1.3$ and $\mathrm{K}_{\mathrm{Ca}} 3.1$ expression. When activated, they dichotomically diverge: $\mathrm{T}_{\mathrm{CM}}$ cells show the usual $\mathrm{K}_{\mathrm{Ca}} 3.1^{\text {high }}$ phenotype, whereas $\mathrm{T}_{\mathrm{EM}}$ cells exhibit a dramatically increased $\mathrm{K}_{\mathrm{V}} 1.3$ expression in the plasma membrane (Ghanshani et al., 2000; Wulff et al., 2003; Cahalan and Chandy, 2009). (For more details with respect to the channel expression of the various subtypes, see Figure 2B.) 
B lymphocytes in PDAC and their corresponding ion channel repertoire. The role of $\mathrm{B}$ cells in the pathology of PDAC is not well defined. In human PDAC, they are associated with a good prognosis (Castino et al., 2016; Brunner et al., 2020). However, this is not adequately mirrored by the existing mouse models (Spear et al., 2019). In 2016, three different research groups showed that B cells have a protumorigenic role in genetically modified mice (KC mice expressing the oncogenic Kras in the pancreas only) and in healthy mice orthotopically injected with KC cells (reviewed in Roghanian et al. (2016)). KMC, a mouse model characterized by the knock-in of one or two copies of Myc (Farrell et al., 2017), develops one of the most aggressive and histologically human-like PDAC. It is not as strongly infiltrated by NK and B cells as the slowly developing KC model. The removal of the $M y c$ gene promotes $\mathrm{NK}$ and $\mathrm{B}$ cells to enter the tumor mass, lengthening the life span of mice (Muthalagu et al., 2020). Some studies merely report B-cell infiltration in PDAC based on their CD20 expression (Brunner et al., 2020), and further classification of the cells based on their activation status (i.e., CD27 expression) is lacking. Other studies, for example, Castino et al., found that interspersed B cells from PDAC show little or no CD27 and other fundamental markers. However, when they organize themselves in tertiary lymphoid tissue structures within the tumor stroma, CD27 expression is upregulated (Castino et al., 2016).

There is a strong relationship between the ion channel expression and the activation status of the B cells (Wulff et al., 2004). Human naive $\left(\operatorname{IgD}^{+} \mathrm{CD} 27^{-}\right)$and early memory $\left(\operatorname{IgD}^{+}\right.$ $\mathrm{CD} 27^{+}$) B cells, just like naive and central memory T-cells, are abundant in $\mathrm{K}_{\mathrm{V}} 1.3$ and virtually lack $\mathrm{K}_{\mathrm{Ca}} 3.1$ (naive: $\mathrm{K}_{\mathrm{V}} 1.3$ : 90-100, $\mathrm{K}_{\mathrm{Ca}}$ 3.1: 5 channels/cell; early memory: $\mathrm{K}_{\mathrm{V}} 1.3$ : 250 , $\mathrm{K}_{\mathrm{Ca}}$ 3.1: 5-10 channels/cell). These cells, when activated, overexpress only $\mathrm{K}_{\mathrm{Ca}} 3.1$ channels (naive: $\mathrm{K}_{\mathrm{V}} 1.3$ : 80-100, $\mathrm{K}_{\mathrm{Ca}}$ 3.1: 550-650 channels/cell; early memory: $\mathrm{K}_{\mathrm{V}} 1.3$ : 150-200; $\mathrm{K}_{\mathrm{Ca}} 3.1$ : 650-750 channels/cell) (Wulff et al., 2004; Cahalan and Chandy, 2009). Late memory class-switched B cells $\left(\operatorname{IgD}^{-} \mathrm{CD} 27^{+}\right)$ have plenty of $\mathrm{K}_{\mathrm{V}} 1.3$ and few $\mathrm{K}_{\mathrm{Ca}} 3.1\left(\mathrm{~K}_{\mathrm{V}} 1.3: 2,200-2,600 ; \mathrm{K}_{\mathrm{Ca}} 3.1\right.$ : 50-70 channels/cell). They tend to further enhance their $\mathrm{K}_{\mathrm{V}} 1.3$ expression when activated $\left(\mathrm{K}_{\mathrm{V}} 1.3: 2,900-3,300 ; \mathrm{K}_{\mathrm{Ca}} 3.1\right.$ : $60-80$ channels/cell).

\section{Adaptive Immunity: Protumor Cells}

Regulatory T-cells in PDAC and their corresponding ion channel repertoire. Human $\mathrm{T}_{\text {reg }}$ cells are important immunosuppressive $\mathrm{CD}^{+}$lymphocytes heavily implicated in autoimmunity. They are usually identified by the signature $\mathrm{CD}^{+} \mathrm{CD} 25^{+}$Foxp $^{+}$(Whiteside, 2015). In contrast to the healthy pancreas (Weisberg et al., 2019), PDAC is heavily infiltrated by $\mathrm{T}_{\text {regs. }}$. They can reach $20-40 \%$ of the whole $\mathrm{CD}^{+}$pool (Shevchenko et al., 2013; Tang et al., 2014; Bazhin et al., 2016). Recently, it has been discovered that PDAC tissues overexpress a cancer-related Foxp3 protein (c-Foxp3) which, through the secretion of CCL5, would recruit a high number of $\mathrm{T}_{\text {reg }}$ cells in the tumor environment (Wang et al., 2017).

Similarly to their helper $\mathrm{CD}^{+}$counterpart, human $\mathrm{T}_{\text {reg }} \mathrm{s}$ also have a high number of voltage-gated $\mathrm{K}_{\mathrm{V}} 1.3$ channels (Estes et al.,
2008; Shao et al., 2018) and a low number of $\mathrm{K}_{\mathrm{Ca}} 3.1$ channels in their membrane (Varga et al., 2009). Intratumoral $\mathrm{T}_{\text {regs }}$ have a peculiar T-cell receptor repertoire whose stimulation may have an important role in their immunosuppressive function (Ahmadzadeh et al., 2019). When human $\mathrm{T}_{\text {regs }}$ get activated by $\mathrm{T}$-cell receptor stimulation, they do not up-regulate $\mathrm{K}_{\mathrm{V}} 1.3$ as normal effector $\mathrm{T}$ cells do (Reneer et al., 2011) and activated human $\mathrm{T}_{\text {reg }}$ s incubated with $\mathrm{K}_{\mathrm{V}} 1.3$ and $\mathrm{K}_{\mathrm{Ca}} 3.1$ blockers do not show any difference in the $\mathrm{Ca}^{2+}$ influx, suggesting that the contribution of these channels to the activation could be minimal (Orbán et al., 2014). Moreover, $\mathrm{T}_{\text {reg }}$ from $\mathrm{K}_{\mathrm{Ca}} 3.1$ knockout mice are able to suppress $\mathrm{T}$-cell proliferation in a comparable manner as wild-type $\mathrm{T}_{\text {regs }} \mathrm{s}$, pointing to a minor role of these channels (Di et al., 2010). Similarly, knocking out $\mathrm{K}_{\mathrm{V}} 1.3$ in mice does not hinder the physiological generation of $\mathrm{T}_{\text {reg }}$ (Gocke et al., 2012). Hence, the role of these $\mathrm{K}^{+}$channels in $\mathrm{T}_{\text {regs }}$ is currently still unclear. CRAC channels are involved in $\mathrm{T}_{\text {reg }}$ development and contribute to their suppressive function (Vaeth et al., 2019).

\section{THERAPEUTICAL APPROACHES AND ION CHANNELS IN PDAC}

Unfortunately, PDAC therapy has remained largely ineffective. Radical surgical resection of the tumor as well as chemotherapeutic agents like gemcitabine combined with nabpaclitaxel and FOLFIRINOX constitutes the standard therapy for PDAC patients (Hessmann et al., 2020). However, 80-90\% of the patients present at an advanced unresectable stage at the time of diagnosis. Even if surgical intervention is possible, recurrence of the cancer lesions will be common (Vincent et al., 2011; Peixoto et al., 2015; Rawla et al., 2019). Therapy resistance is in part due to the fibrotic microenvironment in PDAC which hinders drugs from reaching their target and due to the immunosuppressive properties of the PDAC tumor microenvironment. Nonetheless, so far, therapeutic targeting of the PDAC tumor microenvironment has not been successful (reviewed in Hessmann et al. (2020)).

\section{Electrolytes and Organic Metabolites in PDAC}

The great majority of the studies using ion channel blockers or activators are aimed to target cancer cells, rather than immune or stroma cells. The therapeutic potential of ion channels of cancer-associated immune and stroma cells has not been analyzed in great detail so far. In a groundbreaking study by Eil et al., it was shown that B16 (mouse) or Mel624 (human) melanoma cells subcutaneously injected into mice create a TME much richer in $\mathrm{K}^{+}$than serum $(40 \mathrm{mM}$ vs. $5 \mathrm{mM})$, probably due to marked necrosis within the tumor (Eil et al., 2016). Since more than $60 \%$ of PDAC cases host micro- and/or macronecrotic spots (Hiraoka et al., 2010), it is plausible to hypothesize that $\mathrm{PDAC}$ is a tumor rich in extracellular $\mathrm{K}^{+}$as well. The $\mathrm{T}$-cell $\left[\mathrm{K}^{+}\right]_{\mathrm{i}}$ is around $130 \mathrm{mM}$, but when cultured in a medium with high $\left[\mathrm{K}^{+}\right]_{\mathrm{o}}$-specular of what happens in vivo- the $\left[\mathrm{K}^{+}\right]_{\mathrm{i}}$ in these cells can rise above 
$150 \mathrm{mM}$ (Eil et al., 2016; Ong et al., 2019). Although the $\left[\mathrm{K}^{+}\right]$ changes would result in the depolarization of the cell membrane, the authors did not find a diminished $\mathrm{Ca}^{2+}$ influx into the T-cells during their activation in high $\left[\mathrm{K}^{+}\right]_{\mathrm{o}}$ (Eil et al., 2016). This is opposite to the generally accepted role of the membrane potential in controlling $\mathrm{Ca}^{2+}$ signaling.

Membrane depolarization could also lead to enhanced IL-2 signaling in $\mathrm{T}_{\text {regs }}$ and, consequently, to suppressed antitumor immune surveillance by such an unbalanced ionic environment (Nagy et al., 2018). The high $\left[\mathrm{K}^{+}\right]$-adapted tumor-infiltrating lymphocytes are less functional than the normal ones. Conversely, decreasing the $\left[\mathrm{K}^{+}\right]_{\mathrm{i}}$ in a forced manner using the $\mathrm{Na}^{+} / \mathrm{K}^{+}$ATPase blocker ouabain renders the $\mathrm{CD} 8^{+}$cells more functional again. Moreover, substituting normal (poorly functioning) immune cells with $\mathrm{CD}^{+}$cells overexpressing the $\mathrm{K}^{+}$efflux channels $\mathrm{K}_{\mathrm{V}} 1.3$ or $\mathrm{K}_{\mathrm{Ca}} 3.1$ boosts their antitumor activity. Tumor growth is slowed down, and this improves the survival (Eil et al., 2016). These findings nicely illustrate how ion channel function and thereby cell function depend on the "correct" ionic composition of the pericellular environment.

The disrupted ion balance in the tumor microenvironment also affects the operation of protumor immune cells. Increasing $\left[\mathrm{Na}^{+}\right]_{\mathrm{o}}$ and $\left[\mathrm{Cl}^{-}\right]_{\mathrm{o}}$ in melanoma as well as lung and breast cancer by the administration of a high salt diet (HSD) inhibits the capacity of MDSCs to suppress antitumor cytotoxic cells. Accordingly, this treatment has made the tumors to shrink in size (Willebrand et al., 2019; He et al., 2020). High $\left[\mathrm{Na}^{+}\right]_{\mathrm{o}}$ and $\left[\mathrm{Cl}^{-}\right]_{\mathrm{o}}$ partially inhibit the function of thymus-derived mouse $\mathrm{T}_{\text {reg }} \mathrm{s}$ as well (Luo et al., 2019), which could also contribute to the less immunosuppressive environment. Whether these electrolytes influence antitumor $\mathrm{CD}^{+}$and $\mathrm{CD}^{+}{ }^{+} \mathrm{T}$-cells is unclear. Melanoma and breast cancer growth in $\mathrm{BABL} / \mathrm{C}-\mathrm{nu} / \mathrm{nu}$ mice, lacking sufficient $\mathrm{T}$-cell-mediated immune reactions, are insensitive to a high salt diet, indicating that $\mathrm{T}$-cell-mediated antitumor response is key to the high salt diet-induced antitumor activity (He et al., 2020). On the other hand, the high salt diet prevents tumors from growing also in $\mathrm{RAG}^{-/-}$mice, despite the lack of $\mathrm{T}$ and $\mathrm{B}$ cells in these animals. This suggests that the high salt diet may act by yet another mechanism independent of immune cell modulation (Willebrand et al., 2019). All these studies clearly show that the electrolyte imbalance in the tumor microenvironment significantly contributes to tumor progression and may shape the immune response.

High salt diet increases the osmolarity in the cancer tissue ( $\mathrm{He}$ et al., 2020), which may influence the volume regulation of immune and cancer cells and link the high-salt diet effects described above to ion channels. Cell volume changes are known to regulate cancer cell migration, invasion, and apoptosis in an ion channel (and transporter)-dependent manner (see for reviews (Bortner and Cidlowski, 2014; Schwab and Stock, 2014)). In addition, cell volume changes in immune cells regulate apoptosis (Bortner and Cidlowski, 2011) and B-cell activation (Cvetkovic et al., 2019). Although the pivotal role of ion channels in volume regulation in immune (Feske et al., 2015) and cancer cells (Morishita et al., 2019) is well established, the relevant ion channels that sense the altered ion concentrations and osmolarity in the PDAC microenvironment are yet to be identified.

In addition to $\left[\mathrm{K}^{+}\right]$, the $\mathrm{pH}$ in the tumor microenvironment also changes characteristically during the progression of the disease. The nondiseased pancreas stroma is deemed to endure postprandial tides of acidic $\mathrm{pH}$ in order to counterbalance the apical excretion of $\mathrm{HCO}_{3}^{-}$ions. During the development of PDAC, the tumor microenvironment becomes very acidic (Pedersen et al., 2017). The extra- and intracellular $\mathrm{pH}$ regulate voltage-gated $\mathrm{K}^{+}$channels of the $\mathrm{K}_{\mathrm{V}} 1$ Shaker family (Starkus et al., 2003). One of the major $\mathrm{K}^{+}$channels in lymphocytes, $\mathrm{K}_{\mathrm{V}} 1.3$, in particular, is uniquely modulated by acidification. A decrease in both $\mathrm{pH}_{\mathrm{i}}$ and $\mathrm{pH}_{\mathrm{o}}$ reduces the peak $\mathrm{K}_{\mathrm{V}} 1.3$ current, and acidification of the extracellular medium slows inactivation kinetics of the current (Deutsch and Lee, 1989). This dual regulation of $\mathrm{K}_{\mathrm{V}} 1.3$ by $\mathrm{pH}_{\mathrm{o}}$ allows very sensitive modulation of the $\mathrm{K}^{+}$conductance of the membrane. Acidification-induced $\mathrm{K}^{+}$current inhibition is counterbalanced, depending on $\mathrm{pH}_{\mathrm{o}}$, by the concomitant slowing of the inactivation kinetics. Interestingly, the slowing of the inactivation kinetics at low $\mathrm{pH}_{\mathrm{o}}$ is reverted to acceleration of the kinetics when acidic extracellular $\mathrm{pH}$ is combined with elevated $\left[\mathrm{K}^{+}\right]_{\mathrm{e}}$ (Somodi et al., 2008). The unique response of $\mathrm{K}_{\mathrm{V}} 1.3$ to extracellular acidification is mediated by reversible protonation of H399 in the external vestibule of the channel guarding the selectivity filter (Somodi et al., 2004). The protonation of $\mathrm{H} 399$ also bears significance on the targeting of the $\mathrm{K}_{\mathrm{V}} 1.3$ channel by peptide and nonpeptide inhibitors as well. For example, tetraethylammonium (Somodi et al., 2004) and peptide blockers (Rodrigues et al., 2003) lose their affinity for $\mathrm{K}_{\mathrm{V}} 1.3$, when $\mathrm{H} 399$ is protonated. This molecular information about $\mathrm{K}_{\mathrm{V}} 1.3$ gating at various $\mathrm{pH}$ and $\mathrm{K}^{+}$concentrations may contribute to the understanding of how the tumor microenvironment interacts with immune cells at the level of ion channels and may allow proper therapeutic ion channel targeting. We refer to our recent review for a more detailed discussion on how cancer progression may be affected by modulation of cation channels in tumor and tumor stroma cells (Pethö et al., 2020).

The disbalance of the tumor microenvironment is not restricted to inorganic electrolytes. It is well known that tumors are rich in ATP and adenosine, which influence cells and their function through purinergic receptors (Feng et al., 2020). The ATP concentration in the interstitial tissue of PDAC is almost 100 times higher than normal pancreatic stroma $(\sim 10 \mu \mathrm{M}$ vs. $100 \mathrm{nM}$ (Hu et al., 2019a)). PDAC cells usually overexpress both CD39 (Künzli et al., 2007) and CD73 (Harvey et al., 2020), which transform ATP to AMP and AMP to adenosine. Thus, it is plausible that PDAC is rich in adenosine as well, which would activate the receptor $\mathrm{A}_{2 \mathrm{~A}} \mathrm{R}$ and inhibit $\mathrm{CD} 8^{+}$ cells via PKA (Chimote et al., 2013). As more thoroughly described later, adenosine also decreases the $\mathrm{K}_{\mathrm{Ca}} 3.1$ conductance of $\mathrm{T}$-cells without affecting the number of channels in the membrane (Chimote et al., 2018). Adenosine exerts in vivo and in vitro an anti-PDAC effect in immunodeficient nu/nu mice (Yang et al., 2019). This means that the outcome of the adenosine action will be the combination 
of inhibiting antitumor immunity and the growth of PDAC. Three clinical trials are currently assessing whether antiadenosine therapy coupled with immuno- and chemotherapies is able to halt PDAC progression (Singh and O'Reilly, 2020).

\section{Pharmacological Targeting of Ion Channels in PDAC}

Ion channel targeting is a well-established therapeutic concept in other medical disciplines that has been successfully applied in the clinical routine for decades. Because of their expression in the plasma membrane, ion channels are easily druggable. Intriguingly, many of the ion channels that are known to drive tumor progression are targeted by drugs currently used for noncancer indications, either as the primary effect or as a side effect. These drugs could in principle be repurposed for cancer treatment as suggested for nontorsadogenic $\mathrm{K}_{\mathrm{V}} 11.1$ blockers (Kale et al., 2015; Pointer et al., 2017). The fact that cancer, stroma, and immune cells rely nearly on the same set of ion channels makes the selection of the right drug a complex quest. Ideally, channel targeting should elicit synergistic effects such as inhibition of tumor and stoma cell proliferation or migration as well as activation of antitumor immune cells or inhibition of tumor-promoting immune cells. This is further complicated by the dynamics/variability of channel expression: in lymphocytes, for example, such expression strongly relies on the activation state of the respective subtype. Moreover, specificity of the channel modulators constitutes another challenge which has not been solved satisfactorily for many channels. However, an increasing number of ion channel protein structures is becoming amenable for in silico drug design (e.g., Brömmel et al. (2020b)). Alternatively, peptide-based blockers or antibody targeting could be more specific alternatives (Duranti and Arcangeli, 2019; Hartung et al., 2020; Tajti et al., 2020). Here, we list potential target ion channels and the existing knowledge about the consequence of their activation/inhibition in immune, stroma, and tumor cells as well.

$\mathrm{K}_{\mathbf{C a}} 3.1$ is a well-studied channel in this context. The specific modulators of $\mathrm{K}_{\mathrm{Ca}} 3.1$ are inhibitors, such as TRAM-34 (Wulff et al., 2000), senicapoc, NS6180, and verapamil (Wulff et al., 2007), and activators such as riluzole (Liu et al., 2013) and 1-EBIO (Devor et al., 1996). Molecular modeling suggests that senicapoc binds to $\mathrm{K}_{\mathrm{Ca}} 3.1$ channels in the open conformation (Brömmel et al., 2020a). The inhibition or activation of an ion channel may result in diminished or augmented cellular functions. For example, two specific inhibitors of $\mathrm{K}_{\mathrm{Ca}} 3.1$ (TRAM-34 and NS6180) boosted in vivo adherent human NK-cell proliferation, degranulation, and capacity of killing erythroleukemic cells in mice (Koshy et al., 2013). Conversely, activation of $\mathrm{K}_{\mathrm{Ca}} 3.1$ channels with 1-EBIO inhibits migration of transformed renal epithelial cells almost as effectively as channel inhibition (Schwab et al., 2006). As discussed above, $\mathrm{T}$ lymphocytes in PDAC are supposedly fairly devoid of $\mathrm{K}_{\mathrm{Ca}} 3.1$; hence, the use of such a blocker should not hinder physiological function of these cells, regardless of $\left[\mathrm{K}^{+}\right]$in the tumor microenvironment. On the other hand, in mice, the adoptive cell transfer of $\mathrm{T}_{\mathrm{CM}}$ cells, a minority in PDAC but rich in $\mathrm{K}_{\mathrm{Ca}} 3.1$, more efficiently combats melanoma than the transfer of the $\mathrm{T}_{\mathrm{EM}}$ subset that poorly expresses $\mathrm{K}_{\mathrm{Ca}} 3.1$ (Klebanoff et al., 2005, 2016). Unfortunately, the consequence of the modulation of $\mathrm{K}_{\mathrm{Ca}} 3.1$ activity of $\mathrm{T}_{\mathrm{EM}}$ and $\mathrm{T}_{\mathrm{CM}}$ cells has not been elaborated yet in tumor models.

$\mathrm{K}_{\mathrm{Ca}} 3.1$ is unique among the $\mathrm{K}^{+}$channels of the immune system since the consequences of both channel inhibition and activation can be studied. Activation of $\mathrm{K}_{\mathrm{Ca}} 3.1$ by 1 -EBIO is able to induce movement in akinetic $\mathrm{CD}^{+}$cells isolated from the peripheral blood of head and neck squamous cell carcinoma patients and ameliorate their IFN- $\gamma$ production (Chimote et al., 2018). Thus, pharmacological activation of $\mathrm{K}_{\mathrm{Ca}} 3.1$ may enhance antitumor activity of $\mathrm{CD}^{+} \mathrm{T}$-cells by overcoming the inhibition of the $\mathrm{K}_{\mathrm{Ca}} 3.1$ activity caused by large amounts of adenosine in cancer stroma and/or localized down-regulation of membraneproximal calmodulin, the $\mathrm{Ca}^{2+}$ sensor of $\mathrm{K}_{\mathrm{Ca}} 3.1$. The diminished association of calmodulin with the channel suppresses the $\mathrm{K}_{\mathrm{Ca}} 3.1$ activity in circulating T-cells and limits their ability to infiltrate adenosine-rich tumor-like microenvironments (Chimote et al., 2020). How NK cells would behave with a $\mathrm{K}_{\mathrm{Ca}} 3.1$ activator has not been studied. It is known however that in patients suffering from amyotrophic lateral sclerosis, riluzole, which is the only disease-modifying therapy for ALS, does not compromise NK cells from entering the spinal cord and the motor cortex (Garofalo et al., 2020). Based on this, we can hypothesize that $\mathrm{K}_{\mathrm{Ca}} 3.1$ activation would not interfere with the antitumor action of NK cells.

In vitro studies also demonstrated that the $\mathrm{K}_{\mathrm{Ca}} 3.1$ activator SKA-346 increases the IFN- $\gamma$ secretion of high $\left[\mathrm{K}^{+}\right]$-inhibited human T-cells by 50\% (Ong et al., 2019). Neither this nor new $\mathrm{K}_{\mathrm{Ca}} 3.1$ activators, like SKA-31 and SKA-121 (Ohya and Kito, 2018), have been tested in PDAC; hence, their usefulness is, in light of our current knowledge, unknown.

It is important to point out that $\mathrm{K}_{\mathrm{Ca}} 3.1$ activators are also targeting cancer cells and stromal cells. This has been shown for multiple cancer entities (see Mohr et al., (2019) for review) including PDAC (Jäger et al., 2004; Bonito et al., 2016; Storck et al., 2017). Riluzole and SKA-31 were successfully used to suppress the expansion of colorectal cancer cell lines, in combination with the $\mathrm{K}_{\mathrm{V}} 11.1$ channel blocker E4031 (Pillozzi et al., 2018) (see below for a detailed discussion of the challenges associated with targeting $\mathrm{K}_{\mathrm{V}} 11$ channels in PDAC therapy). Another study by Sun et al. showed that riluzole is capable of inhibiting the proliferation and partly killing several human PDAC cell lines (Sun et al., 2019). These effects, in combination with the aforementioned effect of $\mathrm{K}_{\mathrm{Ca}} 3.1$ activators in rebalancing $\mathrm{T}$-cell $\left[\mathrm{K}^{+}\right]_{\mathrm{i}}$, could synergistically act in the treatment of malignancies by targeting the $\mathrm{K}_{\mathrm{Ca}} 3.1$ channel.

Although riluzole has been defined and used as a $\mathrm{K}_{\mathrm{Ca}} 3.1$ activator (Pillozzi et al., 2018), this has to be viewed with caution since its specificity is very limited and it inhibits a series of other ion channels, such as $\mathrm{K}_{\mathrm{V}} 11.1$ (Pillozzi et al., 2018) and, most notably, several voltage-gated sodium channels (Nav1.x) (Song et al., 1997; Djamgoz and Onkal, 2012). Several human carcinomas express those $\mathrm{Na}_{V} s$, which promote invasiveness and metastasis under hypoxic conditions (Djamgoz et al., 2019). Inhibition of the hypoxia-sensitive 
persistent component of the $\mathrm{Na}_{\mathrm{V}}$ current $\left(\mathrm{INa}_{\mathrm{P}}\right)$ by riluzole suppresses cancer cell invasiveness in vitro (Djamgoz and Onkal, 2012). There is evidence that aggressive PDAC cell lines express $\mathrm{Na}_{\mathrm{V}} 1.5$ and $\mathrm{Na}_{V} 1.6$, but these channels do not seem to play a major functional role in PDAC cells. $\mathrm{Na}_{\mathrm{V}}$ channel activity becomes measurable only upon EGFR inhibition (Bonito, 2017). Hence, we can suppose that riluzole will not influence PDAC growth by its direct action on $\mathrm{Na}_{\mathrm{V}}$. The aforementioned effects of the "broad-spectrum" ion channel inhibitor riluzole on PDAC cell lines (Sun et al., 2019) are therefore more likely to be attributed to its action on the $\mathrm{K}_{\mathrm{Ca}} 3.1$ or $\mathrm{K}_{\mathrm{V}} 11.1$ channels. Nonetheless, the use of a broad-spectrum ion channel modulator can be justified when it yields the desired phenotypic effects (e.g., inhibition of migration and proliferation). Phenotypical drug screening is at least as successful as molecular screening which aims at a single molecularly defined target (Zheng et al., 2013).

Riluzole has pleiotropic effects, including dampening of excitotoxicity through interruption of glutamatergic transmission in the central nervous system (Benavides et al., 1985). This effect may be mediated by the inhibition of the activation of NMDA glutamate receptors (Debono et al., 1993). In addition to the inhibition of glutamatergic transmission, the beneficial effects of riluzole in the treatment of ALS may include inhibition of presynaptic voltage-gated $\mathrm{Ca}^{2+}$ channels and the inhibition of $\mathrm{Na}_{\mathrm{V}}$ channels and block of the persistent $\mathrm{Na}^{+}$currents in motoneurons ((Lamanauskas and Nistri, 2008), and see Cheah et al. (2010) for review). Thus, the use of riluzole as a $\mathrm{K}_{\mathrm{Ca}} 3.1$ activator may be limited by its effects on the central nervous system.

The action of $\mathrm{Na}_{\mathrm{V}}$ inhibitors is further complicated as human immature dendritic cells express $\mathrm{Na}_{V} 1.7$ (Zsiros et al., 2009). Silencing $\mathrm{Na}_{\mathrm{V}} 1.7$ shifts the membrane potential to more hyperpolarized values in $\mathrm{CD} \mathrm{a}^{+}$immature dendritic cells. This results in decreased cell migration, which otherwise is a hallmark of a functionally immature dendritic cells (Kis-Toth et al., 2011). How this would impact in PDAC, a tumor known for its paucity in dendritic cell infiltration (Hegde et al., 2020), has not been explored yet.

The ATP-rich PDAC environment could also enhance immunosuppression through P2X7, which is present in both T lymphocytes (Feske et al., 2012) as well as in cancer (Giannuzzo et al., 2015) and stellate cells in PDAC (Haanes et al., 2012). This cation-selective ion channel is important for the infiltration of $\mathrm{T}$ lymphocytes into the tumor, since $\mathrm{P} 2 \mathrm{X}^{-/-}$mice have a suboptimal immune response (De Marchi et al., 2019). Interestingly, inhibiting $\mathrm{P} 2 \mathrm{X} 7$ with a selective antagonist like A740003 causes an increase in the percentage of infiltrating $\mathrm{CD}^{+}$cells and a significant drop in tumor weight and $\mathrm{T}_{\text {reg }}$ abundance (De Marchi et al., 2019). Whether these results, obtained with a mouse melanoma model, can be translated to immune modulation in a "cold" tumor like PDAC is unclear: the few reports about in vivo administration of $\mathrm{P} 2 \mathrm{X} 7$ antagonists (AZ10606120 and A438079) did not analyze the involvement of the immune system (Mohammed et al., 2017) or used immunodeficient nude mice (Giannuzzo et al., 2016).

\section{Challenges of Using $K_{v} 11$ Channels as Therapeutic Target in PDAC}

The most critical issue for using $\mathrm{K}_{\mathrm{V}} 11.1$ channel blockers in PDAC therapy have and still will be their cardiac side effects. Indeed, $\mathrm{K}_{\mathrm{V}} 11.1$ channels are highly expressed in the heart, representing the molecular correlate of the rapid repolarizing current $\mathrm{I}_{\mathrm{Kr}}$ (Sanguinetti et al., 1995; Trudeau et al., 1995). Due to their peculiar gating properties, these channels are very effective in sustaining fast repolarizations in cardiac myocytes (Sanguinetti, 2010). For these reasons, pharmacological inhibition or malfunction of the $K_{V} 11.1$ channel can lead to potentially lifethreatening arrhythmias, such as the long QT syndrome (LQT) (Sanguinetti, 2010; Mitcheson and Arcangeli, 2014).

Many $\mathrm{K}_{\mathrm{V}} 11.1$ channel blockers like the methanesulfonanilide E4031, which belong to class III of antiarrhythmic drugs (Ågren et al., 2019), require an open channel to gain access to the channel pore. They block the $\mathrm{K}^{+}$flow and hence can delay heart repolarization (Mitcheson and Arcangeli, 2014; Chen et al., 2016), thus lengthening the QT interval. The capacity of different compounds to block $\mathrm{K}_{\mathrm{V}} 11.1$ channels and induce QT prolongation (the so-called "QT liability") differs among structurally diverse compounds (Sanguinetti, 2010; Authier et al., 2017) so that some drugs effectively block $K_{V} 11.1$ channels but do not cause arrhythmias. These drugs are addressed as "nontorsadogenic $\mathrm{K}_{\mathrm{V}} 11.1$ blockers." These drugs may represent good candidates for anticancer therapy (Cernuda et al., 2019).

An example is represented by $R$-roscovitine, a cyclin-dependent kinase $(\mathrm{CDK})$ inhibitor that, although blocking $\mathrm{K}_{\mathrm{V}} 11.1$ currents in an open channel manner, shows no use dependency. This suggests rapid block and unblock kinetics (Cernuda et al., 2019). Thus, R-roscovitine could be used to target $\mathrm{K}_{\mathrm{V}} 11.1$ for PDAC therapy. Besides this compound, other studies have pointed out a potential for many "nontorsadogenic" $K_{V} 11.1$ blockers (Pointer et al., 2017) and drugs which bind the $\mathrm{K}_{\mathrm{V}} 11.1$ channel in a specific conformation (Becchetti et al., 2019). For example, the macrolide antibiotic clarithromycin, which is commonly used for bacterial infection, such as $H$. pylori, binds to $\mathrm{K}_{\mathrm{V}} 11.1$ in the closed conformation and shows a good antitumor activity in colorectal cancer (Petroni et al., 2020). Because it is already in clinical use for bacterial infections, it could also potentially serve as an antitumor drug in epithelial cancers like colorectal cancer and PDAC, as already shown in lymphomas (Ferreri et al., 2018).

Another approach is to target the $\mathrm{K}_{\mathrm{V}} 11.1$ subunit trafficking to the membrane. Up to now, several molecules have been shown to interfere with trafficking without having any effect on the channel itself. These include arsenic trioxide, geldanamycin, pentamidine, and probucol (Chen et al., 2016). Notably, arsenic trioxide has been and is still used as an anticancer drug, especially in leukemias (Hoonjan et al., 2018).

Yet another approach is to target $\mathrm{K}_{\mathrm{V}} 11.1$ channels with antibodies. The clinical potential of monoclonal antibodies has emerged in the last decade. However, due to the cardiovascular side effects seen for many drugs, targeting the $\mathrm{K}_{\mathrm{V}} 11.1$ channel with single-chain function blocking antibodies is also challenging and not preferred. $\mathrm{K}_{\mathrm{V}} 11.1$ channel-specific antibodies, such as the singlechain variable fragment (scFv), anti-Kv11.1 ScFv, are more relevant 


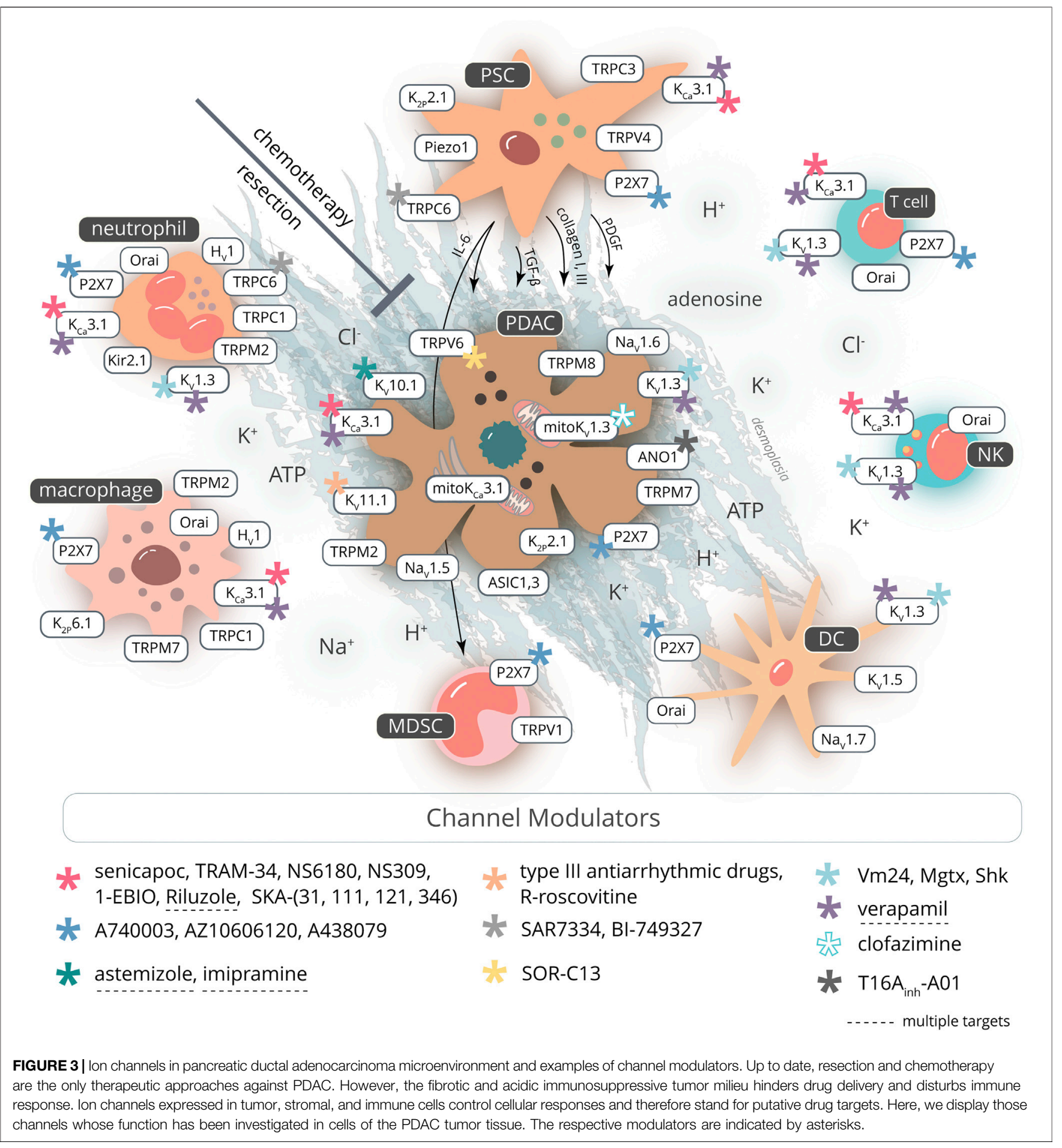

for cancer diagnosis, rather than for cancer treatment (Duranti et al., 2018). The risk of cardiac side effects can be reduced by employing bispecific antibodies. $\mathrm{K}_{\mathrm{V}} 11.1$ interacts with $\beta 1$ integrins in PDAC, which is a tumor-specific feature of $\mathrm{K}_{\mathrm{V}} 11.1$ channels (Arcangeli and Becchetti, 2017). A convenient approach would therefore be to target this complex with a bifunctional single-chain diabody ( $\mathrm{scDb}$ ). This would increase the antibody-cancer cell specificity and reduce cardiovascular side effects. It may be taken as a proof of principle for therapeutic ion channel targeting that a monoclonal antibody against $\mathrm{K}_{\mathrm{V}} 10.1$ reduces tumor volume in a human pancreatic cancer xenograft mice model (Gómez-Varela et al., 2007).

Finally, antibody-drug conjugates (ADC) are biopharmaceutical drugs that are used for targeted therapy (e.g., Pahl et al. (2018)). The combination of cancer specificity 
and cytotoxicity makes them good candidates for next-generation cancer therapy (Parslow et al., 2016). An anti- $\mathrm{K}_{\mathrm{V}} 11.1 / \beta 1 \mathrm{scDb}$ could potentially be linked to cytotoxic drugs to create highly specific ADCs for pancreatic cancer treatment.

\section{OUTLOOK}

It remains an unsolved challenge to provide PDAC patients with an efficient therapy. New therapeutic strategies are urgently needed since none of the current treatment options yields satisfactory results. Presently, it is controversially debated whether the desmoplastic PDAC stroma and microenvironment can be targeted therapeutically. The conflicting results of these studies indicate that the properties and function of stromal cells such as pancreatic stellate cells and PDAC-infiltrating immune cells are far from being fully understood. In our view, an important class of membrane proteins has been neglected in this context: ion channels. They have been shown to be important drivers of aggressive cancer cell properties and related to all hallmarks of cancer. Being membrane proteins, ion channels are in a position to modulate, sense, and transduce properties of the tumor microenvironment. However, their roles in pancreatic cancer cells and in cells of the PDAC microenvironment are largely unexplored.

We collected the current knowledge of ion channels in PDAC with a particular focus on immune and stromal cells and discussed the feasibility of therapeutic ion channel targeting. Figure 3 gives a graphical overview. Many tumors (mis-)use ion channels as highlighted for PDAC in this review. Based on the rapidly growing mechanistic knowledge about ion channels in PDAC, we are convinced that ion channel targeting offers a chance for therapeutic intervention.

We conclude that the choice of the right blocker or activator must be accurately rationalized, at least until we obtain enough data from electrophysiological measurements. Such data are still lacking for PDAC-infiltrating immune cells (Panyi et al., 2014). Similarly, there is hardly any electrophysiological data on stromal cells like PSCs. Studying ion channel activity directly in tumor-derived immune or stromal cells is an important issue. Their channel expression could show distinct differences from that of peripheral blood mononuclear cells or stromal cells isolated from a healthy pancreas. Moreover, it is imperative to consider the microenvironmental conditions under these circumstances. Up-regulation of channel expression may well be counterbalanced by characteristic properties of the tumor microenvironment such as the tumor acidity (Pethö et al., 2020). Since no $\mathrm{K}_{\mathrm{V}} 1.3$ activators are available at the moment (Chandy and Norton, 2016), $\mathrm{K}_{\mathrm{Ca}} 3.1$ activators appear promising in boosting tumor-infiltrating lymphocytes. Repurposing of riluzole is a good candidate for therapeutic $\mathrm{K}_{\mathrm{Ca}} 3.1$ activation; however, the lack of selectivity for $\mathrm{K}_{\mathrm{Ca}} 3.1$ might limit its application. At the same time, $\mathrm{K}_{\mathrm{Ca}} 3.1$ inhibitors could activate NK cells and stop cancer cells or stromal cells from proliferating and/or migrating. Only in vivo studies will reveal in the future which arm of the balance we should put our weights on when developing channel-targeting PDAC therapies. Thus, crossing $\mathrm{K}_{\mathrm{Ca}} 3.1^{-/-}$mice with transgenic breast cancer mouse models provided evidence that the impact $\mathrm{K}_{\mathrm{Ca}} 3.1$ targeting in cancer cells may be further modulated by $\mathrm{K}_{\mathrm{Ca}} 3.1$ targeting in noncancerous cells (Steudel et al., 2017). In this context, the right choice of the animal model is crucial, since mouse lymphocytes possess a different set of ion channels than rat and human ones (Beeton and Chandy, 2005). Such studies also need to evaluate repurposed drugs that are already in clinical use or have been tested in phase III clinical trials for other indications such as the $\mathrm{K}_{\mathrm{Ca}} 3.1$ blocker senicapoc (Ataga et al., 2011).

Another channel modulator that might serve as a target for drug repurposing is clofazimine. It inhibits $\mathrm{K}_{\mathrm{V}} 1.3$, thereby inducing apoptosis in PDAC cells and reducing primary tumor weight in vivo (Zaccagnino et al., 2017). It is already used for treatment of autoimmune disease and leprosy (Garrelts, 1991). However, $\mathrm{K}_{\mathrm{V}} 1.3$ block, inhibition of $\mathrm{Na}^{+} / \mathrm{K}^{+}$-ATPase of activated T-cells (Anderson et al., 1986), and the release of ROS and $\mathrm{PGE}_{2}$ from bystander neutrophils (Anderson et al., 1986) inhibit T-cell proliferation and thus may compromise antitumor immunity as well. Follow-up studies are needed to tackle already existing ion channel modulators (inhibitors or activators) for a fast translation into the clinic for PDAC patients. We anticipate that combining innovative animal models with repurposed ion channel targeting drugs-potentially in combination with existing chemotherapeutic therapies-will open up exciting new options. Clearly, such studies would enormously profit from building larger (inter-)national research consortia that can address the diverse channel-related aspects of PDAC pathophysiology in a concerted manner.

\section{AUTHOR CONTRIBUTIONS}

All authors of this review contributed to designing and writing this manuscript.

\section{FUNDING}

This work was funded by the Marie Skłodowska-Curie Innovative Training Network (ITN) (grant Agreement number: 813834 pHioniC - H2020-MSCA-ITN-2018). AS thanks the support from the Deutsche Forschungsgemeinschaft (DFG; SCHW 407/17-1 \& SCHW 407/22-1; GRK 2515/1, Chembion) and IZKF Münster (Schw2/020/18). The National Research, Development, and Innovation Office, Hungary, grant OTKA K119417 (GP); the Ministry of Human Capacities, Hungary, grant EFOP-3.6.2-162017-00006 (GP); and the Ministry of Finance, Hungary grant GINOP-2.3.2-15-2016-00015 (GP) are highly appreciated. The project is cofinanced by the European Union and the European Regional Development Fund. This project was supported by AIRC, Grant N ${ }^{\circ}$ IG 15627 and IG 21510 to AA, PRIN Italian Ministry of University and Research (MIUR) "Leveraging basic knowledge of ion channel network in cancer for innovative therapeutic strategies (LIONESS)" 20174TB8KW to AA.

\section{ACKNOWLEDGMENTS}

The authors wish to thank past and present members of our laboratories whose enthusiastic work made it possible to develop 
the concepts described in this review. All the images in Figure 1 are kind gifts from E. Lastraioli, University of Florence, and Prof. G. Perrone Campus Bio-medico, University of Rome. Finally, we

\section{REFERENCES}

Abraham, D. M., Lee, T. E., Watson, L. J., Mao, L., Chandok, G., Wang, H. G., et al. (2018). The two-pore domain potassium channel TREK-1 mediates cardiac fibrosis and diastolic dysfunction. J. Clin. Invest. 128, 4843-4855. doi:10.1172/ JCI95945

Adapala, R. K., Thoppil, R., Luther, D. J., Paruchuri, S., Gary, J., Chilian, W. M., et al. (2013). Integrating mechanical and soluble signals. J. Mol. Cell. Cardiol. 54, 45-52. doi:10.1016/j.yjmcc.2012.10.016.TRPV4

Ågren, R., Nilsson, J., and Århem, P. (2019). Closed and open state dependent block of potassium channels cause opposing effects on excitability - a computational approach. Sci. Rep. 9, 1-10. doi:10.1038/s41598-019-44564-x

Ahmadzadeh, M., Pasetto, A., Jia, L., Deniger, D. C., Stevanović, S., Robbins, P. F., et al. (2019). Tumor-infiltrating human $\mathrm{CD}^{+}$regulatory $\mathrm{T}$-cells display a distinct TCR repertoire and exhibit tumor and neoantigen reactivity. Sci. Immunol. 4, eaao4310. doi:10.1126/sciimmunol.aao4310

Anderson, R., Lukey, P., Van Rensburg, C., and Dippenaar, U. (1986). Clofaziminemediated regulation of human polymorphonuclear leukocyte migration by prooxidative inactivation of both leukoattractants and cellular migratory responsiveness. Int. J. Immunopharmacol. 8, 605-620. doi:10.1016/0192-0561(86)90033-0

Arcangeli, A., and Becchetti, A. (2006). Complex functional interaction between integrin receptors and ion channels. Trends Cell Biol. 16, 631-639. doi:10.1016/ j.tcb.2006.10.003

Arcangeli, A., and Becchetti, A. (2017). hERG channels: from antitargets to novel targets for cancer therapy. Clin. Cancer Res. 23, 3-5. doi:10.1158/1078-0432. CCR-16-2322

Ataga, K. I., Reid, M., Ballas, S. K., Yasin, Z., Bigelow, C., James, L. S., et al. (2011). Improvements in haemolysis and indicators of erythrocyte survival do not correlate with acute vaso-occlusive crises in patients with sickle cell disease: a phase III randomized, placebo-controlled, double-blind study of the Gardos channel blocker senicap. Br. J. Haematol. 153, 92-104. doi:10.1111/j.1365-2141. 2010.08520.x

Authier, S., Pugsley, M. K., Koerner, J. E., Fermini, B., Redfern, W. S., Valentin, J.P., et al. (2017). Proarrhythmia liability assessment and the comprehensive in vitro Proarrhythmia Assay (CiPA): an industry survey on current practice. J. Pharmacol. Toxicol. Methods. 86, 34-43. doi:10.1016/j.vascn.2017.02.021

Barilla, R. M., Diskin, B., Caso, R. C., Lee, K. B., Mohan, N., Buttar, C., et al. (2019). Specialized dendritic cells induce tumor-promoting IL- $10^{+} \mathrm{IL}_{-} 17^{+}$FoxP $3^{\text {neg }}$ regulatory $\mathrm{CD}^{+}{ }^{+} \mathrm{T}$-cells in pancreatic carcinoma. Nat. Commun. 10, 1424. doi:10.1038/s41467-019-09416-2

Bauer, I., Grozio, A., Lasiglie, D., Basile, G., Sturla, L., Magnone, M., et al. (2012). The NAD+-dependent histone deacetylase SIRT6 promotes cytokine production and migration in pancreatic cancer cells by regulating $\mathrm{Ca}^{2+}$ responses. J. Biol. Chem. 287, 40924-40937. doi:10.1074/jbc.M112.405837

Bazhin, A. V., Yang, Y., D’Haese, J. G., Werner, J., Philippov, P. P., and Karakhanova, S. (2016). The novel mitochondria-targeted antioxidant SkQ1 modulates angiogenesis and inflammatory micromilieu in a murine orthotopic model of pancreatic cancer. Int. J. Cancer. 139, 130-139. doi:10.1002/ijc.30054

Becchetti, A., Crescioli, S., Zanieri, F., Petroni, G., Mercatelli, R., Coppola, S., et al. (2017). The conformational state of hERG1 channels determines integrin association, downstream signaling, and cancer progression. Sci. Signal. 10, eaaf3236. doi:10.1126/scisignal.aaf3236

Becchetti, A., Petroni, G., and Arcangeli, A. (2019). Ion channel conformations regulate integrin-dependent signaling. Trends Cell Biol. 29, 298-307. doi:10. 1016/j.tcb.2018.12.005

Beceiro, S., Radin, J. N., Chatuvedi, R., Piazuelo, M. B., Horvarth, D. J., Cortado, H., et al. (2017). TRPM2 ion channels regulate macrophage polarization and gastric inflammation during Helicobacter pylori infection. Mucosal Immunol. 10, 493-507. doi:10.1038/mi.2016.60

Becker, A. E., Hernandez, Y. G., Frucht, H., and Lucas, A. L. (2014). Pancreatic ductal adenocarcinoma: risk factors, screening, and early detection. World J. Gastroenterol. 20, 11182-11198. doi:10.3748/wjg.v20.i32.11182 would like to mention that this review helped us keep the spirits up during the COVID-19 pandemic in 2020 when work in our laboratories was severely restrained or impossible.

Beeton, C., and Chandy, K. G. (2005). Potassium channels, memory T-cells, and multiple sclerosis. Neuroscientist. 11, 550-562. doi:10.1177/1073858405278016

Benavides, J., Camelin, J. C., Mitrani, N., Flamand, F., Uzan, A., Legrand, J.-J., et al. (1985). 2-Amino-6-trifluoromethoxy benzothiazole, a possible antagonist of excitatory amino acid neurotransmission-II biochemical properties. Neuropharmacology. 24, 1085-1092. doi:10.1016/0028-3908(85)90196-0

Bianchi, G., Vuerich, M., Pellegatti, P., Marimpietri, D., Emionite, L., Marigo, I., et al. (2014). ATP/P2X7 axis modulates myeloid-derived suppressor cell functions in neuroblastoma microenvironment. Cell Death Dis. 5, e1135. doi:10.1038/cddis.2014.109

Biswas, S. K., and Mantovani, A. (2010). Macrophage plasticity and interaction with lymphocyte subsets: cancer as a paradigm. Nat. Immunol. 11, 889-896. doi:10.1038/ni.1937

Bittner, S., Ruck, T., Fernández-Orth, J., and Meuth, S. G. (2014). TREK-king the blood-brain-barrier. J. Neuroimmune Pharmacol. 9, 293-301. doi:10.1007/ s11481-014-9530-8

Blando, J., Sharma, A., Higa, M. G., Zhao, H., Vence, L., Yadav, S. S., et al. (2019). Comparison of immune infiltrates in melanoma and pancreatic cancer highlights VISTA as a potential target in pancreatic cancer. Proc. Natl. Acad. Sci. U.S.A. 116, 1692-1697. doi:10.1073/pnas.1811067116

Bonito, B. (2017). Studies of ion channel mechanisms in pancreatic ductal adenocarcinoma (PDAC). Imp. Coll. Lond. [Epub ahead of print]. doi:10. $25560 / 45534$

Bonito, B., Sauter, D. R. P., Schwab, A., Djamgoz, M. B. A., and Novak, I. (2016). KCa3.1 (Ik) modulates pancreatic cancer cell migration, invasion and proliferation: anomalous effects on TRAM-34. Pflugers Arch. Eur. J. Physiol. 468, 1865-1875. doi:10.1007/s00424-016-1891-9

Bortner, C. D., and Cidlowski, J. A. (2011). Life and death of lymphocytes: a volume regulation affair. Cell. Physiol. Biochem 28, 1079-1088. doi:10.1159/000335864

Bortner, C. D., and Cidlowski, J. A. (2014). Ion channels and apoptosis in cancer. Philos. Trans. R. Soc. B Biol. Sci. 369, 20130104. doi:10.1098/rstb.2013.0104

Brevet, M., Fucks, D., Chatelain, D., Regimbeau, J. M., Delcenserie, R., Sevestre, H., et al. (2009). Deregulation of 2 potassium channels in pancreas adenocarcinomas: implication of $\mathrm{K}_{\mathrm{V}} 1.3$ gene promoter methylation. Pancreas. 38, 649-654. doi:10.1097/MPA.0b013e3181a56ebf

Brömmel, K., Maskri, S., Bulk, E., Pethő, Z., Rieke, M., Budde, T., et al. (2020a). Costaining of $\mathrm{K}_{\mathrm{Ca}} 3.1$ channels in NSCLC cells with a small-molecule fluorescent probe and antibody-based indirect immunofluorescence. ChemMedChem. [Epub ahead of print]. doi:10.1002/cmdc.202000652

Brömmel, K., Maskri, S., Maisuls, I., Konken, C. P., Rieke, M., Pethő, Z., et al. (2020b). Synthesis of small-molecule fluorescent probes for the in vitro imaging of calcium-activated potassium channel $\mathrm{K}_{\mathrm{Ca}} 3.1$. Angew. Chem. Int. Ed. Engl. 59, 8277-8284. doi:10.1002/anie.202001201

Brunner, M., Maier, K., Rümmele, P., Jacobsen, A., Merkel, S., Benard, A., et al. (2020). Upregulation of CD20 positive B-cells and B-cell aggregates in the tumor infiltration zone is associated with better survival of patients with pancreatic ductal adenocarcinoma. Int. J. Mol. Sci. 21, 1179. doi:10.3390/ ijms 21051779

Bulk, E., Ay, A. S., Hammadi, M., Ouadid-Ahidouch, H., Schelhaas, S., Hascher, A., et al. (2015). Epigenetic dysregulation of KCa3.1 channels induces poor prognosis in lung cancer. Int. J. Cancer. 137, 1306-1317. doi:10.1002/ijc.29490

Bulk, E., Todesca, L. M., and Schwab, A. (2020). Ion channels in lung cancer. Rev. Physiol. Biochem. Pharmacol. [Epub ahead of print]. doi:10.1007/ 112_2020_29

Cahalan, M. D., and Chandy, K. G. (2009). The functional network of ion channels in T lymphocytes. Immunol. Rev. 231, 59-87. doi:10.1111/j.1600-065X.2009. 00816.x

Carstens, J. L., De Sampaio, P. C., Yang, D., Barua, S., Wang, H., Rao, A., et al. (2017). Spatial computation of intratumoral T-cells correlates with survival of patients with pancreatic cancer. Nat. Commun. 8, 15095. doi:10.1038/ ncomms 15095

Castino, G. F., Cortese, N., Capretti, G., Serio, S., Di Caro, G., Mineri, R., et al. (2016). Spatial distribution of B cells predicts prognosis in human pancreatic 
adenocarcinoma. Oncoimmunology. 5, e1085147. doi:10.1080/2162402X.2015. 1085147

Cernuda, B., Fernandes, C. T., Allam, S. M., Orzillo, M., Suppa, G., Chang, Z. C., et al. (2019). The molecular determinants of R-roscovitine block of hERG channels. PLoS One. 14, e0217733. doi:10.1371/journal.pone.0217733

Chandy, K. G., and Norton, R. S. (2016). Immunology: channelling potassium to fight cancer. Nature. 537, 497-499. doi:10.1038/nature19467

Chauhan, A., Sun, Y., Sukumaran, P., Quenum Zangbede, F. O., Jondle, C. N., Sharma, A., et al. (2018). M1 macrophage polarization is dependent on TRPC1mediated calcium entry. iScience. 8, 85-102. doi:10.1016/j.isci.2018.09.014

Cheah, B. C., Vucic, S., Krishnan, A., and Kiernan, M. C. (2010). Riluzole, neuroprotection and amyotrophic lateral sclerosis. Curr. Med. Chem. 17, 1942-1959. doi:10.2174/092986710791163939

Chen, L., Sampson, K. J., and Kass, R. S. (2016). Cardiac delayed rectifier potassium channels in health and disease. Card. Electrophysiol. Clin. 8, 307-322. doi:10. 1016/j.ccep.2016.01.004

Chen, Q., Zhou, Y., Zhou, L., Fu, Z., Yang, C., Zhao, L., et al. (2020). TRPC6dependent $\mathrm{Ca}^{2+}$ signaling mediates airway inflammation in response to oxidative stress via ERK pathway. Cell Death Dis. 11, 170. doi:10.1038/ s41419-020-2360-0

Chimote, A. A., Balajthy, A., Arnold, M. J., Newton, H. S., Hajdu, P., Qualtieri, J., et al. (2018). A defect in KCa3.1 channel activity limits the ability of CD8+ Tcells from cancer patients to infiltrate an adenosine-rich microenvironment. Sci. Signal. 11, eaaq1616. doi:10.1126/scisignal.aaq1616

Chimote, A. A., Gawali, V. S., Newton, H. S., Wise-Draper, T. M., and Conforti, L. (2020). A compartmentalized reduction in membrane-proximal calmodulin reduces the immune surveillance capabilities of $\mathrm{CD} 8+\mathrm{T}$-cells in head and neck cancer. Front. Pharmacol. 11, 143. doi:10.3389/fphar.2020.00143

Chimote, A. A., Hajdu, P., Kucher, V., Boiko, N., Kuras, Z., Szilagyi, O., et al. (2013). Selective inhibition of KCa3.1 channels mediates adenosine regulation of the motility of human T-cells. J. Immunol. 191, 6273-6280. doi:10.4049/ jimmunol.1300702

Clark, C. E., Hingorani, S. R., Mick, R., Combs, C., Tuveson, D. A., and Vonderheide, R. H. (2007). Dynamics of the immune reaction to pancreatic cancer from inception to invasion. Cancer Res. 67, 9518-9527. doi:10.1158/ 0008-5472.CAN-07-0175

Comes, N., Serrano-Albarrás, A., Capera, J., Serrano-Novillo, C., Condom, E., Ramón Y Cajal, S., et al. (2015). Involvement of potassium channels in the progression of cancer to a more malignant phenotype. Biochim. Biophys. Acta Biomembr. 1848, 2477-2492. doi:10.1016/j.bbamem.2014.12.008

Cox, J. H., Hussell, S., Snødergaard, H., Roepstorff, K., Bui, J. V., Deer, J. R., et al. (2013). Antibody-mediated targeting of the Orail calcium channel inhibits Tcell function. PLoS One. 8, e82944. doi:10.1371/journal.pone.0082944

Crottès, D., Lin, Y. H. T., Peters, C. J., Gilchrist, J. M., Wiita, A. P., Jan, Y. N., et al. (2019). TMEM16A controls EGF-induced calcium signaling implicated in pancreatic cancer prognosis. Proc. Natl. Acad. Sci. U.S.A. 116, 13026-13035. doi:10.1073/pnas.1900703116

Cruse, G., Singh, S. R., Duffy, S. M., Doe, C., Saunders, R., Brightling, C. E., et al. (2011). Functional $\mathrm{K}_{\mathrm{Ca}} 3.1 \mathrm{~K}^{+}$channels are required for human fibrocyte migration. J. Allergy Clin. Immunol. 128, 1303-1309. doi:10.1016/j.jaci.2011.07.047.e2

Cruz-Monserrate, Z., Roland, C. L., Deng, D., Arumugam, T., Moshnikova, A., Andreev, O. A., et al. (2014). Targeting pancreatic ductal adenocarcinoma acidic microenvironment. Sci. Rep. 4, 4410. doi:10.1038/srep04410

Cucu, D., Chiritoiu, G., Petrescu, S., Babes, A., Stanica, L., Duda, D. G., et al. (2014). Characterization of functional transient receptor potential melastatin 8 channels in human pancreatic ductal adenocarcinoma cells. Pancreas. 43, 795-800. doi:10.1097/MPA.0000000000000106

Cvetkovic, L., Perisic, S., Titze, J., Jäck, H. M., and Schuh, W. (2019). The impact of hyperosmolality on activation and differentiation of B lymphoid cells. Front. Immunol. 10, 828. doi:10.3389/fimmu.2019.00828

Dauer, P., Zhao, X., Gupta, V. K., Sharma, N., Kesh, K., Gnamlin, P., et al. (2018). Inactivation of cancer-associated-fibroblasts disrupts oncogenic signaling in pancreatic cancer cells and promotes its regression. Canc. Res. 78, 1321-1333. doi:10.1158/0008-5472.CAN-17-2320

De Marchi, E., Orioli, E., Pegoraro, A., Sangaletti, S., Portararo, P., Curti, A., et al. (2019). The P2X7 receptor modulates immune cells infiltration, ectonucleotidases expression and extracellular ATP levels in the tumor microenvironment. Oncogene. 38, 3636-3650. doi:10.1038/s41388-0190684-y

De Marchi, U., Sassi, N., Fioretti, B., Catacuzzeno, L., Cereghetti, G. M., Szabò, I., et al. (2009). Intermediate conductance $\mathrm{Ca}^{2+}$-activated potassium channel (KCa3.1) in the inner mitochondrial membrane of human colon cancer cells. Cell Calcium. 45, 509-516. doi:10.1016/j.ceca.2009.03.014

De Monte, L., Reni, M., Tassi, E., Clavenna, D., Papa, I., Recalde, H., et al. (2011). Intratumor $\mathrm{T}$ helper type 2 cell infiltrate correlates with cancer-associated fibroblast thymic stromal lymphopoietin production and reduced survival in pancreatic cancer. J. Exp. Med. 208, 469-478. doi:10.1084/jem.20101876

Debono, M. W., Le Guern, J., Canton, T., Doble, A., and Pradier, L. (1993). Inhibition by riluzole of electrophysiological responses mediated by rat kainate and NMDA receptors expressed in Xenopus oocytes. Eur. J. Pharmacol. 235, 283-289. doi:10.1016/0014-2999(93)90147-A

DeCoursey, T. E., Morgan, D., Musset, B., and Cherny, V. V (2016). Insights into the structure and function of $\mathrm{H}_{\mathrm{V}} 1$ from a meta-analysis of mutation studies. J. Gen. Physiol. 148, 97-118. doi:10.1085/jgp.201611619

Deicher, A., Andersson, R., Tingstedt, B., Lindell, G., Bauden, M., and Ansari, D. (2018). Targeting dendritic cells in pancreatic ductal adenocarcinoma. Canc. Cell Int. 18, 85. doi:10.1186/s12935-018-0585-0

Delierneux, C., Kouba, S., Shanmughapriya, S., Potier-Cartereau, M., Trebak, M., and Hempel, N. (2020). Mitochondrial calcium regulation of redox signaling in cancer. Cells. 9, 432. doi:10.3390/cells9020432

Desai, B. N., and Leitinger, N. (2014). Purinergic and calcium signaling in macrophage function and plasticity. Front. Immunol. 5, 580. doi:10.3389/ fimmu.2014.00580

Deutsch, C., and Lee, S. C. (1989). Modulation of K+ currents in human lymphocytes by pH. J. Physiol. 413, 399-413. doi:10.1113/jphysiol.1989. sp017660

Devor, D. C., Singh, A. K., Frizzell, R. A., and Bridges, R. J. (1996). Modulation of $\mathrm{Cl}^{-}$secretion by benzimidazolones. I. Direct activation of a $\mathrm{Ca}^{2+}$-dependent $\mathrm{K}^{+}$ channel. Am. J. Physiol. 271, L775-L784. doi:10.1152/ajplung.1996.271.5.1775

Dhennin-Duthille, I., Gautier, M., Faouzi, M., Guilbert, A., Brevet, M., Vaudry, D. et al. (2011). High expression of transient receptor potential channels in human breast cancer epithelial cells and tissues: correlation with pathological parameters. Cell. Physiol. Biochem. 28, 813-822. doi:10.1159/000335795

Di, A., Xiong, S., Ye, Z., Malireddi, R. K. S., Kometani, S., Zhong, M., et al. (2018). The TWIK2 potassium efflux channel in macrophages mediates NLRP3 inflammasome-induced inflammation. Immunity. 49, 56-65.e4. doi:10.1016/j.immuni.2018.04.032

Di Caro, G., Cortese, N., Castino, G. F., Grizzi, F., Gavazzi, F., Ridolfi, C., et al. (2015). Dual prognostic significance of tumour-Associated macrophages in human pancreatic adenocarcinoma treated or untreated with chemotherapy. Gut. 65, 1710-1720. doi:10.1136/gutjnl-2015-309193

Di, L., Srivastava, S., Zhdanova, O., Ding, Y., Li, Z., Wulff, H., et al. (2010). Inhibition of the $\mathrm{K}^{+}$channel KCa3.1 ameliorates $\mathrm{T}$ cell-mediated colitis. Proc. Natl. Acad. Sci. U.S.A. 107, 1541-1546. doi:10.1073/pnas.0910133107

Ding, X. W., Luo, H. S., Jin, X., Yan, J. J., and Ai, Y. W. (2007). Aberrant expression of Eag1 potassium channels in gastric cancer patients and cell lines. Med. Oncol. 24, 345-350. doi:10.1007/s12032-007-0015-y

Djamgoz, M. B. A., and Onkal, R. (2012). Persistent current blockers of voltagegated sodium channels: a clinical opportunity for controlling metastatic disease. Recent Pat. Anti-Canc. Drug Discov. 8, 66-84. doi:10.2174/15748928130107

Djamgoz, M. B. A., Coombes, R. C., and Schwab, A. (2014). Ion transport and cancer: from initiation to metastasis. Philos. Trans. R. Soc. Lond. B. Biol. Sci. 369, 20130092. doi:10.1098/rstb.2013.0092

Djamgoz, M. B. A., Fraser, S. P., and Brackenbury, W. J. (2019). In vivo evidence for voltage-gated sodium channel expression in carcinomas and potentiation of metastasis. Cancers. 11, 1675. doi:10.3390/cancers11111675

Dong, H., Shim, K. N., Li, J. M. J., Estrema, C., Ornelas, T. A., Nguyen, F., et al. (2010). Molecular mechanisms underlying $\mathrm{Ca}^{2+}$-mediated motility of human pancreatic duct cells. Am. J. Physiol. - Cell Physiol. 299, 1493-1503. doi:10.1152/ ajpcell.00242.2010

Dovmark, T. H., Saccomano, M., Hulikova, A., Alves, F., and Swietach, P. (2017). Connexin- 43 channels are a pathway for discharging lactate from glycolytic pancreatic ductal adenocarcinoma cells. Oncogene. 36, 4538-4550. doi:10.1038/ onc.2017.71 
Dunn, G. P., Bruce, A. T., Ikeda, H., Old, L. J., and Schreiber, R. D. (2002). Cancer immunoediting: from immunosurveillance to tumor escape. Nat. Immunol. 3 , 991-998. doi:10.1038/ni1102-991

Duranti, C., and Arcangeli, A. (2019). Ion channel targeting with antibodies and antibody fragments for cancer diagnosis. Basel, Switzerland: Antibodies, Vol. 8. doi:10.3390/antib8020033

Duranti, C., Carraresi, L., Sette, A., Stefanini, M., Lottini, T., Crescioli, S., et al. (2018). Generation and characterization of novel recombinant anti-hERG1 scFv antibodies for cancer molecular imaging. Oncotarget. 9, 34972-34989. doi:10.18632/oncotarget.26200

Eil, R., Vodnala, S. K., Clever, D., Klebanoff, C. A., Sukumar, M., Pan, J. H., et al. (2016). Ionic immune suppression within the tumour microenvironment limits T-cell effector function. Nature. 537, 539-543. doi:10.1038/nature19364

El Chemaly, A., Nunes, P., Jimaja, W., Castelbou, C., and Demaurex, N. (2014). Hv1 proton channels differentially regulate the $\mathrm{pH}$ of neutrophil and macrophage phagosomes by sustaining the production of phagosomal ROS that inhibit the delivery of vacuolar ATPases. J. Leukoc. Biol. 95, 827-839. doi:10.1189/jlb.0513251

El Chemaly, A., Okochi, Y., Sasaki, M., Arnaudeau, S., Okamura, Y., and Demaurex, N. (2010). VSOP/Hv1 proton channels sustain calcium entry, neutrophil migration, and superoxide production by limiting cell depolarization and acidification. J. Exp. Med. 207, 129-139. doi:10.1084/jem. 20091837

Estes, D. J., Memarsadeghi, S., Lundy, S. K., Marti, F., Mikol, D. D., Fox, D. A., et al. (2008). High-throughput profiling of ion channel activity in primary human lymphocytes. Anal. Chem. 80, 3728-3735. doi:10.1021/ ac800164v

Ezhilarasan, D., Sokal, E., and Najimi, M. (2018). Hepatic fibrosis: it is time to go with hepatic stellate cell-specific therapeutic targets. Hepatobiliary Pancreat. Dis. Int. 17, 192-197. doi:10.1016/j.hbpd.2018.04.003

Fanger, C. M., Neben, A. L., and Cahalan, M. D. (2000). Differential Ca 2+ influx, K Ca channel activity, and $\mathrm{Ca}^{2+}$ clearance distinguish $\mathrm{Th} 1$ and $\mathrm{Th} 2$ lymphocytes. J. Immunol. 164, 1153-1160. doi:10.4049/jimmunol.164.3.1153

Faouzi, M., Hague, F., Geerts, D., Ay, A. S., Potier-Cartereau, M., Ahidouch, A., et al. (2016). Functional cooperation between KCa3.1 and TRPC1 channels in human breast cancer: role in cell proliferation and patient prognosis. Oncotarget. 7, 36419-36435. doi:10.18632/oncotarget.9261

Farfariello, V., Prevarskaya, N., and Gkika, D. (2020). ion channel profiling in prostate cancer: toward cell population-specific screening. Rev. Physiol. Biochem. Pharmacol. [Epub ahead of print]. doi:10.1007/112_2020_22

Farrell, A. S., Joly, M. M., Allen-Petersen, B. L., Worth, P. J., Lanciault, C., Sauer, D., et al. (2017). MYC regulates ductal-neuroendocrine lineage plasticity in pancreatic ductal adenocarcinoma associated with poor outcome and chemoresistance. Nat. Commun. 8, 1728. doi:10.1038/s41467-017-01967-6

Fecher-Trost, C., Wissenbach, U., and Weissgerber, P. (2017). TRPV6: from identification to function. Cell Calcium. 67, 116-122. doi:10.1016/j.ceca.2017. 04.006

Fels, B., Bulk, E., Pethö, Z., and Schwab, A. (2018). The role of TRP channels in the metastatic cascade. Pharmaceuticals. 11, 48. doi:10.3390/ph11020048

Fels, B., Nielsen, N., and Schwab, A. (2016). Role of TRPC1 channels in pressuremediated activation of murine pancreatic stellate cells. Eur. Biophys. J. 45, 657-670. doi:10.1007/s00249-016-1176-4

Feng, J., Yu, J., Pan, X., Li, Z., Chen, Z., Zhang, W., et al. (2014). HERG1 functions as an oncogene in pancreatic cancer and is downregulated by miR-96. Oncotarget. 5, 5832-5844. doi:10.18632/oncotarget.2200

Feng, L. L., Cai, Y. Q., Zhu, M. C., Xing, L. J., and Wang, X. (2020). The yin and yang functions of extracellular ATP and adenosine in tumor immunity. Canc. Cell Int. 20, 110. doi:10.1186/s12935-020-01195-x

Ferdek, P. E., and Jakubowska, M. A. (2017). Biology of pancreatic stellate cells-more than just pancreatic cancer. Pflugers Arch. Eur. J. Physiol. 469, 1039-1050. doi:10.1007/s00424-017-1968-0

Fernández, A., Pupo, A., Mena-Ulecia, K., and Gonzalez, C. (2016). Pharmacological modulation of proton channel hvl in cancer therapy: future perspectives. Mol. Pharmacol. 90, 385-402. doi:10.1124/mol.116.103804

Ferreri, A. J. M., Cecchetti, C., Kiesewetter, B., Sassone, M., Calimeri, T., Perrone, S., et al. (2018). Clarithromycin as a 'repurposing drug' against MALT lymphoma. Br. J. Haematol. 182, 913-915. doi:10.1111/bjh.14878
Feske, S., Skolnik, E. Y., and Prakriya, M. (2012). Ion channels and transporters in lymphocyte function and immunity. Nat. Rev. Immunol. 12, 532-547. doi:10. $1038 /$ nri3233

Feske, S., Wulff, H., and Skolnik, E. Y. (2015). Ion channels in innate and adaptive immunity. Ann. Rev. Immunol. 33, 291-353. doi:10.1146/annurev-immunol032414-112212

Freise, C., Heldwein, S., Erben, U., Hoyer, J., Köhler, R., Jöhrens, K., et al. (2015). $\mathrm{K}+$-channel inhibition reduces portal perfusion pressure in fibrotic rats and fibrosis associated characteristics of hepatic stellate cells. Liver Int. 35, 1244-1252. doi:10.1111/liv.12681

Fu, S., Hirte, H., Welch, S., Ilenchuk, T. T., Lutes, T., Rice, C., et al. (2017). First-inhuman phase I study of SOR-C13, a TRPV6 calcium channel inhibitor, in patients with advanced solid tumors. Invest. New Drugs. 35, 324-333. doi:10. 1007/s10637-017-0438-Z

Fu, Y., Liu, S., Zeng, S., and Shen, H. (2018). The critical roles of activated stellate cells-mediated paracrine signaling, metabolism and onco-immunology in pancreatic ductal adenocarcinoma. Mol. Cancer. 17, 62. doi:10.1186/s12943018-0815-z

Gabrilovich, D. I., Ostrand-Rosenberg, S., and Bronte, V. (2012). Coordinated regulation of myeloid cells by tumours. Nat. Rev. Immunol. 12, 253-268. doi:10. 1038/nri3175

Galon, J., and Bruni, D. (2019). Approaches to treat immune hot, altered and cold tumours with combination immunotherapies. Nat. Rev. Drug Discov. 18, 197-218. doi:10.1038/s41573-018-0007-y

Galon, J., Mlecnik, B., Bindea, G., Angell, H. K., Berger, A., Lagorce, C., et al. (2014). Towards the introduction of the 'Immunoscore' in the classification of malignant tumours. J. Pathol. 232, 199-209. doi:10.1002/path.4287

Gao, Y., Hanley, P. J., Rinné, S., Zuzarte, M., and Daut, J. (2010). Calcium-activated $\mathrm{K}^{+}$channel $\left(\mathrm{K}_{\mathrm{Ca}} 3.1\right)$ activity during $\mathrm{Ca}^{2+}$ store depletion and store-operated $\mathrm{Ca}(2+)$ entry in human macrophages. Cell Calcium. 48, 19-27. doi:10.1016/j. ceca.2010.06.002

García-Ferreiro, R. E., Kerschensteiner, D., Major, F., Monje, F., Stühmer, W., and Pardo, L. A. (2004). Mechanism of block of hEag1 $\mathrm{K}^{+}$channels by imipramine and astemizole. J. Gen. Physiol. 124, 301-317. doi:10.1085/jgp.200409041

Garofalo, S., Cocozza, G., Porzia, A., Inghilleri, M., Raspa, M., Scavizzi, F., et al. (2020). Natural killer cells modulate motor neuron-immune cell cross talk in models of Amyotrophic Lateral Sclerosis. Nat. Commun. 11, 1773. doi:10.1038/ s41467-020-15644-8

Garrelts, J. C. (1991). Clofazimine: a review of its use in leprosy and Mycobacterium avium complex infection. DICP. 25, 525-531. doi:10.1177/ 106002809102500513

Gavrilova-Ruch, O., Schonherr, K., Gessner, G., Schonherr, R., Klapperstuck, T., Wohlrab, W., et al. (2002). Effects of imipramine on ion channels and proliferation of IGR1 melanoma cells $\backslash$ rCardiac complications of radiation therapy. J. Membr. Biol. 188, 137-149. doi:10.1007/s00232-001-0181-3

Gershkovitz, M., Caspi, Y., Fainsod-Levi, T., Katz, B., Michaeli, J., Khawaled, S., et al. (2018). TRPM2 mediates neutrophil killing of disseminated tumor cells. Cancer Res. 78, 2680-2690. doi:10.1158/0008-5472.CAN-17-3614

Ghanshani, S., Wulff, H., Miller, M. J., Rohm, H., Neben, A., Gutman, G. A., et al. (2000). Up-regulation of the IKCal potassium channel during T-cell activation: molecular mechanism and functional consequences. J. Biol. Chem. 275, 37137-37149. doi:10.1074/jbc.M003941200

Giannuzzo, A., Pedersen, S. F., and Novak, I. (2015). The P2X7 receptor regulates cell survival, migration and invasion of pancreatic ductal adenocarcinoma cells. Mol. Canc. 14, 203. doi:10.1186/s12943-015-0472-4

Giannuzzo, A., Saccomano, M., Napp, J., Ellegaard, M., Alves, F., and Novak, I. (2016). Targeting of the P2X7 receptor in pancreatic cancer and stellate cells. Int. J. Canc. 139, 2540-2552. doi:10.1002/ijc.30380

Gillies, R. J., Raghunand, N., Karczmar, G. S., and Bhujwalla, Z. M. (2002). MRI of the tumor microenvironment. J. Magn. Reson. Imag. 16, 430-450. doi:10.1002/ jmri.10181

Girault, A., Ahidouch, A., and Ouadid-Ahidouch, H. (2020). Roles for Ca2+ and $\mathrm{K}+$ channels in cancer cells exposed to the hypoxic tumour microenvironment. Biochim. Biophys. Acta - Mol. Cell Res. 1867, 118644. doi:10.1016/j.bbamcr. 2020.118644

Gnerlich, J. L., Mitchem, J. B., Weir, J. S., Sankpal, N. V., Kashiwagi, H., Belt, B. A., et al. (2010). Induction of Th17 cells in the tumor microenvironment improves 
survival in a murine model of pancreatic cancer. J. Immunol. 185, 4063-4071. doi:10.4049/jimmunol.0902609

Gocke, A. R., Lebson, L. A., Grishkan, I. V., Hu, L., Nguyen, H. M., Whartenby, K. A., et al. (2012). Kv1.3 deletion biases T-cells toward an immunoregulatory phenotype and renders mice resistant to autoimmune Encephalomyelitis. J. Immunol. 188, 5877-5886. doi:10.4049/jimmunol.1103095

Gómez-Varela, D., Zwick-Wallasch, E., Knötgen, H., Sánchez, A., Hettmann, T., Ossipov, D., et al. (2007). Monoclonal antibody blockade of the human Eag1 potassium channel function exerts antitumor activity. Cancer Res. 67, 7343-7349. doi:10.1158/0008-5472.CAN-07-0107

Gürlevik, E., Fleischmann-Mundt, B., Brooks, J., Demir, I. E., Steiger, K., Ribback, S., et al. (2016). Administration of gemcitabine after pancreatic tumor resection in mice induces an antitumor immune response mediated by natural killer cells. Gastroenterology. 151, 338-350. doi:10.1053/j.gastro.2016.05.004.e7

Gwack, Y., Srikanth, S., Oh-hora, M., Hogan, P. G., Lamperti, E. D., Yamashita, M., et al. (2008). Hair loss and defective T- and B-cell function in mice lacking ORAI1. Mol. Cell. Biol. 28, 5209-5222. doi:10.1128/mcb.00360-08

Haanes, K. A., Schwab, A., and Novak, I. (2012). The P2X7 receptor supports both life and death in fibrogenic pancreatic stellate cells. PLoS One. 7, e51164. doi:10. 1371/journal.pone.0051164

Habtezion, A., Edderkaoui, M., and Pandol, S. J. (2016). Macrophages and pancreatic ductal adenocarcinoma. Cancer Lett. 381, 211-216. doi:10.1016/j. canlet.2015.11.049

Haeberle, L., Steiger, K., Schlitter, A. M., Safi, S. A., Knoefel, W. T., Erkan, M., et al. (2018). Stromal heterogeneity in pancreatic cancer and chronic pancreatitis. Pancreatology. 18, 536-549. doi:10.1016/j.pan.2018.05.004

Han, Y., Shewan, A. M., and Thorn, P. (2016). HCO3- transport through anoctamin/transmembrane protein ANO1/TMEM16A in pancreatic acinar cells regulates luminal pH. J. Biol. Chem. 291, 20345-20352. doi:10.1074/jbc. M116.750224

Hartel, M., Di Mola, F. F., Selvaggi, F., Mascetta, G., Wente, M. N., Felix, K., et al. (2006). Vanilloids in pancreatic cancer: potential for chemotherapy and pain management. Gut. 55, 519-528. doi:10.1136/gut.2005.073205

Hartung, F., Krüwel, T., Shi, X., Pfizenmaier, K., Kontermann, R., Chames, P., et al. (2020). A novel anti-Kv10.1 nanobody fused to single-chain TRAIL enhances apoptosis induction in cancer cells. Front. Pharmacol. 11, 686. doi:10.3389/ fphar.2020.00686

Harvey, J. B., Phan, L. H., Villarreal, O. E., and Bowser, J. L. (2020). CD73's potential as an immunotherapy target in gastrointestinal cancers. Front. Immunol. 11, 16-18. doi:10.3389/fimmu.2020.00508

Hashim, A. I., Zhang, X., Wojtkowiak, J. W., Martinez, G. V., and Gillies, R. J. (2011). Imaging $\mathrm{pH}$ and metastasis. NMR Biomed. 24, 582-591. doi:10.1002/ nbm.1644.Imaging

Hayashi, M., and Novak, I. (2013). Molecular basis of potassium channels in pancreatic duct epithelial cells. Channels. 7, 432-441. doi:10.4161/chan.26100

Hayashi, M., Wang, J., Hede, S. E., and Novak, I. (2012). An intermediateconductance $\mathrm{Ca}^{2+}$-activated $\mathrm{K}^{+}$channel is important for secretion in pancreatic duct cells. Am. J. Physiol. Cell Physiol. 303, C151-C159. doi:10. 1152/ajpcell.00089.2012

He, W., Xu, J., Mu, R., Li, Q., Lv, D. lun., Huang, Z., et al. (2020). High-salt diet inhibits tumour growth in mice via regulating myeloid-derived suppressor cell differentiation. Nat. Commun. 11, 1-17. doi:10.1038/s41467-02015524-1

Hegde, S., Krisnawan, V. E., Herzog, B. H., Zuo, C., Breden, M. A., Knolhoff, B. L., et al. (2020). Dendritic cell paucity leads to dysfunctional immune surveillance in pancreatic cancer. Canc. Cell. 37, 289-307.e9. doi:10.1016/j.ccell.2020.02.008

Hegde, V. L., Nagarkatti, P. S., and Nagarkatti, M. (2011). Role of myeloid-derived suppressor cells in amelioration of experimental autoimmune hepatitis following activation of TRPV1 receptors by cannabidiol. PLoS One. 6, e18281. doi:10.1371/journal.pone.0018281

Hemmerlein, B., Weseloh, R. M., de Queiroz, F. M., Knötgen, H., Sánchez, A., Rubio, M. E., et al. (2006). Overexpression of Eag1 potassium channels in clinical tumours. Mol. Canc. 5, 41. doi:10.1186/1476-4598-5-41

Henke, E., Nandigama, R., and Ergün, S. (2020). Extracellular matrix in the tumor microenvironment and its impact on cancer therapy. Front. Mol. Biosci. 6, 1-24. doi:10.3389/fmolb.2019.00160

Henríquez, C., Riquelme, T. T., Vera, D., Julio-Kalajzić, F., Ehrenfeld, P., Melvin, J. E., et al. (2016). The calcium-activated potassium channel KCa3.1 plays a central role in the chemotactic response of mammalian neutrophils. Acta Physiol. 216, 132-145. doi:10.1111/apha.12548

Hessmann, E., Buchholz, S. M., Demir, I. E., Singh, S. K., Gress, T. M., Ellenrieder, V., et al. (2020). Microenvironmental determinants of pancreatic cancer. Physiol. Rev. 100, 1707-1751. doi:10.1152/physrev.00042.2019

High, R. A., Randtke, E. A., Jones, K. M., Lindeman, L. R., Ma, J. C., Zhang, S., et al. (2019). Extracellular acidosis differentiates pancreatitis and pancreatic cancer in mouse models using acidoCEST MRI. Neoplasia. 21, 1085-1090. doi:10. 1016/j.neo.2019.09.004

Hiraoka, N., Ino, Y., Sekine, S., Tsuda, H., Shimada, K., Kosuge, T., et al. (2010). Tumour necrosis is a postoperative prognostic marker for pancreatic cancer patients with a high interobserver reproducibility in histological evaluation. $B r$. J. Cancer. 103, 1057-1065. doi:10.1038/sj.bjc.6605854

Hoffmann, E. K., Lambert, I. H., and Pedersen, S. F. (2009). Physiology of cell volume regulation in vertebrates. Physiol. Rev. 89, 193-277. doi:10.1152/ physrev.00037.2007

Honoré, E. (2007). The neuronal background K2P channels: focus on TREK1. Nat. Rev. Neurosci. 8, 251-261. doi:10.1038/nrn2117

Hoonjan, M., Jadhav, V., and Bhatt, P. (2018). Arsenic trioxide: insights into its evolution to an anticancer agent. J. Biol. Inorg. Chem. JBIC a Publ. Soc. Biol. Inorg. Chem. 23, 313-329. doi:10.1007/s00775-018-1537-9

Hu, H., Hang, J. J., Han, T., Zhuo, M., Jiao, F., and Wang, L. W. (2016). The M2 phenotype of tumor-associated macrophages in the stroma confers a poor prognosis in pancreatic cancer. Tumor Biol. 37, 8657-8664. doi:10.1007/ s13277-015-4741-z

Hu, H., Jiao, F., Han, T., and Wang, L.-W. (2015). Functional significance of macrophages in pancreatic cancer biology. Tumour Biol. J. Int. Soc. Oncodevelopmental Biol. Med. 36, 9119-9126. doi:10.1007/s13277-015-4127-2

Hu, L. P., Zhang, X. X., Jiang, S. H., Tao, L. Y., Li, Q., Zhu, L. L., et al. (2019a). Targeting purinergic receptor $\mathrm{P} 2 \mathrm{Y} 2$ prevents the growth of pancreatic ductal adenocarcinoma by inhibiting cancer cell glycolysis. Clin. Canc. Res. 25, 1318-1330. doi:10.1158/1078-0432.CCR-18-2297

Hu, S., Yang, J., Shangguan, J., Eresen, A., Li, Y., Ma, Q., et al. (2019b). Natural killer cell-based adoptive transfer immunotherapy for pancreatic ductal adenocarcinoma in a $\mathrm{Kras}^{\mathrm{LSL}-\mathrm{G} 12 \mathrm{D}} \mathrm{p} 53^{\mathrm{LSL}-\mathrm{R} 172 \mathrm{HP}} \mathrm{dx1}$-Cre mouse model. Am. J. Cancer Res. 9, 1757-1765.

Huang, X., and Jan, L. Y. (2014). Targeting potassium channels in cancer. J. Cell. Biol. 206, 151-162. doi:10.1083/jcb.201404136

Ijichi, H., Chytil, A., Gorska, A. E., Aakre, M. E., Bierie, B., Tada, M., et al. (2011). Inhibiting Cxcr2 disrupts tumor-stromal interactions and improves survival in a mouse model of pancreatic ductal adenocarcinoma. J. Clin. Invest. 121, 4106-4117. doi:10.1172/JCI42754

Ivanova, E. A., and Orekhov, A. N. (2015). T Helper lymphocyte subsets and plasticity in autoimmunity and cancer: an overview. Biomed Res. Int. 2015, 327470. doi:10.1155/2015/327470.2015

Jäger, H., Dreker, T., Buck, A., Giehl, K., Gress, T., and Grissmer, S. (2004). Blockage of intermediate-conductance $\mathrm{Ca}^{2+}$-activated $\mathrm{K}^{+}$channels inhibit human pancreatic cancer cell growth in Vitro. Mol. Pharmacol. 65, 630-638. doi:10.1124/mol.65.3.630

Jiang, S.-H., Zhu, L. L., Zhang, M., Li, R. K., Yang, Q., Yan, J. Y., et al. (2019). GABRP regulates chemokine signalling, macrophage recruitment and tumour progression in pancreatic cancer through tuning KCNN4-mediated $\mathrm{Ca} 2+$ signalling in a GABA-independent manner. Gut. 68, 1994-2006. doi:10. 1136/gutjnl-2018-317479

Jiang, S., Zhu, L., Yang, J., Hu, L., Gu, J., Xing, X., et al. (2017). Integrated expression profiling of potassium channels identifys KCNN4 as a prognostic biomarker of pancreatic cancer. Biochem. Biophys. Res. Commun. 494, 113-119. doi:10.1016/j.bbrc.2017.10.072

Jin, S., Chin, J., Kitson, C., Woods, J., Majmudar, R., Carvajal, V., et al. (2013). Natural regulatory T-cells are resistant to calcium release-activated calcium (CRAC/ORAI) channel inhibition. Int. Immunol. 25, 497-506. doi:10.1093/ intimm/dxt013

Kale, V. P., Amin, S. G., and Pandey, M. K. (2015). Targeting ion channels for cancer therapy by repurposing the approved drugs. Biochim. Biophys. Acta. 1848, 2747-2755. doi:10.1016/j.bbamem.2015.03.034

Karmakar, M., Katsnelson, M. A., Dubyak, G. R., and Pearlman, E. (2016). Neutrophil P2X7 receptors mediate NLRP3 inflammasome-dependent IL-1 $\beta$ secretion in response to ATP. Nat. Commun. 7, 10555. doi:10.1038/ncomms10555 
Kindzelskii, A. L., and Petty, H. R. (2005). Ion channel clustering enhances weak electric field detection by neutrophils: apparent roles of SKF96365-sensitive cation channels and myeloperoxidase trafficking in cellular responses. Eur. Biophys. J. 35, 1-26. doi:10.1007/s00249-005-0001-2

Kis-Toth, K., Hajdu, P., Bacskai, I., Szilagyi, O., Papp, F., Szanto, A., et al. (2011). Voltage-gated sodium channel Nav1.7 maintains the membrane potential and regulates the activation and chemokine-induced migration of a monocytederived dendritic cell subset. J. Immunol. 187, 1273-1280. doi:10.4049/ jimmunol.1003345

Klebanoff, C. A., Gattinoni, L., Torabi-Parizi, P., Kerstann, K., Cardones, A. R., Finkelstein, S. E., et al. (2005). Central memory self/tumor-reactive $\mathrm{CD}^{8+} \mathrm{T}$ cells confer superior antitumor immunity compared with effector memory Tcells. Proc. Natl. Acad. Sci. U.S.A. 102, 9571-9576. doi:10.1073/pnas. 0503726102

Klebanoff, C. A., Scott, C. D., Leonardi, A. J., Yamamoto, T. N., Cruz, A. C., Ouyang, C., et al. (2016). Memory T cell-driven differentiation of naive cells impairs adoptive immunotherapy. J. Clin. Invest. 126, 318-334. doi:10.1172/ JCI81217

Klumpp, L., Sezgin, E. C., Skardelly, M., Eckert, F., and Huber, S. M. (2018). KCa3.1 channels and glioblastoma: in vitro studies. Curr. Neuropharmacol. 16, 627-635. doi:10.2174/1570159X15666170808115821

Knudsen, E. S., Vail, P., Balaji, U., Ngo, H., Botros, I. W., Makarov, V., et al. (2017). Stratification of pancreatic ductal adenocarcinoma: combinatorial genetic, stromal, and immunologic markers. Clin. Cancer Res. 23, 4429-4440. doi:10. 1158/1078-0432.CCR-17-0162

Kondratska, K., Kondratskyi, A., Yassine, M., Lemonnier, L., Lepage, G., Morabito, A., et al. (2014). Orail and STIM1 mediate SOCE and contribute to apoptotic resistance of pancreatic adenocarcinoma. Biochim. Biophys. Acta - Mol. Cell Res. 1843, 2263-2269. doi:10.1016/j.bbamcr.2014.02.012

Koshy, S., Wu, D., Hu, X., Tajhya, R. B., Huq, R., Khan, F. S., et al. (2013). Blocking KCa3.1 channels increases tumor cell killing by a subpopulation of human natural killer lymphocytes. PLoS One. 8, 1-11. doi:10.1371/journal.pone. 0076740

Kovalenko, I., Glasauer, A., Schöckel, L., Sauter, D. R. P. P., Ehrmann, A., Sohler, F., et al. (2016). Identification of $\mathrm{K}_{\mathrm{Ca}} 3.1$ channel as a novel regulator of oxidative phosphorylation in a subset of pancreatic carcinoma cell lines. PLoS One. 11, 1-20. doi:10.1371/journal.pone. 0160658

Krause, K. H., and Welsh, M. J. (1990). Voltage-dependent and Ca2+-activated ion channels in human neutrophils. J. Clin. Invest. 85, 491-498. doi:10.1172/ JCI114464

Kuntze, A., Goetsch, O., Fels, B., Najder, K., Unger, A., Wilhelmi, M., et al. (2020). Protonation of Piezol impairs cell-matrix interactions of pancreatic stellate cells. Front. Physiol. 11, 1-15. doi:10.3389/fphys.2020.00089

Künzli, B. M., Berberat, P. O., Giese, T., Csizmadia, E., Kaczmarek, E., Baker, C., et al. (2007). Upregulation of CD39/NTPDases and P2 receptors in human pancreatic disease. Am. J. Physiol. - Gastrointest. Liver Physiol. 292, 223-231. doi:10.1152/ajpgi.00259.2006

Kurahara, H., Shinchi, H., Mataki, Y., Maemura, K., Noma, H., Kubo, F., et al. (2011). Significance of M2-polarized tumor-associated macrophage in pancreatic cancer. J. Surg. Res. 167, e211-9. doi:10.1016/j.jss.2009.05.026

Lachowski, D., Cortes, E., Pink, D., Chronopoulos, A., Karim, S. A., Morton, J. P., et al. (2017). Substrate rigidity controls activation and durotaxis in pancreatic stellate cells. Sci. Rep. 7, 1-12. doi:10.1038/s41598-017-02689-x

Lamanauskas, N., and Nistri, A. (2008). Riluzole blocks persistent $\mathrm{Na}+$ and $\mathrm{Ca} 2+$ currents and modulates release of glutamate via presynaptic NMDA receptors on neonatal rat hypoglossal motoneurons in vitro. Eur. J. Neurosci. 27, 2501-2514. doi:10.1111/j.1460-9568.2008.06211.x

Lastraioli, E., Guasti, L., Crociani, O., Polvani, S., Hofmann, G., Witchel, H., et al. (2004). herg1 gene and HERG1 protein are overexpressed in colorectal cancers and regulate cell invasion of tumor cells. Cancer Res. 64, 606-611. doi:10.1158/ 0008-5472.CAN-03-2360

Lastraioli, E., Perrone, G., Sette, A., Fiore, A., Crociani, O., Manoli, S., et al. (2015). HERG1 channels drive tumour malignancy and may serve as prognostic factor in pancreatic ductal adenocarcinoma. Br. J. Canc. 112, 1076-1087. doi:10.1038/ bjc. 2015.28

Lauritzen, I., Chemin, J., Honoré, E., Jodar, M., Guy, N., Lazdunski, M., et al. (2005). Cross-talk between the mechano-gated K2P channel TREK-1 and the actin cytoskeleton. EMBO Rep. 6, 642-648. doi:10.1038/sj.embor.7400449
Leanza, L., Romio, M., Becker, K. A., Azzolini, M., Trentin, L., Managò, A., et al. (2017). Direct pharmacological targeting of a mitochondrial ion channel selectively Kills tumor cells in vivo. Canc. Cell. 31, 516-531.e10. doi:10. 1016/j.ccell.2017.03.003

Leppkes, M., Maueröder, C., Hirth, S., Nowecki, S., Günther, C., Billmeier, U., et al. (2016). Externalized decondensed neutrophil chromatin occludes pancreatic ducts and drives pancreatitis. Nat. Commun. 7, 10973. doi:10.1038/ ncomms10973

Leslie, T. K., James, A. D., Zaccagna, F., Grist, J. T., Deen, S., Kennerley, A., et al. (2019). Sodium homeostasis in the tumour microenvironment. Biochim. Biophys. Acta - Rev. Cancer. 1872, 188304. doi:10.1016/j.bbcan.2019.07.001

Li, S. Q., Su, N., Gong, P., Zhang, H. B., Liu, J., Wang, D., et al. (2017). The expression of formyl peptide receptor 1 is correlated with tumor invasion of human colorectal cancer. Sci. Rep. 7, 5918. doi:10.1038/s41598-01706368-9

Lin, B. L., Matera, D., Doerner, J. F., Zheng, N., Del Camino, D., Mishra, S., et al. (2019). In vivo selective inhibition of TRPC6 by antagonist BI 749327 ameliorates fibrosis and dysfunction in cardiac and renal disease. Proc. Natl. Acad. Sci. U.S.A. 116, 10156-10161. doi:10.1073/pnas.1815354116

Lin, R., Wang, Y., Chen, Q., Liu, Z., Xiao, S., Wang, B., et al. (2018). TRPM2 promotes the proliferation and invasion of pancreatic ductal adenocarcinoma. Mol. Med. Rep. 17, 7537-7544. doi:10.3892/mmr.2018.8816

Lindemann, O., Rossaint, J., Najder, K., Schimmelpfennig, S., Hofschröer, V., Wälte, M., et al. (2020). Intravascular adhesion and recruitment of neutrophils in response to CXCL1 depends on their TRPC6 channels. J. Mol. Med. 98, 349-360. doi:10.1007/s00109-020-01872-4

Lindemann, O., Strodthoff, C., Horstmann, M., Nielsen, N., Jung, F., Schimmelpfennig, S., et al. (2015). TRPC1 regulates fMLP-stimulated migration and chemotaxis of neutrophil granulocytes. Biochim. Biophys. Acta. 1853, 2122-2130. doi:10.1016/j.bbamcr.2014.12.037

Lindemann, O., Umlauf, D., Frank, S., Schimmelpfennig, S., Bertrand, J., Pap, T., et al. (2013). TRPC6 regulates CXCR2-mediated chemotaxis of murine neutrophils. J. Immunol. 190, 5496-5505. doi:10.4049/jimmunol.1201502

Ling, Q., and Kalthoff, H. (2020). Transportome malfunctions and the hallmarks of pancreatic cancer. Rev. Physiol. Biochem. Pharmacol. [Epub ahead of print]. doi:10.1007/112_2020_20

Lioudyno, M. I., Kozak, J. A., Penna, A., Safrina, O., Zhang, S. L., Sen, D., et al. (2008). Orail and STIM1 move to the immunological synapse and are upregulated during T-cell activation. Proc. Natl. Acad. Sci. U.S.A. 105, 2011-2016. doi:10.1073/pnas.0706122105

Liu, B. S., Ferreira, R., Lively, S., and Schlichter, L. C. (2013). Microglial SK3 and SK4 currents and activation state are modulated by the neuroprotective drug, riluzole. J. Neuroimmune Pharmacol. 8, 227-237. doi:10.1007/s11481-0129365-0

Liu, J., Hu, G., Gong, Y., Yu, Q., He, B., Li, W., et al. (2018). Silencing of TRPM8 inhibits aggressive tumor phenotypes and enhances gemcitabine sensitivity in pancreatic cancer. Pancreatol. Off. J. Int. Assoc. Pancreatol. 18, 935-944. doi:10. 1016/j.pan.2018.08.011

Liu, Q., Li, Y., Niu, Z., Zong, Y., Wang, M., Yao, L., et al. (2016). Atorvastatin (Lipitor) attenuates the effects of aspirin on pancreatic cancerogenesis and the chemotherapeutic efficacy of gemcitabine on pancreatic cancer by promoting M2 polarized tumor associated macrophages. J. Exp. Clin. Cancer Res. 35, 1-16. doi:10.1186/s13046-016-0304-4

Lohneis, P., Sinn, M., Bischoff, S., Jühling, A., Pelzer, U., Wislocka, L., et al. (2017). Cytotoxic tumour-infiltrating $\mathrm{T}$ lymphocytes influence outcome in resected pancreatic ductal adenocarcinoma. Eur. J. Cancer. 83, 290-301. doi:10.1016/j. ejca.2017.06.016

Luo, Y., Xue, Y., Wang, J., Dang, J., Fang, Q., Huang, G., et al. (2019). Negligible effect of sodium chloride on the development and function of TGF- $\beta$-induced CD4 + Foxp3 + regulatory T-cells. Cell Rep. 26, 1869-1879.e3 doi:10.1016/j. celrep.2019.01.066

Mace, T. A., Ameen, Z., Collins, A., Wojcik, S., Mair, M., Young, G. S., et al. (2013). Pancreatic cancer-associated stellate cells promote differentiation of myeloidderived suppressor cells in a StAT3-dependent manner. Cancer Res. 73, 3007-3018. doi:10.1158/0008-5472.CAN-12-4601

Mahadevan, D., and Von Hoff, D. D. (2007). Tumor-stroma interactions in pancreatic ductal adenocarcinoma. Mol. Cancer Ther. 6, 1186-1197. doi:10. 1158/1535-7163.MCT-06-0686 
Maleki Vareki, S. (2018). High and low mutational burden tumors versus immunologically hot and cold tumors and response to immune checkpoint inhibitors. J. Immunother. Canc. 6, 157. doi:10.1186/s40425-018-0479-7

Manoli, S., Coppola, S., Duranti, C., Lulli, M., Magni, L., Kuppalu, N., et al. (2019). The activity of $\mathrm{Kv} 11.1$ potassium channel modulates F-Actin organization during cell migration of pancreatic ductal adenocarcinoma cells. Cancers. 11, 135. doi: $10.3390 /$ cancers 11020135

Marsh, J., Jackman, C. P., Tang, S.-N., Shankar, S., and Srivastava, R. K. (2014). Embelin suppresses pancreatic cancer growth by modulating tumor immune microenvironment. Front. Biosci. 19, 113. doi:10.2741/4198

Masamune, A., Kotani, H., Sörgel, F. L., Chen, J. M., Hamada, S., Sakaguchi, R., et al. (2020). Variants that affect function of calcium channel TRPV6 are associated with early-onset chronic pancreatitis. Gastroenterology. 158, 1626-1641.e8. doi:10.1053/j.gastro.2020.01.005

Masia, R., Krause, D. S., and Yellen, G. (2015). The inward rectifier potassium channel Kir2.1 is expressed in mouse neutrophils from bone marrow and liver. Am. J. Physiol. - Cell Physiol. 308, C264-C276. doi:10.1152/ajpcell.00176.2014

Matzner, N., Zemtsova, I. M., Xuan, N. T., Duszenko, M., Shumilina, E., and Lang, F. (2008). Ion channels modulating mouse dendritic cell functions. J. Immunol. 181, 6803-6809. doi:10.4049/jimmunol.181.10.6803

McAllister, F., Bailey, J. M., Alsina, J., Nirschl, C. J., Sharma, R., Fan, H., et al. (2014). Oncogenic kras activates a hematopoietic-to-epithelial IL-17 signaling axis in preinvasive pancreatic neoplasia. Canc. Cell. 25, 621-637. doi:10.1016/j. ccr.2014.03.014

McCarl, C.-A., Khalil, S., Ma, J., Oh-hora, M., Yamashita, M., Roether, J., et al. (2010). Store-operated $\mathrm{Ca}^{2+}$ entry through ORAI1 is critical for T cell-mediated autoimmunity and allograft rejection. J. Immunol. 185, 5845-5858. doi:10.4049/ jimmunol.1001796

McDonald, B., Pittman, K., Menezes, G. B., Hirota, S. A., Slaba, I., Waterhouse, C. C. M., et al. (2010). Intravascular danger signals guide neutrophils to sites of sterile inflammation. Science. 330, 362-366. doi:10.1126/science.1195491

McKay, C. J., Glen, P., and McMillan, D. C. (2008). Chronic inflammation and pancreatic cancer. Best Pract. Res. Clin. Gastroenterol. 22, 65-73. doi:10.1016/j. bpg.2007.11.007

Meyer, R., and Heinemann, S. H. (1998). Characterization of an eag-like potassium channel in human neuroblastoma cells. J. Physiol. 508, 49-56. doi:10.1111/j. 1469-7793.1998.049br.x

Meyer, R., Schönherr, R., Gavrilova-Ruch, O., Wohlrab, W., and Heinemann, S. H. (1999). Identification of ether a go-go and calcium-activated potassium channels in human melanoma cells. J. Membr. Biol. 171, 107-115. doi:10. 1007/s002329900563

Mitcheson, J., and Arcangeli, A. (2014). "CHAPTER 11," in The therapeutic potential of hERG1 $\mathrm{K}^{+}$channels for treating cancer and cardiac arrhythmias. (Royal Society of Chemistry), 258-296. doi:10.1039/9781849735087-00258

Miyai, Y., Esaki, N., Takahashi, M., and Enomoto, A. (2020). Cancer-associated fibroblasts that restrain cancer progression: hypotheses and perspectives. Cancer Sci. 111, 1047-1057. doi:10.1111/cas.14346

Mohammed, A., Janakiram, N. B., Madka, V., Pathuri, G., Li, Q., Ritchie, R., et al. (2017). Lack of chemopreventive effects of P2X7R inhibitors against pancreatic cancer. Oncotarget. 8, 97822-97834. doi:10.18632/oncotarget.22085

Mohr, C. J., Steudel, F. A., Gross, D., Ruth, P., Lo, W.-Y., Hoppe, R., et al. (2019). Cancer-associated intermediate conductance $\mathrm{Ca}^{2+}$-activated $\mathrm{K}^{+}$channel $\mathrm{K}_{\mathrm{Ca}}$ 3.1. Cancers. 11, 109. doi:10.3390/cancers11010109

Møller, L. S., Fialla, A. D., Schierwagen, R., Biagini, M., Liedtke, C., Laleman, W., et al. (2016). The calcium-Activated potassium channel KCa3.1 is an important modulator of hepatic injury. Sci. Rep. 6, 1-12. doi:10.1038/srep28770

Morishita, K., Watanabe, K., and Ichijo, H. (2019). Cell volume regulation in cancer cell migration driven by osmotic water flow. Canc. Sci. 110, 2337-2347. doi:10. 1111/cas.14079

Mroczko, B., Groblewska, M., Gryko, M., K $\square$ dra, B., and Szmitkowski, M. (2010). Diagnostic usefulness of serum Interleukin 6 (IL-6) and C-Reactive Protein (CRP) in the differentiation between pancreatic cancer and chronic pancreatitis. J. Clin. Lab. Anal. 24, 256-261. doi:10.1002/jcla.20395

Murugaiyan, G., and Saha, B. (2009). Protumor vs antitumor functions of IL-17. J. Immunol. 183, 4169-4175. doi:10.4049/jimmunol.0901017

Muthalagu, N., Monteverde, T., Raffo-Iraolagoitia, X., Wiesheu, R., Whyte, D., Hedley, A., et al. (2020). Repression of the type I interferon pathway underlies MYC \& KRAS-dependent evasion of NK \& B cells in pancreatic ductal adenocarcinoma. Cancer Discov. [Epub ahead of print] doi:10.1158/21598290.cd-19-0620

Mutini, C., Falzoni, S., Ferrari, D., Chiozzi, P., Morelli, A., Baricordi, O. R., et al. (1999). Mouse dendritic cells express the P2X7 purinergic receptor: characterization and possible participation in antigen presentation. J. Immunol. 163, 1958-1965.

Nagy, É., Mocsár, G., Sebestyén, V., Volkó, J., Papp, F., Tóth, K., et al. (2018). Membrane potential distinctly modulates mobility and signaling of IL-2 and IL-15 receptors in T-cells. Biophys. J. 114, 2473-2482. doi:10.1016/j.bpj.2018.04.038

Najder, K., Musset, B., Lindemann, O., Bulk, E., Schwab, A., and Fels, B. (2018). The function of TRP channels in neutrophil granulocytes. Pflugers Arch. 470, 1017-1033. doi:10.1007/s00424-018-2146-8

Nejati, R., Goldstein, J. B., Wang, H., Halperin, D. M., Wang, H., Hejazi, N., et al. (2017). Prognostic significance of tumor-infiltrating lymphocytes in patients with pancreatic ductal adenocarcinoma treated with neoadjuvant chemotherapy. Pancreas. 46, 1180-1187. doi:10.1097/MPA. 0000000000000914

Nielsen, N., Kondratska, K., Ruck, T., Hild, B., Kovalenko, I., Schimmelpfennig, S., et al. (2017). TRPC6 channels modulate the response of pancreatic stellate cells to hypoxia. Pflugers Arch. Eur. J. Physiol. 469, 1567-1577. doi:10.1007/s00424017-2057-0

Nilius, B., and Wohlrab, W. (1992). Potassium channels and regulation of proliferation of human melanoma cells. J. Physiol. 445, 537-548. doi:10. 1113/jphysiol.1992.sp018938

Nywening, T. M., Belt, B. A., Cullinan, D. R., Panni, R. Z., Han, B. J., Sanford, D. E., et al. (2018). Targeting both tumour-associated CXCR2+ neutrophils and CCR2+ macrophages disrupts myeloid recruitment and improves chemotherapeutic responses in pancreatic ductal adenocarcinoma. Gut. 67, 1112-1123. doi:10.1136/gutjnl-2017-313738

Oberg, H. H., Wesch, D., Kalyan, S., and Kabelitz, D. (2019). Regulatory interactions between neutrophils, tumor cells and T-cells. Front. Immunol. 10, 1690. doi:10.3389/fimmu.2019.01690

Öhlund, D., Handly-Santana, A., Biffi, G., Elyada, E., Almeida, A. S., Ponz-Sarvise, M., et al. (2017). Distinct populations of inflammatory fibroblasts and myofibroblasts in pancreatic cancer. J. Exp. Med. 214, 579-596. doi:10.1084/ jem.20162024

Ohya, S., and Kito, H. (2018). Ca2+-Activated K+ channel KCa3.1 as a therapeutic target for immune disorders. Biol. Pharm. Bull. 41, 1158-1163. doi:10.1248/bpb. b18-00078

Olive, K. P., Jacobetz, M. a., Davidson, C. J., Gopinathan, A., McIntyre, D., Honess, D., et al. (2011). Inhibition of Hedgehog signaling. Science. 324, 1457-1461. doi:10.1126/science.1171362

Olive, K. P., Jacobetz, M. A., Davidson, C. J., Gopinathan, A., McIntyre, D., Honess, D., et al. (2009). Inhibition of Hedgehog signaling enhances delivery of chemotherapy in a mouse model of pancreatic cancer. Science. 324, 1457-1461. doi:10.1126/science.1171362

Omary, M. B., Lowe, A. W., Pandol, S. J., Omary, M. B., Lugea, A., Lowe, A. W., et al. (2007a). The pancreatic stellate cell: a star on the rise in pancreatic diseases find the latest version : review series the pancreatic stellate cell : a star on the rise in pancreatic diseases. J. Clin. Invest. 117, 50-59. doi:10.1172/ JCI30082.50

Omary, M. B., Lugea, A., Lowe, A. W., and Pandol, S. J. (2007b). The pancreatic stellate cell: a star on the rise in pancreatic diseases. J. Clin. Invest. 117, 50-59. doi:10.1172/JCI30082

Ong, S. T., Ng, A. S., Ng, X. R., Zhuang, Z., Wong, B. H. S., Prasannan, P., et al. (2019). Extracellular $\mathrm{K}^{+}$dampens T-cell functions: implications for immune suppression in the tumor microenvironment. Bioelectricity. 1, 169-179. doi:10. 1089/bioe.2019.0016

Orbán, C., Bajnok, A., Vásárhelyi, B., Tulassay, T., and Toldi, G. (2014). Different calcium influx characteristics upon Kv1.3 and IKCal potassium channel inhibition in T helper subsets. Cytom. Part A. 85, 636-641. doi:10.1002/ cyto.a. 22479

Ouadid-Ahidouch, H., Le Bourhis, X., Roudbaraki, M., Toillon, R. A., Delcourt, P., and Prevarskaya, N. (2001). Changes in the K+ current-density of MCF-7 cells during progression through the cell cycle: possible Involvement of a h-ether.agogo K+ channel. Recept. Chann. 7, 345-356.

Ousingsawat, J., Spitzner, M., Puntheeranurak, S., Terracciano, L., Tornillo, L., Bubendorf, L., et al. (2007). Expression of voltage-gated potassium channels in 
human and mouse colonic carcinoma. Clin. Cancer Res. 13, 824-831. doi:10. 1158/1078-0432.CCR-06-1940

Özdemir, B. C., Pentcheva-Hoang, T., Carstens, J. L., Zheng, X., Wu, C. C., Simpson, T. R., et al. (2014). Depletion of carcinoma-associated fibroblasts and fibrosis induces immunosuppression and accelerates pancreas cancer with reduced survival. Canc. Cell. 25, 719-734. doi:10.1016/j.ccr.2014.04.005

Pahl, A., Lutz, C., and Hechler, T. (2018). Amanitins and their development as a payload for antibody-drug conjugates. Drug Discov. Today. Technol. 30, 85-89. doi:10.1016/j.ddtec.2018.08.005

Panyi, G., Beeton, C., and Felipe, A. (2014). Ion channels and anti-cancer immunity. Philos. Trans. R. Soc. B Biol. Sci. 369, 20130106. doi:10.1098/rstb. 2013.0106

Panyi, G., Possani, L., de la Vega, R. C., Gaspar, R., and Varga, Z. (2006). K+ channel blockers: novel tools to inhibit T-cell activation leading to specific immunosuppression. Curr. Pharm. Des. 12, 2199-2220. doi:10.2174/ 138161206777585120

Pardo, L. A., and Stühmer, W. (2014). The roles of $\mathrm{K}^{+}$channels in cancer. Nat. Rev. Canc. 14, 39-48. doi:10.1038/nrc3635

Pardo, L. A., Del Camino, D., Sánchez, A., Alves, F., Brüggemann, A., Beckh, S., et al. (1999). Oncogenic potential of EAG K ${ }^{+}$channels. EMBO J. 18, 5540-5547. doi:10.1093/emboj/18.20.5540

Parslow, A. C., Parakh, S., Lee, F.-T., Gan, H. K., and Scott, A. M. (2016). Antibodydrug conjugates for cancer therapy. Biomedicines. 4, 14. doi:10.3390/ biomedicines 4030014

Pedersen, S. F., Novak, I., Alves, F., Schwab, A., and Pardo, L. A. (2017). Alternating $\mathrm{pH}$ landscapes shape epithelial cancer initiation and progression: focus on pancreatic cancer. BioEssays. 39. doi:10.1002/bies.201600253

Peixoto, R. D. A., Speers, C., Mcgahan, C. E., Renouf, D. J., Schaeffer, D. F., and Kennecke, H. F. (2015). Prognostic factors and sites of metastasis in unresectable locally advanced pancreatic cancer. Canc. Med. 4, 1171-1177. doi:10.1002/cam4.459

Pethö, Z., Najder, K., Bulk, E., and Schwab, A. (2019). Mechanosensitive ion channels push cancer progression. Cell Calcium. 80, 79-90. doi:10.1016/j.ceca. 2019.03.007

Pethő, Z., Najder, K., Carvalho, T., McMorrow, R., Todesca, L. M., Rugi, M., et al. (2020). pH-channeling in cancer: how pH-dependence of cation channels shapes cancer pathophysiology. Cancers. 12, 2484. doi:10.3390/ cancers 12092484

Petroni, G., Bagni, G., Iorio, J., Duranti, C., Lottini, T., Stefanini, M., et al. (2020). Clarithromycin inhibits autophagy in colorectal cancer by regulating the hERG1 potassium channel interaction with PI3K. Cell Death Dis. 11, 161. doi:10.1038/s41419-020-2349-8

Pillozzi, S., Brizzi, M. F., Balzi, M., Crociani, O., Cherubini, A., Guasti, L., et al. (2002). HERG potassium channels are constitutively expressed in primary human acute myeloid leukemias and regulate cell proliferation of normal and leukemic hemopoietic progenitors. Leukemia. 16, 1791-1798. doi:10.1038/sj.leu.2402572

Pillozzi, S., D’Amico, M., Bartoli, G., Gasparoli, L., Petroni, G., Crociani, O., et al. (2018). The combined activation of $\mathrm{K}_{\mathrm{Ca}} 3.1$ and inhibition of $\mathrm{K}_{\mathrm{V}} 11.1 / \mathrm{hERG} 1$ currents contribute to overcome Cisplatin resistance in colorectal cancer cells. Br. J. Cancer. 118, 200-212. doi:10.1038/bjc.2017.392

Piro, G., Simionato, F., Carbone, C., Frizziero, M., Malleo, G., Zanini, S., et al. (2017). A circulating TH2 cytokines profile predicts survival in patients with resectable pancreatic adenocarcinoma. Oncoimmunology. 6, e1322242. doi:10. 1080/2162402X.2017.1322242

Pointer, K. B., Clark, P. A., Eliceiri, K. W., Salamat, M. S., Robertson, G. A., and Kuo, J. S. (2017). Administration of non-torsadogenic human Ether-à-go-goRelated Gene inhibitors is associated with better survival for high hERGexpressing glioblastoma patients. Clin. Cancer Res. 23, 73-80. doi:10.1158/ 1078-0432.CCR-15-3169

Poschke, I., Faryna, M., Bergmann, F., Flossdorf, M., Lauenstein, C., Hermes, J., et al. (2016). Identification of a tumor-reactive T-cell repertoire in the immune in fi ltrate of patients with resectable pancreatic ductal adenocarcinoma. Oncoimmunology. 5, e1240859. doi:10.1080/2162402X.2016.1240859

Prevarskaya, N., Skryma, R., and Shuba, Y. (2018). Ion channels in cancer: are cancer hallmarks oncochannelopathies?. Physiol. Rev. 98, 559-621. doi:10.1152/ physrev.00044.2016

Provenzano, P. P., Cuevas, C., Chang, A. E., Goel, V. K., Von Hoff, D. D., and Hingorani, S. R. (2012). Enzymatic targeting of the stroma ablates physical barriers to treatment of pancreatic ductal adenocarcinoma. Canc. Cell. 21, 418-429. doi:10.1016/j.ccr.2012.01.007

Puche, J. E., Saiman, Y., and Friedman, S. L. (2013). Hepatic stellate cells and liver fibrosis. Compr. Physiol. 3, 1473-1492. doi:10.1002/cphy.c120035

Rahaman, S. O., Grove, L. M., Paruchuri, S., Southern, B. D., Abraham, S., Niese, K. A., et al. (2014). TRPV4 mediates myofibroblast differentiation and pulmonary fibrosis in mice. J. Clin. Invest. 124, 5225-5238. doi:10.1172/JCI75331

Ramsey, I. S., Ruchti, E., Kaczmarek, J. S., and Clapham, D. E. (2009). Hv1 proton channels are required for high-level NADPH oxidase-dependent superoxide production during the phagocyte respiratory burst. Proc. Natl. Acad. Sci. U.S.A. 106, 7642-7647. doi:10.1073/pnas.0902761106

Raphaël, M., Lehen'kyi, V., Vandenberghe, M., Beck, B., Khalimonchyk, S., Vanden Abeele, F., et al. (2014). TRPV6 calcium channel translocates to the plasma membrane via Orai1-mediated mechanism and controls cancer cell survival. Proc. Natl. Acad. Sci. U.S.A. 111, E3870-E3879. doi:10.1073/pnas. 1413409111

Rawla, P., Sunkara, T., and Gaduputi, V. (2019). Epidemiology of pancreatic cancer: global trends, Etiology and risk factors. World J. Oncol. 10, 10-27. doi:10.14740/wjon1166

Redmond, J., and Buchanan, P. (2017). Role of ion channels in natural killer cell function towards cancer. Discov. Med. 23, 353-360.

Reneer, M. C., Estes, D. J., Vélez-Ortega, A. C., Norris, A., Mayer, M., and Marti, F. (2011). Peripherally induced human regulatory T-cells uncouple Kv1.3 activation from TCR-associated signaling. Eur. J. Immunol. 41, 3170-3175. doi:10.1002/eji.201141492

Roach, K. M., and Bradding, P. (2019). $\mathrm{Ca}^{2+}$ signalling in fibroblasts and the therapeutic potential of $\mathrm{K}_{\mathrm{Ca}} 3.1$ channel blockers in fibrotic diseases. $\mathrm{Br}$. J. Pharmacol. 177, 1003-1024. doi:10.1111/bph.14939

Roach, K. M., Duffy, S. M., Coward, W., Feghali-Bostwick, C., Wulff, H., and Bradding, P. (2013). The $\mathrm{K}^{+}$channel $\mathrm{K}_{\mathrm{Ca}} 3.1$ as a novel target for idiopathic pulmonary fibrosis. PLoS One. 8, e85244. doi:10.1371/journal.pone.0085244

Rodrigues, A. R. A., Arantes, E. C., Monje, F., Stühmer, W., and Varanda, W. A. (2003). Tityustoxin-K(alpha) blockade of the voltage-gated potassium channel Kv1.3. Br. J. Pharmacol. 139, 1180-1186. doi:10.1038/sj.bjp.0705343

Roghanian, A., Fraser, C., Kleyman, M., and Chen, J. (2016). B cells promote pancreatic tumorigenesis. Canc. Discov. 6, 230-232. doi:10.1158/2159-8290. CD-16-0100

Rybarczyk, P., Gautier, M., Hague, F., Dhennin-Duthille, I., Chatelain, D., KerrConte, J., et al. (2012). Transient receptor potential melastatin-related 7 channel is overexpressed in human pancreatic ductal adenocarcinomas and regulates human pancreatic cancer cell migration. Int. J. Cancer. 131, 851-861. doi:10. $1002 /$ ijc. 27487

Rybarczyk, P., Vanlaeys, A., Brassart, B., Dhennin-Duthille, I., Chatelain, D., Sevestre, H., et al. (2017). The transient receptor potential melastatin 7 channel regulates pancreatic cancer cell invasion through the hsp90a/uPA/ MMP2 pathway. Neoplasia (United States). 19, 288-300. doi:10.1016/j.neo. 2017.01.004

Saéz, P. J., Vargas, P., Shoji, K. F., Harcha, P. A., Lennon-Duméni, A. M., and Saéz, J. C. (2017). ATP promotes the fast migration of dendritic cells through the activity of pannexin 1 channels and P2X7 receptors. Sci. Signal. 10, eaah7107. doi:10.1126/scisignal.aah7107

Sakata, R., Ueno, T., Nakamura, T., Ueno, H., and Sata, M. (2004). Mechanical stretch induces TGF- $\beta$ synthesis in hepatic stellate cells. Eur. J. Clin. Invest. 34, 129-136. doi:10.1111/j.1365-2362.2004.01302.x

Sakellariou-Thompson, D., Forget, M. A., Creasy, C., Bernard, V., Zhao, L., Kim, Y. U., et al. (2017). 4-1BB agonist focuses CD8+ tumor-infiltrating T-Cell growth into a distinct repertoire capable of tumor recognition in pancreatic cancer. Clin. Cancer Res. 23, 7263-7275. doi:10.1158/1078-0432.CCR-17-0831

Sanguinetti, M. C. (2010). HERG1 channelopathies. Pflugers Arch. Eur. J. Physiol. 460, 265-276. doi:10.1007/s00424-009-0758-8

Sanguinetti, M. C., Jiang, C., Curran, M. E., and Keating, M. T. (1995). A mechanistic link between an inherited and an acquired cardiac arrhythmia: HERG encodes the IKr potassium channel. Cell. 81, 299-307. doi:10.1016/00928674(95) $90340-2$

Saurer, L., Reber, P., Schaffner, T., Büchler, M. W., Buri, C., Kappeler, A., et al. (2000). Differential expression of chemokines in normal pancreas and in chronic pancreatitis. Gastroenterology. 118, 356-367. doi:10.1016/S00165085(00)70218-6 
Sauter, D. R. P., Novak, I., Pedersen, S. F., Larsen, E. H., and Hoffmann, E. K. (2015). ANO1 (TMEM16A) in pancreatic ductal adenocarcinoma (PDAC). Pflugers Arch. Eur. J. Physiol. 467, 1495-1508. doi:10.1007/s00424-014-1598-8

Sauter, D. R. P., Sørensen, C. E., Rapedius, M., Brüggemann, A., and Novak, I. (2016). pH-sensitive $\mathrm{K}+$ channel TREK-1 is a novel target in pancreatic cancer. Biochim. Biophys. Acta - Mol. Basis Dis. 1862, 1994-2003. doi:10.1016/j.bbadis. 2016.07.009

Schappe, M. S., Szteyn, K., Stremska, M. E., Mendu, S. K., Downs, T. K., Seegren, P. V., et al. (2018). Chanzyme TRPM7 mediates the Ca2+ influx essential for lipopolysaccharide-induced toll-like receptor 4 Endocytosis and macrophage activation. Immunity. 48, 59-74. doi:10.1016/j.immuni.2017.11.026.e5

Schilling, T., Miralles, F., and Eder, C. (2014). TRPM7 regulates proliferation and polarisation of macrophages. J. Cell Sci. 127, 4561-4566. doi:10.1242/jcs.151068

Schnipper, J., Dhennin-duthille, I., and Ahidouch, A. (2020). Ion channel signature in healthy pancreas and pancreatic ductal adenocarcinoma. Front. Pharmacol. 11, 568993. doi:10.3389/fphar.2020.568993

Schwab, A., and Stock, C. (2014). Ion channels and transporters in tumour cell migration and invasion. Philos. Trans. R. Soc. B Biol. Sci. 369, 20130102. doi:10. 1098/rstb.2013.0102

Schwab, A., Nechyporuk-Zloy, V., Gassner, B., Schulz, C., Kessler, W., Mally, S., et al. (2012). Dynamic redistribution of calcium sensitive potassium channels $\mathrm{hK}_{\mathrm{Ca}} 3.1$ in migrating cells. J. Cell. Physiol. 227, 686-696. doi:10.1002/jcp.22776

Schwab, A., Wulf, A., Schulz, C., Kessler, W., Nechyporuk-Zloy, V., Römer, M., et al. (2006). Subcellular distribution of calcium-sensitive potassium channels (Ik1) in migrating cells. J. Cell. Physiol. 206, 86-94. doi:10.1002/jcp.20434

Segerstolpe, Å., Palasantza, A., Eliasson, P., Andersson, E.-M., Andréasson, A.-C., Sun, X., et al. (2016). Single-cell transcriptome profiling of human pancreatic islets in health and type 2 diabetes. Cell Metab. 24, 593-607. doi:10.1016/j.cmet. 2016.08.020

Shao, P. P., Liu, C. J., Xu, Q., Zhang, B., Li, S. H., Wu, Y., et al. (2018). Eplerenone reverses cardiac fibrosis via the suppression of Tregs by inhibition of Kv1.3 channel. Front. Physiol. 9, 899. doi:10.3389/fphys.2018.00899

Sharma, S., Goswami, R., Zhang, D. X., and Rahaman, S. O. (2019). TRPV4 regulates matrix stiffness and TGF $\beta 1$-induced epithelial-mesenchymal transition. J. Cell. Mol. Med. 23, 761-774. doi:10.1111/jcmm.13972

Shevchenko, I., Karakhanova, S., Soltek, S., Link, J., Bayry, J., Werner, J., et al. (2013). Low-dose gemcitabine depletes regulatory T-cells and improves survival in the orthotopic Panc02 model of pancreatic cancer. Int. J. Cancer. 133, 98-107. doi:10.1002/ijc.27990

Shi, Y., Sahu, R. P., and Srivastava, S. K. (2008). Triphala inhibits both in vitro and in vivo xenograft growth of pancreatic tumor cells by inducing apoptosis. $B M C$ Canc. 8, 294. doi:10.1186/1471-2407-8-294

Shurin, M. R., Lu, L., Kalinski, P., Stewart-Akers, A. M., and Lotze, M. T. (1999). Th1/Th2 balance in cancer, transplantation and pregnancy. Springer Semin Immunopathol. 21, 339-359. doi:10.1007/BF00812261

Silva-Santos, J. E. D. A., Santos-Silva, M. C., De Queiroz Cunha, F., and Assreuy, J. (2002). The role of ATP-sensitive potassium channels in neutrophil migration and plasma exudation. J. Pharmacol. Exp. Therapeut. 300, 946-951. doi:10. 1124/jpet.300.3.946

Singh, R. R., and O'Reilly, E. M. (2020). New treatment strategies for metastatic pancreatic ductal adenocarcinoma. Drugs. 80, 647-669. doi:10.1007/s40265020-01304-0

Somodi, S., Hajdu, P., Gáspár, R., Panyi, G., and Varga, Z. (2008). Effects of changes in extracellular $\mathrm{pH}$ and potassium concentration on Kv1.3 inactivation. Eur. Biophys. J. 37, 1145-1156. doi:10.1007/s00249-008-0267-2

Somodi, S., Varga, Z., Hajdu, P., Starkus, J. G., Levy, D. I., Gáspár, R., et al. (2004). pH-dependent modulation of Kv1.3 inactivation: role of His399. Am. J. Physiol. Cell Physiol. 287, C1067-C1076. doi:10.1152/ajpcell.00438.2003

Song, H., Dong, M., Zhou, J., Sheng, W., Li, X., and Gao, W. (2018). Expression and prognostic significance of TRPV6 in the development and progression of pancreatic cancer. Oncol. Rep. 39, 1432-1440. doi:10.3892/or.2018.6216

Song, J. H., Huang, C. S., Nagata, K., Yeh, J. Z., and Narahashi, T. (1997). Differential action of riluzole on tetrodotoxin-sensitive and tetrodotoxinresistant sodium channels. J. Pharmacol. Exp. Therapeut. 282, 707-714.

Songa, Y., Zhan, L., Yu, M., Huang, C., Meng, X., Taotao, M., et al. (2014). TRPV4 channel inhibits TGF- $\beta 1$-induced proliferation of hepatic stellate cells. PLoS One. 9, e101179. doi:10.1371/journal.pone.0101179
Spear, S., Candido, J. B., McDermott, J. R., Ghirelli, C., Maniati, E., Beers, S. A., et al (2019). Discrepancies in the tumor microenvironment of spontaneous and orthotopic murine models of pancreatic cancer uncover a new immunostimulatory phenotype for B cells. Front. Immunol. 10, 542. doi:10. 3389/fimmu.2019.00542

Sperb, N., Tsesmelis, M., and Wirth, T. (2020). Crosstalk between tumor and stromal cells in pancreatic ductal adenocarcinoma. Int. J. Mol. Sci. 21, 5486. doi:10.3390/ijms 21155486

Starkus, J. G., Varga, Z., Schönherr, R., and Heinemann, S. H. (2003). Mechanisms of the inhibition of Shaker potassium channels by protons. Pflugers Arch. Eur. J. Physiol. 447, 44-54. doi:10.1007/s00424-003-1121-0

Steele, C. W., Karim, S. A., Leach, J. D. G., Bailey, P., Upstill-Goddard, R., Rishi, L., et al. (2016). CXCR2 inhibition profoundly suppresses metastases and augments immunotherapy in pancreatic ductal adenocarcinoma. Canc. Cell. 29, 832-845. doi:10.1016/j.ccell.2016.04.014

Steudel, F. A., Mohr, C. J., Stegen, B., Nguyen, H. Y., Barnert, A., Steinle, M., et al. (2017). SK4 channels modulate $\mathrm{Ca}(2+)$ signalling and cell cycle progression in murine breast cancer. Mol. Oncol. 11, 1172-1188. doi:10.1002/1878-0261.12087

Storck, H., Hild, B., Schimmelpfennig, S., Sargin, S., Nielsen, N., Zaccagnino, A., et al. (2017). Ion channels in control of pancreatic stellate cell migration. Oncotarget. 8, 769-784. doi:10.18632/oncotarget.13647

Stromnes, I. M., Hulbert, A., Pierce, R. H., Greenberg, P. D., and Hingorani, S. R. (2017). T-cell localization, activation, and clonal expansion in human pancreatic ductal adenocarcinoma. Cancer Immunol. Res. 5, 978-991. doi:10. 1158/2326-6066.CIR-16-0322

Stylianopoulos, T., Martin, J. D., Chauhan, V. P., Jain, S. R., Diop-Frimpong, B., Bardeesy, N., et al. (2012). Causes, consequences, and remedies for growthinduced solid stress in murine and human tumors. Proc. Natl. Acad. Sci. U.S.A. 109, 15101-15108. doi:10.1073/pnas.1213353109

Sun, Q., Zhou, C., Ma, R., Guo, Q., Huang, H., Hao, J., et al. (2018). Prognostic value of increased integrin-beta 1 expression in solid cancers: a meta-analysis. Onco Targets Ther. 11, 1787-1799. doi:10.2147/OTT.S155279

Sun, R., He, X., Jiang, X., and Tao, H. (2019). The new role of riluzole in the treatment of pancreatic cancer through the apoptosis and autophagy pathways. J. Cell. Biochem. [Epub ahead of print]. doi:10.1002/jcb.29533

Sunami, Y., and Kleeff, J. (2019). Immunotherapy of pancreatic cancer. Prog. Mol. Biol. Transl. Sci. 164, 189-216. doi:10.1016/bs.pmbts.2019.03.006

Szteyn, K., Yang, W., Schmid, E., Lang, F., and Shumilina, E. (2012). Lipopolysaccharide-sensitive $\mathrm{H}^{+}$current in dendritic cells. Am. J. Physiol. Cell Physiol. 303, 204-212. doi:10.1152/ajpcell.00059.2012

Tajti, G., Wai, D. C. C., Panyi, G., and Norton, R. S. (2020). The voltage-gated potassium channel $\mathrm{K}_{\mathrm{V}} 1.3$ as a therapeutic target for venom-derived peptides. Biochem. Pharmacol. 114146. doi:10.1016/j.bcp.2020.114146

Takesue, S., Ohuchida, K., Shinkawa, T., Otsubo, Y., Matsumoto, S., Sagara, A., et al. (2020). Neutrophil extracellular traps promote liver micrometastasis in pancreatic ductal adenocarcinoma via the activation of cancer-associated fibroblasts. Int. J. Oncol. 56, 596-605. doi:10.3892/ijo.2019.4951

Tang, Y., Xu, X., Guo, S., Zhang, C., Tang, Y., Tian, Y., et al. (2014). An increased abundance of tumor-infiltrating regulatory $\mathrm{t}$ cells is correlated with the progression and prognosis of pancreatic ductal adenocarcinoma. PLoS One. 9, e91551. doi:10.1371/journal.pone.0091551

Tao, L., Zhang, L., Peng, Y., Tao, M., Li, L., Xiu, D., et al. (2016). Neutrophils assist the metastasis of circulating tumor cells in pancreatic ductal adenocarcinoma: a new hypothesis and a new predictor for distant metastasis. Medicine (Baltimore). 95, e4932. doi:10.1097/MD.0000000000004932

Tawfik, D., Zaccagnino, A., Bernt, A., Szczepanowski, M., Klapper, W., Schwab, A., et al. (2020). The A818-6 system as an in-vitro model for studying the role of the transportome in pancreatic cancer. BMC Canc. 20, 264. doi:10.1186/s12885020-06773-w

Thyagarajan, A., Alshehri, M. S. A., Miller, K. L. R., Sherwin, C. M., Travers, J. B., and Sahu, R. P. (2019). Myeloid-derived suppressor cells and pancreatic cancer: implications in novel therapeutic approaches. Cancers. 11, 1627. doi:10.3390/ cancers 11111627

Toldi, G., Folyovich, A., Simon, Z., Zsiga, K., Kaposi, A., Mészáros, G., et al. (2011) Lymphocyte calcium influx kinetics in multiple sclerosis treated without or with interferon beta. J. Neuroimmunol. 237, 80-86. doi:10.1016/j.jneuroim.2011. 06.008 
Toldi, G., Kaposi, A., Zsembery, Á., Treszl, A., Tulassay, T., and Vásárhelyi, B. (2012). Human Th1 and Th2 lymphocytes are distinguished by calcium flux regulation during the first $10 \mathrm{~min}$ of lymphocyte activation. Immunobiology. 217, 37-43. doi:10.1016/j.imbio.2011.08.007

Trovato, R., Fiore, A., Sartori, S., Canè, S., Giugno, R., Cascione, L., et al. (2019). Immunosuppression by monocytic myeloid-derived suppressor cells in patients with pancreatic ductal carcinoma is orchestrated by STAT3. J. Immunother. Canc. 7, 255. doi:10.1186/s40425-019-0734-6

Trudeau, M. C., Warmke, J. W., Ganetzky, B., and Robertson, G. A. (1995). HERG, a human inward rectifier in the voltage-gated potassium channel family. Science. 269, 92-95. doi:10.1126/science.7604285

Urrego, D., Tomczak, A. P., Zahed, F., Stühmer, W., and Pardo, L. A. (2014). Potassium channels in cell cycle and cell proliferation. Philos. Trans. R. Soc. Lond. B Biol. Sci. 369, 20130094. doi:10.1098/rstb.2013.0094

Vaeth, M., Wang, Y. H., Eckstein, M., Yang, J., Silverman, G. J., Lacruz, R. S., et al. (2019). Tissue resident and follicular Treg cell differentiation is regulated by CRAC channels. Nat. Commun. 10, 1183. doi:10.1038/s41467-019-08959-8

Vaeth, M., Yang, J., Yamashita, M., Zee, I., Eckstein, M., Knosp, C., et al. (2017). ORAI2 modulates store-operated calcium entry and T cell-mediated immunity. Nat. Commun. 8, 14714. doi:10.1038/ncomms 14714

Varga, Z., Csepany, T., Papp, F., Fabian, A., Gogolak, P., Toth, A., et al. (2009). Potassium channel expression in human $\mathrm{CD} 4+$ regulatory and naïve $\mathrm{T}$-cells from healthy subjects and multiple sclerosis patients. Immunol. Lett. 124, 95-101. doi:10.1016/j.imlet.2009.04.008

Vesely, M. D., Kershaw, M. H., Schreiber, R. D., and Smyth, M. J. (2011). Natural innate and adaptive immunity to cancer. Annu. Rev. Immunol. 29, 235-271. doi:10.1146/annurev-immunol-031210-101324

Vincent, A., Herman, J., Schulick, R., Hruban, R. H., and Goggins, M. (2011). Pancreatic cancer. Lancet. 378, 607-620. doi:10.1016/S0140-6736(10)62307-0

Von Ahrens, D., Bhagat, T. D., Nagrath, D., Maitra, A., and Verma, A. (2017). The role of stromal cancer-associated fibroblasts in pancreatic cancer. J. Hematol. Oncol. 10, 76. doi:10.1186/s13045-017-0448-5

Wang, J., Haanes, K. A., and Novak, I. (2013). Purinergic regulation of CFTR and $\mathrm{Ca} 2+$-activated $\mathrm{Cl}$-channels and $\mathrm{K}^{+}$channels in human pancreatic duct epithelium. Am. J. Physiol. - Cell Physiol. 304, 673-684. doi:10.1152/ajpcell. 00196.2012

Wang, Q., Bai, L., Luo, S., Wang, T., Yang, F., Xia, J., et al. (2020a). TMEM16A $\mathrm{Ca} 2+$-activated $\mathrm{Cl}-$ channel inhibition ameliorates acute pancreatitis via the IP3R/Ca2+/NFkB/IL-6 signaling pathway. J. Adv. Res. 23, 25-35. doi:10.1016/j. jare.2020.01.006

Wang, S., Li, Y., Xing, C., Ding, C., Zhang, H., Chen, L., et al. (2020b). Tumor microenvironment in chemoresistance, metastasis and immunotherapy of pancreatic cancer. Am. J. Cancer Res. 10, 1937-1953.

Wang, X., Lang, M., Zhao, T., Feng, X., Zheng, C., Huang, C., et al. (2017). CancerFOXP3 directly activated CCL5 to recruit FOXP ${ }^{+}$Treg cells in pancreatic ductal adenocarcinoma. Oncogene. 36, 3048-3058. doi:10.1038/onc.2016.458

Wang, Y., Fang, T., Huang, L., Wang, H., Zhang, L., Wang, Z., et al. (2018). Neutrophils infiltrating pancreatic ductal adenocarcinoma indicate higher malignancy and worse prognosis. Biochem. Biophys. Res. Commun. 501, 313-319. doi:10.1016/j.bbrc.2018.05.024

Weber, K. S., Hildner, K., Murphy, K. M., and Allen, P. M. (2010). Trpm4 differentially regulates Th1 and Th2 function by altering calcium signaling and NFAT localization. J. Immunol. 185, 2836-2846. doi:10.4049/jimmunol. 1000880

Weisberg, S. P., Carpenter, D. J., Chait, M., Dogra, P., Gartrell-Corrado, R. D., Chen, A. X., et al. (2019). Tissue-Resident memory T-cells mediate immune homeostasis in the human pancreas through the PD-1/PD-L1 pathway. Cell Rep. 29, 3916-3932. doi:10.1016/j.celrep.2019.11.056.e5

Wen, Z., Liao, Q., Zhao, J., Hu, Y., You, L., Lu, Z., et al. (2014). High expression of interleukin-22 and its receptor predicts poor prognosis in pancreatic ductal adenocarcinoma. Ann. Surg. Oncol. 21, 125-132. doi:10.1245/s10434-0133322-x

Whiteside, T. (2015). The role of regulatory T-cells in cancer immunology. ImmunoTargets Ther. 4, 159-171. doi:10.2147/itt.s55415

Willebrand, R., Hamad, I., Van Zeebroeck, L., Kiss, M., Bruderek, K., Geuzens, A., et al. (2019). High salt inhibits tumor growth by enhancing anti-tumor immunity. Front. Immunol. 10, 1-15. doi:10.3389/fimmu.2019.01141
Williams, S., Bateman, A., and O'Kelly, I. (2013). Altered expression of two-pore domain potassium (K2P) channels in cancer. PLoS One. 8, e74589. doi:10.1371/ journal.pone. 0074589

Wörmann, S. M., Diakopoulos, K. N., Lesina, M., and Algül, H. (2014). The immune network in pancreatic cancer development and progression. Oncogene. 33, 2956-2967. doi:10.1038/onc.2013.257

Wu, L., Saxena, S., Awaji, M., and Singh, R. K. (2019). Tumor-associated neutrophils in Cancer: going pro. Cancers. 11, 564. doi:10.3390/ cancers 11040564

Wulff, H., Calabresi, P. A., Allie, R., Yun, S., Pennington, M., Beeton, C., et al. (2003). The voltage-gated Kv1.3 K+ channel in effector memory T-cells as new target for MS. J. Clin. Invest. 111, 1703-1713. doi:10.1172/JCI16921

Wulff, H., Castle, N. A., and Pardo, L. A. (2009). Voltage-gated potassium channels as therapeutic targets. Nat. Rev. Drug Discov. 8, 982-1001. doi:10. $1038 /$ nrd2983

Wulff, H., Knaus, H.-G., Pennington, M., and Chandy, K. G. (2004). K + channel expression during $\mathrm{B}$ cell differentiation: implications for immunomodulation and autoimmunity. J. Immunol. 173, 776-786. doi:10.4049/jimmunol.173.2.776

Wulff, H., Kolski-Andreaco, A., Sankaranarayanan, A., Sabatier, J.-M., and Shakkottai, V. (2007). Modulators of small- and intermediate-conductance calcium-activated potassium channels and their therapeutic indications. Curr. Med. Chem. 14, 1437-1457. doi:10.2174/092986707780831186

Wulff, H., Miller, M. J., Hänsel, W., Grissmer, S., Cahalan, M. D., and Chandy, K. G. (2000). Design of a potent and selective inhibitor of the intermediateconductance $\mathrm{Ca}^{2+}$-activated $\mathrm{K}^{+}$channel, IKCal: a potential immunosuppressant. Proc. Natl. Acad. Sci. U.S.A. 97, 8151-8156. doi:10. 1073/pnas.97.14.8151

Wynn, T. A., and Ramalingam, T. R. (2012). Mechanisms of fibrosis: therapeutic translation for fibrotic disease. Nat. Med. 18, 1028-1040. doi:10.1038/nm.2807

$\mathrm{Xu}, \mathrm{R} ., \mathrm{Li}, \mathrm{C} ., \mathrm{Wu}, \mathrm{Y}$., Shen, L., Ma, J., Qian, J., et al. (2017). Role of $\mathrm{K}_{\mathrm{Ca}} 3.1$ channels in macrophage polarization and its relevance in atherosclerotic plaque instability. Arterioscler. Thromb. Vasc. Biol. 37, 226-236. doi:10.1161/ ATVBAHA.116.308461

Xu, T., Du, X. W., Hu, J. B., Zhu, Y. F., Wu, H. L., Dai, G. P., et al. (2018). Anticancer effect of miR-96 inhibitor in bladder cancer cell lines. Oncol. Lett. 15, 3814-3819. doi:10.3892/ol.2018.7745

Yako, Y. Y., Kruger, D., Smith, M., and Brand, M. (2016). Cytokines as biomarkers of pancreatic ductal adenocarcinoma: a systematic review. PLoS One. 11, e0154016. doi:10.1371/journal.pone.0154016

Yamamoto, S., Shimizu, S., Kiyonaka, S., Takahashi, N., Wajima, T., Hara, Y., et al. (2008). TRPM2-mediated Ca2+ influx induces chemokine production in monocytes that aggravates inflammatory neutrophil infiltration. Nat. Med. 14, 738-747. doi:10.1038/nm1758

Yang, D., Zhang, Q., Ma, Y., Che, Z., Zhang, W., Wu, M., et al. (2019). Augmenting the therapeutic efficacy of adenosine against pancreatic cancer by switching the Akt/p21-dependent senescence to apoptosis. EBioMedicine. 47, 114-127. doi:10.1016/j.ebiom.2019.08.068

Yee, N. S. (2017). Role of TRPM7 in cancer: potential as molecular biomarker and therapeutic target. Pharmaceuticals. 10, 39. doi:10.3390/ph10020039

Yee, N. S, Zhou, W., and Lee, M. (2010). Transient receptor potential channel TRPM8 is over-expressed and required for cellular proliferation in pancreatic adenocarcinoma. Cancer Lett. 297, 149-155. doi:10.1038/jid.2014.371

Yee, N. S., Kazi, A. A., Li, Q., Yang, Z., Berg, A., and Yee, R. K. (2015). Aberrant over-expression of TRPM7 ion channels in pancreatic cancer: required for cancer cell invasion and implicated in tumor growth and metastasis. Biol. Open. 4, 507-514. doi:10.1242/bio.20137088

Yee, N. S., Zhou, W., and Liang, I.-C. (2011). Transient receptor potential ion channel Trpm7 regulates exocrine pancreatic epithelial proliferation by $\mathrm{Mg} 2+-$ sensitive Socs3a signaling in development and cancer. Dis. Model. Mech. 4, 240-254. doi:10.1242/dmm.004564

Zaccagnino, A., Managò, A., Leanza, L., Gontarewitz, A., Linder, B., Azzolini, M., et al. (2017). Tumor-reducing effect of the clinically used drug clofazimine in a SCID mouse model of pancreatic ductal adenocarcinoma. Oncotarget. 8, 38276-38293. doi:10.18632/oncotarget.11299

Zaccagnino, A., Pilarsky, C., Tawfik, D., Sebens, S., Trauzold, A., Novak, I., et al. (2016). In silico analysis of the transportome in human pancreatic ductal adenocarcinoma. Eur. Biophys. J. 45, 749-763. doi:10.1007/s00249-016-1171-9 
Zhan, L., and Li, J. (2018). The role of TRPV4 in fibrosis. Gene. 642, 1-8. doi:10. 1016/j.gene.2017.10.067

Zhang, L. P., Ma, F., Abshire, S. M., and Westlund, K. N. (2013). Prolonged high fat/alcohol exposure increases TRPV4 and its functional responses in pancreatic stellate cells. Am. J. Physiol. - Regul. Integr. Comp. Physiol. 304, R702-R711. doi:10.1152/ajpregu.00296.2012

Zhang, R., Liu, Q., Peng, J., Wang, M., Li, T., Liu, J., et al. (2020). CXCL5 overexpression predicts a poor prognosis in pancreatic ductal adenocarcinoma and is correlated with immune cell infiltration. J. Canc. 11, 2371-2381. doi:10.7150/jca.40517

Zhao, H., Guo, E., Hu, T., Sun, Q., Wu, J., Lin, X., et al. (2016). KCNN4 and S100A14 act as predictors of recurrence in optimally debulked patients with serous ovarian cancer. Oncotarget. 7, 43924-43938. doi:10.18632/oncotarget. 9721

Zhao, L. M., Wang, L. P., Wang, H. F., Ma, X. Z., Zhou, D. X., and Deng, X. L. (2015). The role of $\mathrm{K}_{\mathrm{Ca}} 3.1$ channels in cardiac fibrosis induced by pressure overload in rats. Pflugers Arch. Eur. J. Physiol. 467, 2275-2285. doi:10.1007/ s00424-015-1694-4

Zhao, L., Zhao, H., and Yan, H. (2018). Gene expression profiling of 1200 pancreatic ductal adenocarcinoma reveals novel subtypes. BMC Canc. 18, 603. doi:10.1186/s12885-018-4546-8

Zheng, W., Thorne, N., and McKew, J. C. (2013). Phenotypic screens as a renewed approach for drug discovery. Drug Discov. Today. 18, 1067-1073. doi:10.1016/j. drudis.2013.07.001

Zhi, D., Zhao, X., Dong, M., and Yan, C. (2017). miR-493 inhibits proliferation and invasion in pancreatic cancer cells and inversely regulated hERG1 expression. Oncol. Lett. 14, 7398-7404. doi:10.3892/ol.2017.7178

Zhou, B., Irwanto, A., Guo, Y. M., Bei, J. X., Wu, Q., Chen, G., et al. (2012). Exome sequencing and digital PCR analyses reveal novel mutated genes related to the metastasis of pancreatic ductal adenocarcinoma. Cancer Biol. Ther. 13, 871-879. doi:10.4161/cbt.20839

Zhu, S., Zhou, H. Y., Deng, S. C., Deng, S. J., He, C., Li, X., et al. (2017). ASIC1 and ASIC3 contribute to acidity-induced EMT of pancreatic cancer through activating Ca2+/RhoA pathway. Cell Death Dis. 8, e2806. doi:10.1038/cddis. 2017.189

Zhu, Y., Knolhoff, B. L., Meyer, M. A., Nywening, T. M., West, B. L., Luo, J., et al. (2014). CSF1/CSF1R blockade reprograms tumor-infiltrating macrophages and improves response to $\mathrm{T}$-cell checkpoint immunotherapy in pancreatic cancer models. Cancer Res. 74, 5057-5069. doi:10.1158/0008-5472.CAN-13-3723

Zhuang, L., Peng, J.-B., Tou, L., Takanaga, H., Adam, R. M., Hediger, M. A., et al. (2002). Calcium-selective ion channel, CaT1, is apically localized in gastrointestinal tract epithelia and is aberrantly expressed in human malignancies. Lab. Invest. 82, 1755-1764. doi:10.1097/01.lab.0000043910.41414.e7

Zsiros, E., Kis-Toth, K., Hajdu, P., Gaspar, R., Bielanska, J., Felipe, A., et al. (2009). Developmental switch of the expression of ion channels in human dendritic cells. J. Immunol. 183, 4483-4492. doi:10.4049/jimmunol.0803003

Conflict of Interest: The authors declare that the research was conducted in the absence of any commercial or financial relationships that could be construed as a potential conflict of interest.

Copyright $\odot 2021$ Hofschröer, Najder, Rugi, Bouazzi, Cozzolino, Arcangeli, Panyi and Schwab. This is an open-access article distributed under the terms of the Creative Commons Attribution License (CC BY). The use, distribution or reproduction in other forums is permitted, provided the original author(s) and the copyright owner(s) are credited and that the original publication in this journal is cited, in accordance with accepted academic practice. No use, distribution or reproduction is permitted which does not comply with these terms. 